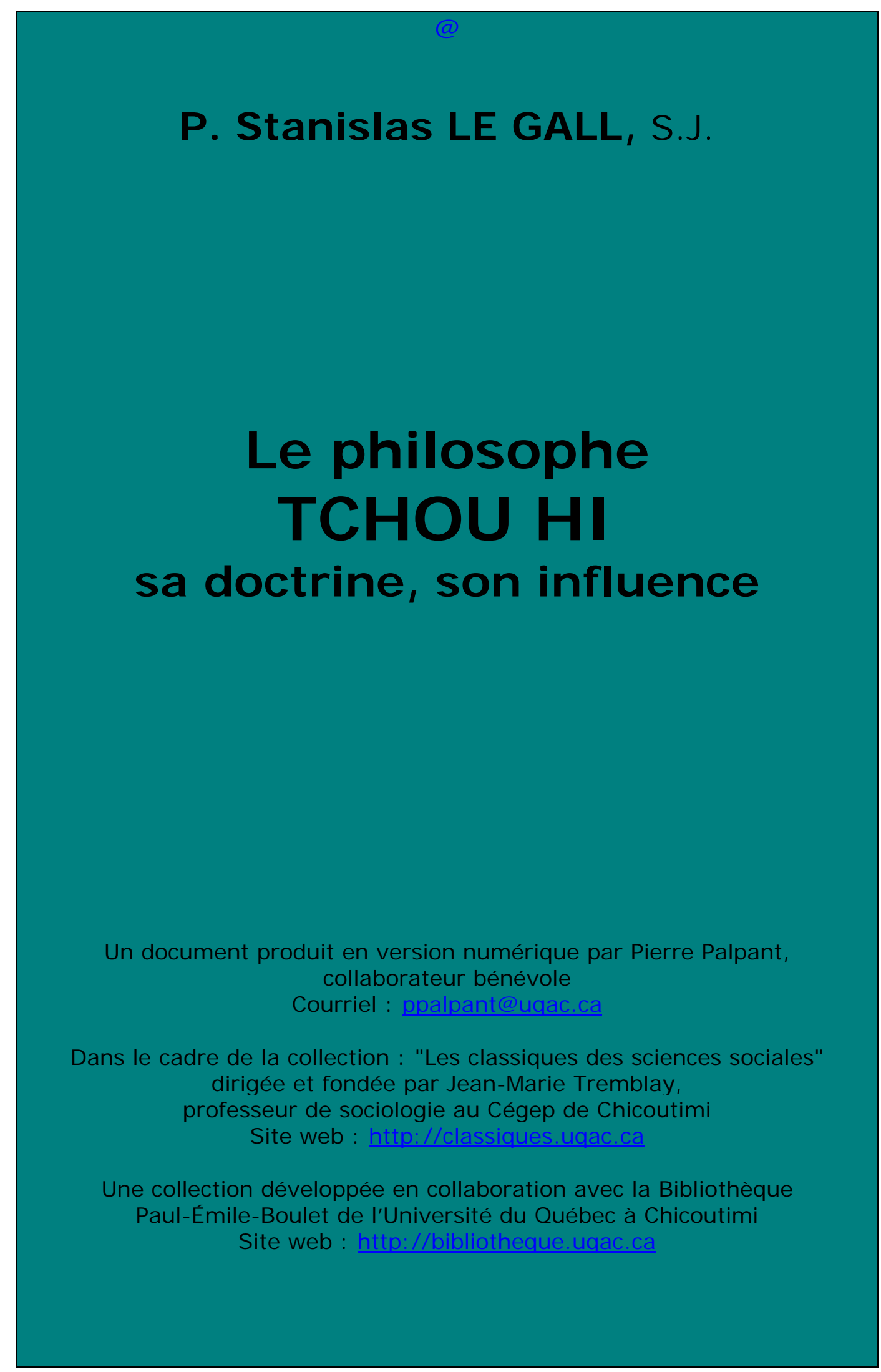




\section{Le philosophe Tchou Hi}

Un document produit en version numérique par Pierre Palpant, collaborateur bénévole,

Courriel : ppalpant@uqac.ca

à partir de :

\section{LE PHILOSOPHE TCHOU HI,} sa doctrine, son influence.

par le P. Stanislas LE GALL, S. J. (1858-1916)

Variétés sinologiques $n^{\circ} 6$, Imprimerie de la Mission catholique de l'orphelinat de T'ou-sé-wé, Chang-hai, 1894, III+134 pages.

Police de caractères utilisée : Verdana, 12,10 et 8 points. Mise en page sur papier format Lettre (US letter), 8.5"x11"

Édition complétée le 15 janvier 2006 à Chicoutimi, Ville de Saguenay, Province de Québec.

Ouvrage numérisé grâce à l'obligeance des Archives et de la Bibliothèque asiatique des Missions Étrangères de Paris

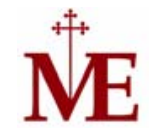

http://www.mepasie.org/ 


\title{
Le philosophe Tchou Hi
}

\section{TABLE DES MATIÈRES}

Préface

\author{
PREMI ÈRE PARTIE \\ COURT EXPOSE HISTORIQUE
}

Chapitre I : Tchou Hi, ses maîtres et ses disciples.

Avènement de la dynastie Song. - Renaissance littéraire. - Chao Yong : jugement du $\mathrm{P}$. Amiot sur son système. - Tcheou Lien-k'i, père de la nouvelle école : jugement du P. Cibot. - Valeur intrinsèque du Iking. - Tchang Tsai et les deux frères Tch'eng. - Yang Che, père de I'École du Sud, et Wang Ngan-che. - Louo Ts'ong-yen et son élève Li Yen-p'ing. - Naissance de Tchou $\mathrm{Hi}$, ses premières études sous la direction de Hou Hien, Lieou Tche-tchong et Lieou Yen-tch'ong. Egarement passager, retour aux vraies traditions. - Sa haine contre les sectes de Lao-tse et de Bouddha. - Travaux littéraires et historiques. - Ses amis Liu Tong-lai et Tchang Tch'e. - Dispute avec Lou Tse-tsing. - Tch'en Choen, son disciple. - Persécution. - Mort. Noms divers sous lesquels il est connu.

Chapitre II : Influence de Tchou Hi.

Découverte de Wang Yang-ming. - Adversaires posthumes: Wang Se-hoai et Mao Si-ho. - Opinion de $\mathrm{M}^{r}$ Meadows contredite par le Rév. Griffith John et $\mathrm{M}^{r}$ J. Edkins. - Hommages rendus à Tchou Hi par les Empereurs. - Décret récent confirmant l'autorité du philosophe et condamnant Mao Si-ho. - Conclusion.

\section{DEUXIÈME PARTIE \\ POINTS PRINCIPAUX DE LA DOCTRINE DE TCHOU HI}

Chapitre I: Principes généraux du monde.

- Evolution cosmique : Eternité de la matière ; l'idée de création manque. - Période Yuen et les douze Hoei.

- Forme et matière ( $\mathrm{Li}$ et $\left.\mathrm{K}^{\prime} \mathrm{i}\right)$.

- Grand Extrême (T'ai-ki) : Enthousiasme de $M^{r}$ E. J. Coulomb. Le néant absolu des Taoïstes et le néant relatif de Tcheou-tse.

- Double mode de la Matière (Yn et Yang) : Remarque du $D^{r} A$. P. Martin. - Opinion de $M^{r}$ J . Legge sur le sens de $Y n$ et Yang dans le I-king. Matérialisme dans les livres chinois très anciens.

Chapitre II : Les trois agents.

- Ciel et Terre (T'ien ti) : Leur formation. - Titres donnés au Ciel, comme au plus parfait des êtres. - T'en et Chang-ti des modernes. - A quelle époque l'idée de Ciel est-elle devenue matérialiste ? - Le sentiment de $\mathrm{M}^{r}$ Legge semble inadmissible. 


\section{Le philosophe Tchou Hi}

- Mythologie et Tradition : Question du Terme. - Opinion du chanoine Mac Clatchie. - Le $D^{r}$ Legge et le I-king.

- Ciel père et Terre mère. Génération spontanée (K'i-hoa). Premier ancêtre de notre race.

- Égalité : T'ien-ming et Tien-tao. - Fraternité universelle. Qualités de la matière qui diversifient les êtres.

Chapitre III: L'homme.

- La nature : Opinion de Confucius et de Mong-tse. - Opinions hétérodoxes de Kao-tse, Siun-tse, Yang-tse et Han Wen-kong.Doctrine de l'école moderne. - Invention du K'i-tche tche sing ou de la nature composée.

- Perfectibilité de l'homme. Le sage (Kiun-tse). - Doctrine de la Rétribution.

- Le Saint ou l'homme parfait: Perfection sans mélange. Impeccabilité. - Connaissance de l'avenir.

- Ames et Esprits (Koei-chen) : Paroles de Confucius dans le Tchong-yong et le Li-ki. - Le lettré superstitieux voit des Esprits partout, dans tous les phénomènes de la nature. - Animaux mystérieux. - Confucius est-il un matérialiste ? Opinion de $M^{r}$ J. Legge et du P. Zottoli. - Vie et Mort.

TROISIÈME PARTIE

TRADUCTION DE LA SECTION 49 DES CEUVRES DE TCHOU HI

Chapitre I : Forme et matière : vue d'ensemble.

Chapitre II : Grand Extrême.

Chapitre III : Ciel et Terre. 


\section{Le philosophe Tchou Hi}

\section{PRÉFACE}

L'auteur a eu surtout en vue dans ce travail d'exposer, selon ses moyens, les idées que le lettré moderne puise dans ses livres, dès les jours de sa première éducation.

Ces livres, personne ne l'ignore, sont le moule commun où se forme, depuis bien des siècles, l'intelligence du peuple chinois. Obscurs par eux-mêmes, à raison de leur antiquité et de leur concision, ils sont accompagnés d'un commentaire classique rédigé dans un style généralement coulant et limpide. Le commentaire officiellement reconnu, et faisant loi aux examens publics, est l'œuvre du célèbre Tchou Hi. Beau diseur autant que philosophe détestable, cet homme est parvenu à imposer, depuis bientôt six siècles, à la masse de ses compatriotes une explication toute matérialiste des anciens livres.

Il est vrai que la plupart, contents d'un vague à peu près, emploient la terminologie du philosophe commentateur, sans se mettre guère en peine d'en rechercher le sens exact. II leur faudrait pour cela, s'ils en avaient le désir, le courage et les moyens, consulter des ouvrages spéciaux, comme le Sing-li ta ts'iuen ou son abrégé Sing-li ts'ing i. Et cela fait, le plus grand nombre ne concevra encore, sans doute, qu'une idée fort vague du système. Le système existe, en effet ; mais il est exposé à l'orientale, sans ordre ni suite, sans précision ni méthode. Nous avons essayé de le dégager des nuages qui l'enveloppent et empêchent d'en distinguer les traits essentiels. 


\section{Le philosophe Tchou Hi}

La présente étude se divisera en trois parties. Dans la première, après avoir brièvement fait connaître les principaux chefs de l'école moderne, que Tchou Hi regardait comme ses maîtres, nous verrons ce dernier les éclipser tous par son talent et acquérir, de son vivant même, une influence aujourd'hui encore presque toute puissante sur l'esprit de ses compatriotes.

Dans la seconde partie, nous nous proposons de grouper en peu de pages les points les plus importants de la doctrine réputée confucéenne, d'après les idées de Tchou $\mathrm{Hi}$. A défaut de la science de nos devanciers qui ont traité ces intéressantes questions, nous aurons, du moins, sur eux l'incontestable avantage de pouvoir produire bon nombre de textes chinois à l'appui de nos assertions. Peut-être même trouvera-t-on nos citations trop nombreuses. Mais l'adage « quod abundat non vitiat » nous semble s'appliquer surtout au genre d'étude qui nous occupe. Nos textes sont principalement empruntés aux Classiques et à leurs commentaires: plusieurs aussi sont extraits des compilations philosophiques ci-dessus mentionnées.

S'il nous arrive parfois, nouveau venu, de combattre sans merci les opinions de quelques vieux sinologues, nous osons compter sur leur généreuse indulgence. A propos surtout de la question si longtemps agitée de T'ien et de Chang-ti, lorsque nous disons que ces mots n'expriment plus à présent l'idée d'un être personnel, et qu'ils semblent même avoir perdu de très bonne heure celte signification, nous regrettons d'être en opposition avec des maîtres en sinologie, notamment avec Mr. J. Legge, le savant et consciencieux traducteur des Classiques chinois. 


\section{Le philosophe Tchou Hi}

La troisième partie contient un extrait du $49^{\mathrm{e}}$ chapitre des Fuvres de Tchou Hi. Nous acons cru devoir n'en traduire que ce qui venait plus directement à notre sujet ; cela suffira pourtant à donner au lecteur une idée de la méthode suivie par le philosophe dans son enseignement. La traduction publiée en 1875 par le chanoine protestant Th. Mac Clatchie, bien que loin d'être parfaite, nous a quelque peu aidé dans notre tâche. Bien à regret, nous ne pouvons en dire autant de l'ouvrage de Mgr. Ch. de Harlez (Philosophie de la Nature, Bruxelles, 1890) : nous aurions souhaité que sa traduction, moins hâtive et moins défectueuse, fût de celles qu'on recommande sans réserves au lecteur. 
Le philosophe Tchou Hi

\author{
PREMIÈRE PARTIE
}

\title{
COURT EXPOSE HISTORIQUE
}




\section{Le philosophe Tchou Hi}

\section{CHAPITRE I \\ TCHOU HI, SES MAÎTRES ET SES DISCIPLES.}

Dans la seconde moitié du $10^{\mathrm{e}}$ siècle, la Chine affaiblie par des révolutions intestines était menacée au dehors par la puissance toujours croissante des Tartares K'i-tan. En 960, les principaux officiers de l'armée, mécontents de voir le sort de l'Empire aux mains d'un enfant, dans des conjonctures si difficiles, se concertèrent pour porter sur le pavoi leur général en chef Tchao K'oang-yng (917-975). Ainsi fut fondée la dynastie Song, une des plus célèbres de la Chine. Sa gloire ne fut pas celle des armes. Sans cesse en butte aux incursions des terribles hordes du Nord, elle dut leur céder successivement des portions considérables de son territoire; puis, en 1227, malgré les expédients de ses habiles politiques, elle leur abandonna les provinces au Nord du Kiang et transporta sa capitale de Pienliang (auj. K'ai-fong-fou), prov. du Ho-nan, à Ling-ngan (auj. Hang-tcheou), prov. du Tché-kiang. Enfin elle disparut après trois siècles, cédant la place à la dynastie mongole. Mais la véritable gloire des Song fut celle des Lettres.

Dès les premières années $\mathrm{du} 11^{\mathrm{e}}$ siècle un élan extraordinaire était donné à la littérature nationale. Toutes les branches à la fois eurent part à cette Renaissance. Des historiographes, des poètes, des philosophes, des commentateurs et des critiques érudits parurent en grand nombre. - La splendeur des Lettres semblait croître en 


\section{Le philosophe Tchou Hi}

intensité, à mesure que l'Empire perdait de sa puissance matérielle et de son étendue.

Chao Yong est le premier par ordre chronologique dans la galerie des hommes célèbres de l'époque des Song. Né en 1011 à Lo-yang, de parents pauvres, il s'adonna de bonne heure à l'étude et s'y livra avec une ardeur passionnée. Après quelques voyages au Centre et au Nord, il revint se fixer définitivement dans la capitale. II y vécut dans une misérable hutte ouverte aux vents et à la pluie, manquant de feu en hiver et d'éventail pour se rafraîchir en été. Mais, content de son sort, il donna à sa hutte le nom poétique de Ngan-lo ouo (nid de la joie tranquille), d'où le nom de [] par lequel ses amis aimaient à le désigner. Li Tche-tsai, magistrat de la ville de Kong-tch'eng, dans la préfecture de Ouei-hoei, fut des premiers à apprécier le talent du Lettré solitaire. II se chargea volontiers de lui communiquer sa connaissance profonde du I-king ; et ses doctes leçons décidèrent Chao Yong à approfondir à son tour les mystères que les Chinois ont de tout temps attribués aux trigrammes de Fou Hi. Il crut bientôt avoir découvert dans les figures du [] et du [] des choses merveilleuses, qu'il développa plus tard dans un grand ouvrage en 60 kiuen. Son fils Pé-wen (1057-1134) y mit la dernière main et le publia sous le titre de []. L'abrégé de la Somme philosophique en contient une partie.

Dans cette œuvre très estimée des Chinois, à raison même de son obscurité, l'auteur donne libre carrière à son imagination. II s'enfonce dans les ténèbres du chaos primordial, où il voit le Ciel et la Terre prendre peu à peu leur forme ; il calcule la durée du monde, assigne le temps précis de sa destruction et celui de sa 


\section{Le philosophe Tchou Hi}

renaissance, et, fixant pour chacune de ces époques un nombre de siècles déterminé, il en compose des périodes qu'il ne soupçonne même pas de s'écarter le moins du monde de la vérité ${ }^{1}$. Voici le jugement du P. Amiot sur cette œuvre que les Lettrés considèrent comme de tout point orthodoxe, bien qu'elle contienne, nous semble-t-il, nombre d'idées taoïstes: «Pour moi, dit-il, qui ai lu quelques ouvrages des Philosophes Grecs, j'ose presque assurer que le système de Chao Yong peut être réduit, en dernière analyse, et à très peu de chose près, au système de Pythagore sur la vertu des nombres; car, ce que le Philosophe grec attribue aux Nombres, le Philosophe Chinois l'attribue aux Koua, ou Trigrammes de Fou Hi. Cependant, quoique ce système, en lui-même et dans son ensemble, soit une pure chimère ; pris séparément, et envisagé dans chacune des parties qui le composent, il renferme quantité de choses curieuses, utiles et même solides $\gg 2$.

Aimé de tous, heureux des découvertes merveilleuses qu'il faisait dans les anciens Livres, Chao Yong passait en paix ses jours dans son pauvre réduit, d'où l'ambition ne put jamais l'arracher. Les hommes les plus éminents dans la politique et les lettres venaient visiter dans son Nid et consulter le Docteur de la Joie Tranquille. Fou Pi, Han K'i, Se-ma Koang, fatigués de la vie orageuse de la cour, s'y donnaient souvent rendez-vous et venaient y chercher quelques instants de paix.

\footnotetext{
${ }^{1}$ V. $2^{\mathrm{e}}$ partie, i itio.

${ }^{2}$ Cf. Mémoires conc. les Chinois, $8^{\mathrm{e}}$ Vol. p. 50. - On pourra se faire quelque idée du genre de l'ouvrage en consultant ce qu'en a traduit Mgr Ch. de Harlez dans son «École Philosophique moderne de la Chine, ou Système de la Nature ». - Bruxelles, 1890.
} 


\section{Le philosophe Tchou Hi}

Vers l'an 1056, arrivèrent à la capitale les deux frères Tch'eng, dont les noms sont à jamais unis dans une commune gloire. Leur oncle Tchang Tsai ou Hong k'iu était déjà célèbre. II donnait des leçons publiques, où il interprétait le I King. Mais lorsqu'il eut entendu les doctes conférences de ses neveux, il se déclara vaincu, leur céda sa chaire avec la peau de tigre qui servait alors d'insigne honorifique aux expositeurs des Symboles, et bientôt après se retira dans la vie privée. II est l'auteur de plusieurs ouvrages connus sous les titres de .... : un recueil de mélanges littéraires porte aussi son nom. Le [] et le [] sont des opuscules philosophiques auxquels Tchou Hi ajouta plus tard des commentaires.

Les deux Tch'eng avaient eu pour maître Tcheou Toen-i, que l'école moderne reconnaît pour son fondateur ${ }^{1}$. Celui-ci était à Nan-ngan au S. O. du Kiang-si, chargé d'un petit commandement militaire, lorsque T'cheng Hiang fit sa connaissance. II voulut devenir son disciple ; mais Tcheou Toen-i lui déclara franchement qu'il le jugeait trop vieux pour réformer ses idées et profiter de ses leçons. Tch'eng Hiang résolut du moins de lui confier l'éducation de ses deux fils. L'aîné Hao, né en 1032, avait alors 14 ans ; le cadet n'en avait que treize.

Tcheou-tse communiqua à ses élèves les principes de sa philosophie, qu'ils devaient transmettre à la postérité dans leurs propres écrits et dans les deux ouvrages de leur maître, qu'ils éditèrent après sa mort, le T'ai-ki t'ou-chou et le T'ong-chou. Plus tard, Tchou Hi y ajouta des commentaires. - « Tcheou

${ }^{1}$ [], appelé aussi [], du nom du hameau au S. du Hou-nan, où il vit le jour la $20^{\mathrm{e}}$ année du règne de Tché-tsong (1017). 


\section{Le philosophe Tchou Hi}

Lien-k'i, dit le P. Cibot ${ }^{1}$, esprit vaste, génie hardi et subtil, se trouva dans un siècle également avide de connaissances et de nouveautés. L'l-king, si souvent commenté et toujours obscur, attira ses regards ; il entreprit d'y porter la lumière en se frayant une nouvelle route et en cherchant le pourquoi du pourquoi de toute la nature, dans les admirables symboles et la glose profonde de ce livre singulier ${ }^{2}$. A force de se p.6 retourner et de métaphysiquer sur les mots, il vint à bout de bâtir son système de I'yn-yang et du Ly-K'y ; système, après tout, qui vaut bien celui des nombres de Pythagore, des qualités de Callistrate, des atomes d'Epicure ...... »

Tchou Hi appelle Tcheou Lien-k'i « notre maître », le restaurateur de la vraie doctrine, le continuateur des traditions antiques. «Depuis la mort de Mong-tse, dit-il, le sens vrai du I

1 Essai sur la Langue des Chinois, $8^{\mathrm{e}}$ vol. des Mémoires concernant les Chinois, p. 166.

2 Livre singulier, sans doute; mais les symboles pris en eux-mêmes, que contiennent-ils d'admirable ? Voici le jugement plus sage, plus modéré du P. Zottoli (Cursus Litter. Sin. $3^{\mathrm{e}}$ Vol. p. 522): «Nil igitur sublime, aut mysteriosum, nil fædum aut vile hic quæras: argutulum potius lusum ibi video ad instructiones morales politicasque eliciendas, ut ad satietatem usque in sinicis passim classicis, obvias, planas, naturales... »- Et Legge, p. 22 de son Introduction du I King, formule ainsi son jugement sur cet ouvrage: «According to our notions, a framer of emblems should be a good deal of a poet ; but those of the Yî only make us think of a dryasdust. Out of more than 350 , the greater number are only grotesque. »Comment est-il donc possible qu'un tel livre ait trouvé des admirateurs et des panégyristes enthousiastes dans plusieurs anciens Missionnaires Jésuites de Chine? Les louanges évidemment exagérées décernées par eux aux anciens Livres Classiques en général, et au I King en particulier, nous semblent difficiles à comprendre autrement que par l'espoir qui les animait d'enrayer tôt ou tard le courant funeste qui, depuis le $12^{\mathrm{e}}$ siècle surtout, entraîne la masse des intelligences cultivées de cet Empire dans le matérialisme le plus absolu, et de les attirer par leurs propres livres, expliqués dans un sens spiritualiste, à la splendeur de la vérité chrétienne. Cette idée préconçue leur fit voir dans les anciens Livres, et surtout dans le I King, dont l'obscurité même permet souvent d'y trouver ce que l'on veut, des mystères sublimes, des vestiges étonnants de clarté de nos dogmes chrétiens. 


\section{Le philosophe Tchou Hi}

King était perdu. Les dynasties Ts'in, Han, Soei, T'ang ont passé tour à tour et cependant personne n'avait encore pu nous révéler les mystères renfermés dans ce Livre. Enfin, sous notre dynastie, les planètes s'étant réunies dans la constellation K'oei ont réellement ouvert pour les lettres une nouvelle ère de splendeur. Ce fut sous cette heureuse influence des astres que notre maître vint au monde; et que, sans les leçons d'aucun maître, il conçut dans son esprit l'ensemble parfait de la doctrine ${ }^{1}$. »- Tcheou Lien-k'i mourut en 1073, à l'âge de 56 ans ; il fut enterré, suivant son désir, près de sa mère à Tan-t'ou, ville de la préfecture de Tchen-kiang. Douze ans plus tard, l'aîné des frères Tch'eng suivait son maître au tombeau. II mourut à Loyang regretté de ses nombreux disciples (1085). Son frère dut accepter, l'année suivante, la charge d'Expositeur officiel des Classiques. Il venait de mettre la dernière main à son grand Commentaire du I King, lorsque l'influence de Se-ma Koang et de Tchou Koang-t'ing le fit élever au p.7 poste important de précepteur du jeune Empereur Tché-tsong qui, cette année-là même (1086), montait sur le trône impérial. Le caractère hautain de I-tch'oan lui attira beaucoup d'ennemis, surtout à la cour. Un censeur présenta même un mémoire au trône, dans

\footnotetext{
${ }^{1}$ La constellation K'oei est formée de quelques étoiles d'Andromède et des Poissons. Les astrologues chinois lui attribuent une influence favorable à la littérature : un temple du dieu des Lettres s'appelle []. - L'an 967, 8 année de T'ai-tsou, fondateur de la dynastie Song, les cinq planètes se rencontrèrent dans cette constellation. L'histoire chinoise parle de plusieurs conjonctions des Planètes. Le Rev. John Charmers A. M. (On the astronomy of the ancient Chinese) dit que ces affirmations ne méritent aucun crédit. II y eut bien, dit-il, quelque rapprochement, une sorte de conjonction imparfaite des Planètes, en mai 204 A. C., au commencement de la dynastie Han. Mais l'unique conjonction réelle des Cinq Planètes est celle qui arriva le 15 septembre 1186 sous la dynastie Song. - (V. Chinese Classics de Legge, Vol. III. Prolegomena p. 101).
} 


\section{Le philosophe Tchou Hi}

lequel il le dénonçait comme un querelleur et un intrigant. Dans ces circonstances, une plaisanterie un peu méchante du poète Sou Tong-p'ouo créa, entre eux et leurs amis respectifs une haine irréconciliable ${ }^{1}$. Les intrigues de ses envieux le forcèrent bientôt à se retirer de la vie publique. II en profita pour travailler à ses Commentaires des Livres Classiques. II mourut en 1107, à l'âge de 74 ans. Ses disciples le nommaient [] du nom d'une rivière qui coule à l'O. de la province du Honan, son pays natal. II fut admis au Temple de Confucius, sous le règne de Li-tsong, la première année de la période. Ses œuvres philosophiques et littéraires ont toujours joui d'une autorité considérable. Elles sont jointes à celles de son frère sous le titre d'Fuvres des deux Tch'eng. Tous deux s'efforcèrent constamment de raviver l'influence de l'antique orthodoxie, en s'opposant avec vigueur aux doctrines Bouddhiques et Taoïstes. Dans son commentaire sur le passage du Len-yu (ch. I, $2^{\mathrm{e}} \mathrm{p} . \mathrm{p}$. 16) où Confucius dit : " II est pernicieux de s'adonner à l'étude des doctrines nouvelles », Tchou $\mathrm{Hi}$ cite cette sentence de Tcheng-tse contre le Bouddhisme: «Les doctrines de cette secte-là semblent plus raisonnables que celle des hérésiarques Yang et Mé; et voilà précisément pourquoi elle est plus dangereuse. Il est du devoir de quiconque aspire à la sagesse de s'en éloigner avec horreur, comme on s'éloigne des chants lascifs et des plaisirs déshonnêtes. Sans cela on y donnera tête baissée. »

\footnotetext{
${ }^{1}$ Sou Tong-p'ouo, bien connu comme poète et commentateur, reçut en 1235 les honneurs du Temple de Confucius; mais en 1845 sa tablette en fut enlevée. La raison de cette dégradation est l'orthodoxie parfois douteuse de ses idées.
} 


\section{Le philosophe Tchou Hi}

Les travaux des frères Tch'eng contribuèrent beaucoup à imprimer à cette époque un mouvement puissant vers l'étude des auteurs classiques dans leurs sources. De nombreux disciples, attirés par leur réputation, étaient accourus de toutes les provinces : ils recueillaient avec avidité leurs enseignements, et, devenus maîtres à leur tour, les communiquaient à leurs élèves. Ainsi les idées nouvelles se répandaient de tous côtés à la fois. Vers la fin du $11^{\mathrm{e}}$ siècle, du vivant même du second des Tch'eng, elles avaient déjà pénétré dans le Fou-kien, où Yang Che les enseignait avec grand succès à des centaines de p.8 disciples. Yang Che était né en 1053 dans la préfecture de Yenp'ing, au Fou-kien. II vécut jusqu'à l'âge de 82 ans (1135). II est regardé comme de l'ère de l'École du Sud. Son plus grand titre de gloire, son éternel honneur aux yeux des Lettrés est d'avoir combattu sans relâche les réformes politiques de l'odieux Wang Ngan-che, ainsi que ses interprétations des Livres canoniques. Ce ministre exécré mourut en 1086. Dix-huit ans plus tard (1104), ses partisans réussirent à faire placer sa tablette dans le Temple de Confucius, et, en 1109, son fils Wang Yu recevait le même honneur. Mais Yang Che écrivit contre ces mesures une si énergique protestation que les tablettes durent être enfin rejetées (1177).

La même année que Yang Che (1135), mourut son compatriote et disciple Louo Ts'ong-yen (né en 1072), qui travailla à propager dans sa province la vraie doctrine des Sages, suivant les principes de Tcheou-tse (MI) et des frères Tch'eng. Le plus célèbre de ses élèves fut Li T'ong, plus connu 


\section{Le philosophe Tchou Hi}

sous le nom littéraire de $\mathrm{Li}$ Yen-p'ing, du nom de la préfecture où il naquit en 1093.

Le même district est plus fier encore d'avoir vu naître un homme dont l'influence sur l'état intellectuel et moral de ses compatriotes n'a été surpassée que par celle de Confucius luimême.

Le Nord de l'Empire venait de tomber depuis peu au pouvoir des Tartares, lorsque Tchou Hi vint au aronde (1150) dans la petite ville de Yeou- $\mathrm{k}^{\prime} \mathrm{i}$, la $4^{\mathrm{e}}$ année du règne de Kao-tsong, premier Empereur de la dynastie méridionale des Song. Sa famille était originaire de Ou-yuen, ville de la préfecture de Sinngan, aujourd'hui Hoei-tcheou fou, dans la province du Nganhoei. II n'avait que quatorze ans lorsqu'il perdit son père. Celuici lui recommanda, avant de mourir, de s'appliquer avec ardeur à l'étude, sous la direction de trois de ses amis, qui jouissaient alors d'une réputation méritée de vertu et de science. C'étaient Hou Hien, Lieou Tche-tchong et Lieou Yen-tch'ong.

A l'âge de 19 ans, le jeune homme fut reçu docteur; et peu après, à son retour de la capitale, il se rendit à Ou-yen pour visiter le tombeau de ses ancêtres, leur faire part de ses succès et réclamer leur assistance. - II paraît que ses premiers maîtres ne lui avaient pas communiqué les principes de la plus pure orthodoxie. Tchou $\mathrm{Hi}$ déplorait plus tard amèrement le temps qu'il avait consacré à l'étude des Livres bouddhiques. Dans la préface qu'il écrivit en tête d'une édition du Len-yu à l'usage des commençants, entre autres conseils qu'il leur donne, il leur recommande d'un ton paternel de ne jamais se laisser prendre au piége des fausses doctrines. Et il termine par ces mots: 


\section{Le philosophe Tchou Hi}

«Autrefois, p.9 hélas! j'eus presque ce malheur; mais, à présent que j'ai pu m'y soustraire, je forme le vœu sincère que vous ne suiviez pas non exemple. Ah! mes petits enfants, déployez sur ce point toute votre énergie et soyez constamment sur vos gardes!»- L'éditeur du [] ajoute à ces paroles le commentaire suivant: "Tchou-tse, dans sa jeunesse, s'était quelque temps fourvoyé dans la secte de Ché (Chakiamouni). A rage de vingt-quatre ans, il reconnut son erreur et, à l'école de maître Li Yen-p'ing, il revint aux vraies traditions. » Ces mots sembleraient indiquer que le jeune Tchou non seulement adopta les doctrines bouddhiques, mais encore qu'il se fit bonze.

Quoi qu'il en soit de cette conjecture, il est certain qu'à partir de l'époque de sa conversion (1154), la $23^{\mathrm{e}}$ année de la période Chao-hing, il ne manquait pas souvent l'occasion de montrer son dédain et sa haine profonde pour les sectes de Bouddha et de Lao-tse. Ces sentiments se rencontrent fréquemment dans ses écrits. II les communiqua aux lettrés de son siècle, et les modernes les puisent encore à son école. Tout lettré qui se respecte doit décrier les Bonzes et vilipender leur doctrine; c'est un lieu commun, une simple boutade sans conséquence; car dans la pratique de nos jours du moins, le Confucianiste le plus enragé réclame à l'occasion les services du bonze ou du Tao-che. II devait en être également ainsi au $12^{\mathrm{e}}$ siècle. Que Tchou Hi lui-même ait été, dans la pratique. inconséquent avec ses théories d'intolérance envers les sectes rivales, nous l'admettons sans peine ; mais qu'il ait encouragé le peuple aux superstitions bouddhiques, comme l'affirme J. Edkins dans son livre sur le Bouddhisme en Chine (pp. 360- 


\section{Le philosophe Tchou Hi}

361), rien absolument ne le prouve, tandis que les preuves du contraire abondent. Et, si le savant auteur ne prétend parler que de la croyance populaire à la rétribution future, nous répondons que Tchou $\mathrm{Hi}$, loin de l'encourager, l'a toujours combattue, comme on le verra plusieurs fois dans la $2^{\mathrm{e}}$ partie de ce travail. En attendant. que le lecteur se reporte à la page 152 du Chinese Buddhism, il y verra ces mots : By insertion in the Sacred Edict, these opinions (i. e. anti-bouddhiques et purement Confucéennes) have been widely spread, and are extensively approved of to the present dynasty. The author (Yong-tcheng) cites the judgment p.10 pronounced by $\mathrm{Chu} \mathrm{Hi}$, the philosopher and critic of the Sung dynasty, saying that the Buddhists care nothing for heaven and earth, or anything that goes on around them, but attend exclusively each to his single mind. They are then condemned for fabricating groundless tales of future happiness and misery. » - II semble qu'il y a contradiction entre ce que dit l'auteur ici (p. 152) et ce qu'il affirme plus loin (p. 360). «That I am not wrong in imputing to the literati who belonged to the later Sung dynasty, and especially $\mathrm{Chu} \mathrm{Hi}$, a principal part in the encouragement of the popular belief in future retribution, may be shown by the chronology ...... Chu fu-tsi witnessed all this, and did not protest against it. He saw also rising round him the novelty of Ch'ung-hwang-miau, with its judicial apparatus.... He saw these things and made no struggle against the extension of superstition » D'ailleurs, cet argument purement négatif ne saurait résister devant les expressions si fortes de mépris et de haine contre l'enseignement bouddhique, qui sortent très 


\section{Le philosophe Tchou Hi}

souvent du pinceau de Tchou $\mathrm{Hi}$, et dont nous avons déjà donné plusieurs spécimens.

Dès les premières années de sa carrière littéraire, Tchou $\mathrm{Hi}$ s'attira l'estime des hommes de lettres les plus célèbres de son époque. Plusieurs saluaient déjà leur maître en celui que la nation entière reconnaîtra bientôt comme le prince de sa Littérature. Un style net et limpide, une tournure de phrase coulante et variée, une érudition plus qu'ordinaire, une critique relativement indépendante, formaient dès lors le caractère de ses écrits. Son premier soin fut de réviser le Ta-hio et le Tchang-yong, auxquels il acquit définitivement rang parmi les Quatre Livres : les textes de ces deux ouvrages formaient jusque-là les chapitres quarante-deux et trente-et-un du Mémorial des Rites. II publia ensuite successivement ses éditions du Len-yu et de Mong-tse, ainsi que différents essais d'interprétation du I-king. Les auteurs qu'il cite de préférence dans ses commentaires sont Han Yu, Tcheou-tse, les deux Tch'eng et Tchang Tsai. II recueillit et publia les œuvres de ces philosophes, qu'il appelait ses maîtres, sans toutefois se croire obligé d'adopter en tout leurs idées. Ses lettres conservées dans le Recueil de ses Fuvres sous le titre de [] ou Mélanges littéraires, nous le montrent en rapport avec bon nombre de savants de son siècle. Aidé de quelques-uns de ses disciples, il revit l'histoire de Se-ma Koang (1009-1086), à laquelle il ajouta un texte ou sommaire de chapitres. II donna pour titre à son ouvrage T'ong-kien kang-mou ${ }^{1}$. «Environ cent

\footnotetext{
1 Se-ma Koang consacra plusieurs des dernières années de sa vie à composer son Abrégé des Histoires nationales de la Chine, depuis l'avènement des Tcheou jusqu'à son temps. Le travail ne fut achevé qu'en 1081, deux ans avant sa mort. Il parut sous le titre de [] ou Miroir général pour aider à bien gouverner. Son ami et collaborateur Lieou Jou, (1052-1078), fut chargé par
} 


\section{Le philosophe Tchou Hi}

ans après l'apparition de l'œuvre ${ }_{p .11}$ de Se-ma Koang, dit le P. de Mailla (Préface de l'Hist. génér. de la Chine), le célèbre Tchou Hi, qui la prisait infiniment, n'y trouva qu'une seule chose à redire, pour qu'elle eût toute la perfection qu'on pouvait lui donner ; il jugea qu'en y ajoutant un texte tel qu'est celui du Tch'oents'ieou de Confucius, qui présente sommairement et d'un coup d'œil ce qu'il y a de principal dans l'histoire, elle serait alors comparable à l'ouvrage de ce philosophe, accompagné des commentaires de Tso K'ieou-ming. Il fit donc, à l'imitation de Confucius, et dans le style laconique du Tch'oen-tsieou, toute I'histoire du T'ong-kien, qu'il y inséra en gros caractères, comme un texte, dont le T'ong-kien ne serait que le commentaire; il appela ce texte Kang-mou, c'est-à-dire le principal de I'histoire qui se présente aux yeux. De là le nom de T'ong-kien kangmou ».

On doit encore à Tchou $\mathrm{Hi}$ quelques biographies de sages lettrés et d'hommes d'Etat éminents de l'antiquité; elles forment, sous le titre de [], la $2^{\mathrm{e}}$ partie du $24^{\mathrm{e}}$ volume de ses Euvres. Mais sa plus grande gloire, aux yeux de ses compatriotes, est d'avoir exposé, aussi clairement qu'elles pouvaient l'être, les conceptions philosophiques de Tcheou Lienk' i, de Tchang-tse, etc, dans ses commentaires du T'ai-ki t'ouchou, du T'ong-chou, du Si-ming, du Tcheng-mong, ainsi que dans les leçons qu'il continua de donner jusqu'à sa mort à de nombreux disciples, leçons dont la substance nous a été soigneusement conservée dans le Yu-lei.

l'Empereur d'ajouter, sous forme d'Introduction aux Annales de Se-ma Kouang, tout ce qui précède les Tcheou et touche à la Période légendaire : c'est le Wai-ki. 


\section{Le philosophe Tchou Hi}

Au nombre de ses plus intimes amis étaient Tchang Tch'e et Liu Tsou-kien, plus connu sous le nom de Liu Tong-lai. On les nommait les «Trois éminences du sud-Est» ${ }^{1}$. Tchang Tch'e avait été formé à l'école de Hou Hong, un fils de Hou Ngan-kouo (1074-1138). Tchou $\mathrm{Hi}$ en parle toujours avec une respectueuse admiration, alors même qu'il réfute ses opinions. Liu Tong-lai se servit de son influence auprès de son illustre ami pour l'amener à publier, avec des notes explicatives, les principaux écrits des quatre premiers maîtres de la Nouvelle Ecole (Tcheou Lien-k'i, Tchang Tsai et les deux frères Tch'eng). Celui-ci accéda à ses désirs et composa son [] (Kin-se-lou), ouvrage en 14 kiuen, qui servit plus que tout autre ${ }_{\text {p.12 }}$ à répandre parmi les lettrés les principes matérialistes de la secte Athéo-politique.

Dans la correspondance de Tchou $\mathrm{Hi}$, une des lettres les plus remarquables est celle qu'il écrivit à Lou Tse-tsing, qui lui avait demandé quelques explications sur les premiers mots du Ou ki eul t'ai ki (I). Ce lettré jouissait d'une grande réputation. II soutenait, avec plus d'opiniâtreté que de logique, plusieurs opinions contraires à celles de Tchou $\mathrm{Hi}$; et ses doctrines ont toujours été regardées, par la majorité des Confucianistes, comme une source de graves erreurs. Un point surtout fut longtemps l'objet d'une vive controverse entre les deux champions. II s'agissait de savoir si, dans la formation intellectuelle et morale, la réflexion doit précéder ou suivre

1 Tchang Tch'e, de son nom littéraire [], était né au Se-tch'oan en 1133 : il fut admis aux honneurs du Temple de Confucius en 1211. - Liu Tsou-kien naquit à [] au Koang-si en 1137 ; sa famille était originaire du Tché-kiang. II mourut en 1181. 


\section{Le philosophe Tchou Hi}

l'enseignement reçu du dehors. Lou Tse-tsing soutenait que l'étude intime, personnelle, avec la réflexion, est le principe et la base de l'éducation; seule elle est indispensable et peut même suppléer tout-à-fait à l'enseignement extérieur. Après une longue dispute, dans laquelle Tchou-tse se fit remarquer, dit-on, par le calme imperturbable qu'il opposa à la fougue de son adversaire, chacun des combattants se retira plus raffermi encore dans ses idées. La méthode suivie dans ce genre de polémique par les philosophes chinois n'est pas du tout celle de la logique occidentale: leur Aristote n'a pas encore paru. Ils se contentent généralement de saisir dans l'argument de leur adversaire quelque point de détail, dont ils montreront facilement l'absurdité, en citant à l'appui des textes, dont l'interprétation elle-même entraînera la discussion sur un autre terrain.

En 1190, Tchou Hi fut chargé de la préfecture de Tchang tcheou. Là encore, outre les occupations de sa charge, il donnait des leçons à de nombreux disciples. Parmi ceux-ci il en remarqua un, dont le talent n'avait rien d'extraordinaire, mais qui montrait pour l'étude une ardeur passionnée, avec une persévérance peu commune. II se nommait Tch'en choen et était né près de Amoy, au Fou-kien (1153). - C'est lui, dit-on, qui le premier employa l'expression Sing-li dans le sens de Philosophie spéculative ${ }^{1}$. II fut l'un des plus enthousiastes admirateurs de son maître, dont il propagea les doctrines dans les provinces du sud.

\footnotetext{
1 Plus tard Hiong Kang-ta l'employa dans un ouvrage qui avait pour titre []. Dès lors, il fut universellement accepté, et on le rencontre passim dans les écrits philosophiques.
} 


\section{Le philosophe Tchou Hi}

Vers cette époque, les ennemis de Tchou Hi et les envieux de sa gloire redoublèrent d'efforts pour le discréditer auprès de l'Empereur Koang-tsoung (1190-1195). Plusieurs mémoires accusateurs parvinrent coup sur coup à la Cour. Un certain Lin $\mathrm{Li}_{\text {p.13 }}$ le représentait comme un révolutionnaire, un conspirateur dangereux. un chef de parti politique, dont il fallait au plus tôt déjouer les sourdes menées. Un autre, Chen Ki-tsou,en termes encore plus violents, l'accuse d'être le chef d'une société secrète, dont les sectateurs, racolés de tous les pays, s'abstiennent de viande et pratiquent des sortilèges. Des réunions suspectes se tiennent tantôt en la ville de Koang-sin, dans la pagode du Lac aux Oies, tantôt à Tchang-cha dans le Temple de la Respectueuse réserve; et tout s'y passe dans le secret le plus profond. Tchou $\mathrm{Hi}$, ajoutait l'accusateur, a manqué à ses devoirs de piété filiale envers sa mère et de soumission à son prince : à plusieurs reprises appelé à la cour, sous le règne de Hiao-tsong (1163-1190), il a obstinément refusé de s'y rendre. Pendant que la cour se réjouissait de la mort de Tchao J ou-yu, il s'est permis de le pleurer. Ses mœurs sont un scandale public ${ }^{1}$. Il donne des leçons aux jeunes gens des plus opulentes familles. dont il reçoit de riches présents.... etc. etc. Ces diatribes haineuses n'eurent pas d'abord le succès qu'en attendaient leurs auteurs. Mais, peu après, un personnage influent revint à la charge et réussit à le faire condamner à la privation de tout emploi et dignité (1196). Trois ans plus tard, l'empereur lui rendit quelques-uns de ses titres officiels; il lui offrit même une 


\section{Le philosophe Tchou Hi}

charge honorable, que l'âge et la maladie ne lui permirent pas d'accepter. Parmi les amis fidèles qui ressentirent le contre-coup de sa disgrâce, et furent poursuivis pour leur attachement aux doctrines du maître, étaient Ts'ai Yuen-ting et son fils Ts'ai Tchen alors âgé de 28 ans. Le père exilé à Tao-tcheou dans le Hou-nan, y mourut en 1198. Son fils, qui l'avait suivi dans son exil, revint alors à Kien-Yang, au Nord du Fou-kien, ramenant le cercueil de son père, qu'il déposa auprès de ses ancêtres.

Vers ce même temps, Tchou Hi commença à ressentir les cruelles infirmités qui ne devaient pas tarder à terminer sa vie. II fut assisté, dans ses derniers jours, par plusieurs de ses disciples. Le plus dévoué de tous à consoler et soulager son maître fut Ts'ai Tchen 2, qui l'assista avec amour et reçut son dernier soupir(1200), la $6^{e}$ année du règne de Ning-tsong. Tchou Hi est connu dans la littérature sous plusieurs noms qu'il prit luimême à différentes époques de sa vie, ou qui lui furent donnés par les lettrés de son temps. Son nom d'enfance fut [], c'est-àdire Enfant de Tch'en (ancien nom de la ville de [], où il naquit). Ensuite il fut nommé [] ou petit ( $\mathrm{Li}$ ) Yen-ping. Son maître Lieou Yen-tchong l'appela, «Grandeur qui se cache:» mais le disciple, par modestie, voulut changer le premier caractère et se nomma «Médiocrité cachée ». Dans la suite, il prit pour nom de plume le nom qu'il avait donné à sa solitude []. Plus tard, il

\footnotetext{
1 «II a séduit deux bonzesses dont il a fait ses concubines favorites ; durant sa magistrature à Nan-k'ang, il a entretenu un commerce criminel avec plusieurs personnes. »

2 Neuf ans après la mort de son maître, $2^{\mathrm{e}}$ année de la période Kia-ting (1209), Ts'ai Tch'en publia son Commentaire du Livre des Annales, qu'il avait commencé, sur son ordre, la première année du règne de Ning-tsong, comme il nous l'apprend au début de la préface de son ouvrage [].
} 


\section{Le philosophe Tchou Hi}

signait de préférence [], ou le vieillard obscur ; puis enfin, sur la fin de sa carrière, [], le vieux solitaire.

Son épithète posthume est Wen, l'accompli; et il est d'ordinaire désigné dans les livres sous le nom de [] ou le philosophe Tchou.

@ 


\section{Le philosophe Tchou Hi}

\section{CHAPITRE II}

\section{INFLUENCE DE TCHOU HI}

Wang Cheou-jen (1472-1528), plus connu sous le nom de Maître Wang Yang-min, raconte, dans une Dissertation sur les pensées de Tchou $\mathrm{Hi}$, en ses dernières années, « comment il fut longtemps troublé de rencontrer dans les écrits de ce philosophe tant de contradictions, qu'il ne comprenait pas qu'elles eussent pu échapper à un si grand génie. Or, pendant qu'il exerçait une charge à la capitale, il se mit avec ardeur à compulser les ouvrages du Maître, et fut heureux d'y trouver la preuve, à n'en pouvoir douter, que sur la fin de sa vie, Tchou-tse s'était bien rendu compte des erreurs qu'il avait émises dans ses écrits et qu'il s'en était amèrement repenti, au point qu'il s'accusait d'avoir parlé comme un insensé. Le mal était désormais irréparable. II eut pourtant la pensée d'en faire une rétractation, en publiant une révision générale de ses ouvrages : la mort ne lui en laissa pas le temps ». - Voilà ce qu'affirme Wang Yangmin. Il est vraiment dommage que, dans une question aussi intéressante, cet auteur ne se donne pas la peine de citer les paroles textuelles de Tchou-tse, ou, du moins, de nous indiquer au juste dans quelle partie de ses écrits il a trouvé cet aveu loyal, quoique un peu tardif, des égarements de son esprit. De plus, il est regrettable qu'il ne nous dise pas clairement et en détail sur quels points de doctrine portaient ces regrets. Peutêtre ne s'agit-il que de quelques opinions contestées, ayant rapport à l'arrangement du texte des Classiques, tel que l'avait 


\section{Le philosophe Tchou Hi}

fixé Tchou $\mathrm{Hi}$; ou bien encore de quelques interprétations peu sûres dans les nombreux Commentaires qu'il avait publiés dans les premières années de sa carrière littéraire, et sur lesquelles il revint au temps de la maturité de son génie. On conçoit qu'il regrettât de voir des erreurs et des contradictions dans les ouvrages écrits par lui, à différentes époques de sa longue vie, et qu'il eût souhaité de laisser à la postérité une édition définitive de ses Fuvres revues et corrigées par lui-même. Les regrets de l'auteur ne portaient sûrement pas sur le fond du système philosophique qu'il avait reçu de ses maîtres et que sa glose a servi à répandre par tout l'Empire et à imposer, pour de longs siècles, à l'intelligence de ses compatriotes. Wang Yangming, comme plus tard Mao Si-ho, et la plupart de ceux que l'on aime à lui opposer, étaient tout aussi matérialistes que Tchou $\mathrm{Hi}^{1}$. Leurs attaques n'ont jamais porté que sur des points de détail, importants sans doute à leurs yeux, mais qui ne sont pour nous que d'un intérêt tout-à-fait secondaire.

Quoi qu'il en soit, peu d'années après la mort du philosophe, la réputation de ses œuvres était déjà si bien établie, que I'Empereur Li-tsong, la seconde année de son règne, (1226) lui décernait le titre de [] Grand Maître. Bientôt, cédant aux vœux des lettrés, il l'admettait au Temple de Confucius (1241), au rang des Sien-jou. «Depuis lors, dit Meadows (The Chinese and their Rebellions), c'est-à-dire depuis le milieu du treizième siècle jusqu'à nos jours, durant une période de six siècles et demi, ses idées philosophiques, morales et politiques ont toujours eu en

\footnotetext{
${ }^{1}$ Pour ce qui regarde Mao Si-ho en particulier, il suffit de lire ses explications sur le Tchong-yong (surtout les chap. 30 et suivants), pour être convaincu de la vérité de ce que nous affirmons.
} 


\section{Le philosophe Tchou Hi}

Chine une autorité suprême ». Le Rév. Griffith John, dans un article publié par le Journal de la Société Asiatique $\left(\mathrm{N}^{\circ} 1\right.$ de Sept. 1860), sous le titre «The Ethics of the Chinese, with special reference to the doctrines of human nature and sin », exprime le regret de ne pouvoir souscrire au jugement du grave auteur sur l'influence actuelle de Tchou Hi. II se croit, au contraire, en mesure d'affirmer que des milliers de lettrés chinois de nos jours ne lisent pas leurs Classiques par les yeux de ce philosophe, mais pensent et jugent par eux-mêmes. L'affirmation est aussi catégorique qu'elle peut l'être ; elle a été répétée depuis par quelques auteurs européens, mais sans plus de preuves à l'appui. En vérité, depuis la fin du $12^{\mathrm{e}}$ siècle, quelle résistance sérieuse l'enseignement philosophique des Song a-t-il jamais rencontrée? Peut-on citer une réfutation du système matérialiste de Tchou-tse, faite par un lettré célèbre, et qui ait réussi, sinon à créer une école indépendante, du moins à détourner quelque peu le funeste courant ?

Au $17^{\mathrm{e}}$ siècle, un certain Wang Se-hoai composa un ouvrage en quatorze chapitres, intitulé Dissertation sur le T'ai-ki t'ouchouo de Tcheou-tse. II y voulait ${ }_{\text {p.17 }}$ déprécier les doctrines des philosophes de la dynastie Song, en montrant que leur T'ai-ki est d'invention taoïste et en opposition avec les principes de l'antique orthodoxie. Mais le résultat de cet effort isolé fut nul, ou à peu près. Avant Wang Se-hoai, dans la première moitié du $16^{\mathrm{e}}$ siècle, Wang Yang-ming avait essayé. de diminuer à son profit l'influence déjà depuis longtemps fortement établie de Tchou $\mathrm{Hi}$. Ces attaques, loin de porter atteinte à l'autorité de celui contre lequel elles étaient dirigées, tournèrent au 


\section{Le philosophe Tchou Hi}

désavantage de leur auteur. II trouva de vigoureux adversaires, entre autres Louo Tcheng-ngan (1465-1547), et il fut réduit à se défendre lui-même; car on ne l'accusait de rien moins que d'être un Bouddhiste déguisé et d'avoir puisé ses théories aux sources empoisonnées de Fou et de Lao-tse.

Un commentateur plus moderne (1623-1713) nommé Mao K'i-ling, plus connu sous le nom de Mao Si-ho, s'est signalé par une indépendance peu commune à contredire les opinions de l'école de Tchou Hi. Mais jusqu'à quel point cet essai a-t-il ébranlé l'autorité de ce dernier? II nous semble que nous ne nous trompons pas en affirmant qu'il reste toujours, pour la masse de ses compatriotes, le chef de l'orthodoxie, le commentateur officiel, le maître incontesté de la nation. Mr. J. Edkins (Chinese Buddhism, p. 361) croit que ce jugement est erroné ; qu'on ne doit pas considérer les vues de ce philosophe comme définitives et comme l'expression acceptée de la pensée chinoise, ancienne et moderne ${ }^{1}$. « Et, de fait, ajoute-t-il, il n'est peut-être pas un auteur qui ait été plus sévèrement jugé et condamné par les écrivains plus récents. » - Mais, demanderons-nous, quels sont ces juges indépendants ? Quelle autorité avaient-ils? Quelle valeur a-t-on attaché à leur jugement ? Quelle influence a pu avoir leur critique personnelle sur la généralité des étudiants et des lettrés ? Autant de points qu'il serait utile d'élucider. En attendant, il nous semble que la vérité est que l'influence de Tchou $\mathrm{Hi}$ demeure encore, hélas! prépondérante. La masse des Chinois ne comprend quelque

\footnotetext{
${ }^{1}$ Some foreign scholars appear to me to have erred in regarding his views as final, and as the accepted expression of Chinese thought, ancient and modern (l. cit.).
} 


\section{Le philosophe Tchou Hi}

chose de ses anciens Livres que d'après l'interprétation qu'il en a donnée dans ses commentaires. Ces commentaires sont dans toutes les écoles de l'Empire, répandant dans les esprits encore tendres les idées matérialistes, dont il est difficile qu'il ne reste quelque trace toute la vie. Les jeunes aspirants au Baccalauréat, lors de leur premier examen, composent une dissertation philosophique, en mettant à contribution les nombreux passages du système de Tchou $\mathrm{Hi}$, qu'ils ont rencontrés passim dans les explications classiques des quatre Livres et des cinq King. p.18 Pourraient-ils donner autre chose que ce qu'ils ont appris sur les bains de l'école?

Les honneurs du Temple de Confucius ne sont décernés qu'aux représentants les plus autorisés de la pensée nationale, aux lettrés orthodoxes et aux hommes d'État les plus influents. Or, parmi les célébrités que la postérité a honorées de cette distinction posthume, combien en trouvera-t-on qui aient fait opposition aux idées matérialistes qu'ont vulgarisées les travaux de Tchou-tse ? Depuis le $13^{\mathrm{e}}$ siècle, parmi plus de quarante sien jou associés au culte des anciens, sages, bien rares sont ceux qui ne se sont pas montrés ardents admirateurs et disciples enthousiastes du coryphée de l'Ecole moderne. C'est qu'ils voyaient sans doute en lui le continuateur des vraies traditions de l'antiquité, obscurcies depuis la mort de Mong-tse. Vers le milieu du $13^{\mathrm{e}}$ siècle, les princes mongols n'avaient pas encore, après cinquante ans de combats, achevé la conquête de la Chine, que déjà ils étaient eux-mêmes subjugués par l'ascendant

d'une civilisation supérieure. En 1280, Koublaï khan (1260-1295) devenait, sous le nom de Che-tsou, seul maître de l'Empire. par 


\section{Le philosophe Tchou Hi}

la mort de Ti-ping, dernier rejeton de la famille impériale des Song. Le chef de la nouvelle dynastie se montra constamment le protecteur des lettres. Ses successeurs imitèrent en cela son habile politique et purent se flatter d'avoir presque fait oublier leur titre odieux de conquérants étrangers. Sous la dynastie nationale des Ming (1368-1644), les études furent aussi florissantes qu'aux plus beaux jours de la littérature ; et toujours les idées de Tchou Hi jouirent d'une autorité sans conteste. La famille impériale considérait en lui une des gloires de son nom. C'est en 1415, la $13^{\mathrm{e}}$ année de Yong-lo (1403-1425) que fut publiée la fameuse compilation du Sing-li ta-ts'iuen, œuvre absolument indigeste, contenant les élucubrations plus ou moins philosophiques tirées des écrits de 120 lettrés. Cette ennuyeuse rapsodie en 70 longs volumes fut le triomphe des idées de Tchou-fou-tse. La $14^{\mathrm{e}}$ année de Tch'ong-tcheng (1642), dernier Empereur des Ming, un décret impérial ordonnait que, par une distinction sans précédent, la tablette de Tchou-tse fût transférée de la place qu'elle occupait parmi les Lettrés célèbres, au rang des 70 disciples immédiats de Confucius. Deux ans après, la dynastie Ming disparaissait sous les coups des Tartares mandchoux. La dynastie étrangère, dès son avènement au pouvoir, suivit la sage politique des Mongols.

Pour attacher à sa cause la masse influente des lettrés, elle montra un zèle extraordinaire à promouvoir l'étude des anciens Livres. Dans ce but, les premiers princes de la nouvelle famille impériale. Entre tous, l'illustre K'ang-hi, Yong-tcheng et K'ienlong ajoutèrent à leurs paroles la force plus grande de l'exemple. Ils devinrent eux-mêmes des p.19 maîtres consommés 


\section{Le philosophe Tchou Hi}

dans la littérature chinoise. Ils ne considérèrent jamais comme un vain titre leur position de Chefs suprêmes du Jou-hiao ; mais, fidèles à leur mandat, ils voulurent diriger les études de leurs nouveaux sujets dans la voie de l'orthodoxie confucéenne. Or, dans ce dessein, ils n'ont pas cru pouvoir leur indiquer de meilleurs modèles, des guides plus sûrs que les philosophes de l'école des Song et surtout Tchou-tse, qu'ils proclamèrent officiellement, à plusieurs reprises, l'interprète le plus autorisé des Livres sacrés.

K'ang-hi (1662-1723) avait appris de bonne heure la doctrine des anciens sages, telle que l'ont comprise et exposée les philosophes Tch'eng et Tchou. Nous en avons la preuve dans les Leçons journalières, ouvrage où les professeurs chinois du jeune monarque tartare consignent, dans un style clair et limpide, les explications sur les Quatre Livres, qu'ils avaient données oralement à leur impérial élève. C'est la $17^{\mathrm{e}}$ année du règne de ce prince (1678), que furent publiées ces Leçons, dont le souverain voulait faire bénéficier son peuple, afin que tous les esprits fussent, comme le sien, formés d'après les principes de la saine orthodoxie ${ }^{1}$. Son zèle pour cette œuvre de vulgarisation de ce qu'il jugeait être la vraie doctrine de Confucius, ne se démentit jamais, jusqu'à la fin de son long règne. En 1712, un décret impérial plaçait Tchou-tse dans la Salle de la Grande Perfection, immédiatement après les Dix Sages. Lorsque, vingt-six ans plus tard (1738), pour cause de symétrie, la tablette de Tse-jouo fut transportée aussi dans

\footnotetext{
1 Deux ans plus tard (1680), parut l'explication du Chou king. "It has, dit Legge, all the qualities which I ascribed to the sister work on the Four Books, being full, perspicuous and elegant ».
} 


\section{Le philosophe Tchou Hi}

cette Salle, l'ordre chronologique seul fit mettre Tchou-tse au douzième rang, le $6^{\mathrm{e}}$ contre le mur de l'Ouest, tandis que la $6^{\mathrm{e}}$ place à l'Est était donnée à son aîné. Ainsi fut complété le nombre des douze Sages, qui, dans le bâtiment principal du Temple, forment, avec ses Quatre Associés, la garde noble du Sage parfait, Confucius.

En 1712, K'ang-hi ordonna à son secrétaire Li Koang-ti de travailler à la publication des Euvres complètes de Tchou-tse. Quelque temps après, Li Koang-ti étant tombé malade, I'Empereur désigna par un décret un autre lettré, Tchang Yuchou pour surveiller le travail. Dans ce décret, K'ang-hi exprimait, dans les termes les plus forts, l'importance capitale qu'il attachait à cette œuvre. En tête de l'ouvrage, l'Empereur écrivit lui-même une préface, où il fait l'éloge le p.20 plus pompeux de l'auteur et de sa doctrine. Un mot la résume: K'ong-tse est grand et Tchou-tse est son prophète !

II nous apprend que, rentré dans sa capitale après sa campagne victorieuse contre les Eleuthes, il résolut de chercher désormais non la gloire des armes, qu'il ne saurait envier à Ts'in Che-hoang ou à Han Ou-ti, mais celle qu'apporte aux princes pacifiques la culture des lettres. Il s'est depuis lors adonné à l'étude avec ardeur: et, après plus de vingt ans d'un travail opiniâtre, il clairement reconnu combien est solide l'enseignement des lettrés de la dynastie Song. Tong Tchongchou et Han wen-hong ${ }^{1}$ n'avaient pas su pénétrer parfaitement la doctrine de Confucius et de Mong-tse. Les travaux de Chao

${ }^{1}$ ( $2^{\mathrm{e}}$ siècle av. J.-C.), littérateur et homme d'État sous [] (140 A. C.) - il fut homme d'État, philosophe et poète célèbre sous la dynastie T'ang (768-824). 


\section{Le philosophe Tchou Hi}

Yong 01011-1077), de Tcheou-tse (1017-1073) et des frères Tcheng (Ming-tao, 1032-1185, et I tchoan, 1033-1107), avaient fait beaucoup pour le progrès des lettres. Mais vint Tchou foutse, qui les éclipsa tous. Réunissant en sa personne la perfection du génie, il renoua enfin le fil des traditions rompu depuis plus de mille ans: dissipant les ténèbres de l'ignorance, il a établi pour toutes les générations à venir une régie d'interprétation invariable, qu'un Saint même, si à l'avenir il en paraissait sur la terre, ne pourrait transgresser.

Et l'Empereur ajoute qu'après une étude consciencieuse et approfondie de la doctrine de Tchou $\mathrm{Hi}$, il demeure pleinement convaincu que sans elle il est impossible de rien comprendre aux mystérieuses relations qui existent entre le ciel et l'homme: sans elle encore, il est impossible de gouverner en paix un Empire si vaste; impossible sans elle au prince de perfectionner sa personne et de faire goûter à ses peuples les fruits si désirables d'un sage gouvernement. En conséquence il charge les Docteurs Hiong Se-liu et $\mathrm{Li}$ Koang-ti de recueillir précieusement jusqu'aux moindres phrases tombées du pinceau du grand maître; et de réunir le tout pour une publication sous le titre de : Fuvres de Tchou-tse. Trois ans plus tard $\left(1717,56^{\mathrm{e}}\right.$ de son règne), K'ang-hi affirmait de nouveau sa haute estime pour les opinions philosophiques de l'Ecole moderne, en ordonnant à son secrétaire Li Koang-ti de former une commission, qui travaillerait à préparer une édition moins indigeste du Sing-li ta-ts'iuen, publié en 1415 par ordre du $3^{e}$ Empereur des Ming. L'ouvrage fut bientôt prêt; il parut en quatre volumes sous le titre de Sing-li tsing-i, ou Imperialis 


\section{Le philosophe Tchou Hi}

editio Medullæ philosophicæ ${ }^{1}$. p.21 Cet abrégé de philosophie a eu I'honneur de plusieurs éditions. En tête de la première, l'Empereur voulut mettre une préface de sa composition. Elle débute ainsi : Depuis les jours de notre jeunesse soixante ans se sont déjà écoulés, et jamais un seul instant les King et les Livres (chou) n'ont quitté nos mains. Les Saints et les Sages, qui se sont succédé depuis les âges reculés de T’ang Yao, de Yu Choen et des trois premières dynasties jusqu'à nos jours, dans les documents qu'ils se sont transmis, ne nous parlaient que de Sing (la Nature). Les lettrés de la dynastie Song furent les premiers à faire usage du terme Sing-li, voulant par là inculquer aux hommes que la perfection de la nature consiste uniquement à conformer tous ses actes aux principes de la droite raison ... Nous faisons savoir à tous les sujets de notre Empire, que quiconque étudiera ce livre y trouvera sûrement de quoi accroître ses connaissances. Fait en l'an 56 de K'ang-hi, $1^{\text {er }}$ jour de la $2^{\mathrm{e}}$ lune du printemps.

Le premier volume du Sing-li tsing-i 2 contient deux ouvrages de Tcheou Lien-k'i, le ...[1] et le ...[2]; avec le ...[1] et le ...[2] de Tchang Tsai. - Le second comprend le ...[7] de Chao Yong ; le ...[4] et le ...[4] ou Traité des Rites domestiques, l'un et l'autre de Tchou $\mathrm{Hi}$; enfin le ...[2] ou Théorie des sons musicaux de Ts'ai Yuen-ting. - Le troisième contient, sous le titre général de [], des principes sur l'éducation morale et intellectuelle, sur les relations sociales et l'étude de la littérature. - Le quatrième est

\footnotetext{
1 L'ouvrage fut, par ordre impérial, traduit en mandchou, afin de conquérir aux idées chinoises ceux dont les armes avaient conquis la Chine.

2 Le chiffre mis après chaque ouvrage indique combien de Livres ou kiuen il occupe dans la grande compilation.
} 


\section{Le philosophe Tchou Hi}

un abrégé de métaphysique, de cosmogonie et de principes sur le gouvernement.

Jusqu'à ces derniers temps, nos plus savants Sinologues semblaient tous reculer devant la tache ardue de traduire dans nos langues d'Occident cette somme philosophique extrêmement orientale pour le fond et pour la forme. Enfin $M^{r} G$. von der Gabelentz et $M^{r} W$. Grube publièrent, I'un le T'ai-ki t'ou-chou, l'autre le T'ong-chou de Tcheou-tse. Après eux, $\mathrm{M}^{\mathrm{gr}} \mathrm{Ch}$. de Harlez, déjà célèbre par ses vastes travaux de traduction et de critique sur l'Avesta ou Livres sacrés du Zoroastrisme, se lançait bravement dans ce nouveau champ d'exploration. En 1890, il offrait au public son «Ecole Philosophique moderne de la Chine, ou Système de la Nature (Sing-li) ». C'était la traduction presque intégrale du premier et du second volumes de la Somme, avec les parties les plus intéressantes des deux autres. L'entreprise, il faut l'avouer, ne manquait pas de difficultés. Le génie ${ }_{p .22}$ chinois diffère tellement du nôtre, qu'une traduction claire et exacte d'un livre quelconque est toujours chose très difficile. Mais la difficulté croît infiniment, lorsqu'il s'agit de rendre en une langue européenne les idées bizarres de ces penseurs creux, qu'on est convenu d'appeler philosophes. Aussi, tout en regrettant que la traduction de $\mathrm{M}^{\mathrm{gr}}$ de Harlez soit trop souvent inexacte et incomplète, nous ne nous en étonnons nullement: le contraire serait merveille. II serait à souhaiter qu'il voulût bien reprendre lui-même son travail et le confronter à nouveau avec le texte original. L'œuvre ainsi perfectionnée rendrait un véritable service non seulement à la science sinologique, mais encore à la 


\section{Le philosophe Tchou Hi}

religion, en montrant où vont aboutir les efforts de la pauvre sagesse humaine, privée des bienfaits de la révélation.

Sous les règnes de K'ang-hi et de Yong-tcheng, fut aussi publiée par ordre impérial la superbe édition des cinq King. En 1718, Li P'ei-ling donna au public sa Collection des plus importants commentaires des lettrés sur les Quatre Livres. - En 1730, paraissait, sous le nom [] ou Commentaire officiel des Quatre Livres avec une paraphrase.

En 1745, la $10^{\mathrm{e}}$ année de K'ien-long, un des lettrés les plus célèbres de la présente dynastie, Wang Pou-ts'ing, publia un ouvrage de compilation fort estimé, sous le titre de [], ou sens vrai des quatre Livres d'après Tchou $\mathrm{Hi}$, augmenté d'autres commentaires. Dans la préface, l'éditeur exalte en ces termes le mérite de Tchou-tse : «Entre les six Canoniques, le plus difficile à expliquer est le I King. Chao-tse tenta de le faire au moyen des nombres; Tch'eng-tse, au moyen du principe $\mathrm{Li}$; mais Tchou-tse seul a su pénétrer à fond et s'approprier la pensée intime des saints qui composèrent ce Livre » - Wang Pou-ts'ing était alors âgé de 74 ans, comme il nous l'apprend lui-même à la fin de sa préface. II se montra toujours un ardent admirateur de Tchou Hi. D'ailleurs, ce qu'il disait à la louange de son maître, les lettrés de son temps l'admettaient, on peut le dire, sans conteste ; et ceux de ce siècle l'admettent encore à la presque unanimité.

La meilleure édition des quatre Livres, œuvre d'un lettré de la dynastie Ming, parut en 1779 par les soins de Tou Ting-hi.

En 1827, une autre édition très soignée, surtout au point de vue typographique, était publiée par Kao Lin, sous le titre de []. 


\section{Le philosophe Tchou Hi}

En 1852, une autre production remarquable du même genre parut sous le nom de Kin tch'eng. Tous ces ouvrages, et bien d'autres encore, sont classiques; ils ont eu de nombreuses éditions et répandent par tout l'Empire les explications du commentateur officiel, qu'ils reproduisent toujours intégralement.

En 1868, la librairie [] publiait au Fou-kien, sous p.23 le haut patronage de Tsouo Tsong-tang alors vice-roi de cette province, une édition nouvelle et considérablement augmentée d'une importante collection des ouvrages littéraires et philosophiques les plus célèbres. La première édition était l'œuvre de Tchang Pé-hing, fameux pour son zèle à vulgariser les doctrines de l'Ecole des Song. Celui-ci vécut en grand renom de savoir, sous les règnes de K'ang-hi et de Kien-long (1652-1725), et a été admis récemment (1878) au Temple de Confucius, à côté de son illustre contemporain Lou P'ing-hou (1630-1692). La nouvelle édition n'a pas moins de 160 volumes, dont 19 contiennent des œuvres littéraires et philosophiques de Tchou Hi.

Terminons ici la série déjà bien longue de ces témoignages en faveur de notre thèse, par un édit impérial paru tout récemment dans la Gazette officielle, par lequel l'Empereur Koang-siu confirme de nouveau l'autorité suprême de Tchou Hi dans la formation intellectuelle et morale de ses compatriotes. Mao Siho, son principal adversaire, y est sévèrement jugé et flétri ; son ouvrage de controverse indépendante y est condamné et mis à l'index. L'impression et la vente en sont prohibées. Dans les examens littéraires, on exclura, avec encore plus de soin que par le passé, toute composition qui soutiendrait des opinions 


\section{Le philosophe Tchou Hi}

contraires à celles du Commentateur officiel. L'enseignement de Tchou $\mathrm{Hi}$ est donc, une fois de plus, proclamé la règle de l'orthodoxie confucéenne. Voici la traduction fidèle de cet important document :

"Décret de Sa majesté Impériale, daté du 15 de la $6^{\mathrm{e}}$ lune ( $20^{\mathrm{e}}$ année de Koang-siu, 17 juillet 1894). L'Examinateur de la province du Ho-nan, Chao Song-nien, Nous a adressé un mémoire, dans lequel il Nous prie de faire respecter la doctrine orthodoxe. «Mao K'i-ling, dit-il, dans un ouvrage intitulé Sechou kai-ts'ouo, ou Corrections d'opinions erronées sur les quatre Livres, abuse de la souplesse de son esprit, pour battre en brèche l'autorité des anciens sages. Dernièrement ce livre, reproduit par la (photo-)lithographie, s'est beaucoup répandu. Quelques lettrés d'une haute intelligence, séduits par les idées nouvelles qui y sont énoncées, en sont venus à croire que les pensées de Tcheng et de Tchou ne font plus loi. Je supplie Votre Majesté de prohiber sévèrement ... etc. » - Le Se-chou kaits'ouo contient en effet plusieurs idées en opposition avec l'explication orthodoxe de nos Livres. II peut donc avoir une influence funeste sur l'esprit des lettrés. Et, puisque déjà cet ouvrage a pénétré jusqu'au Ho-nan, il est bien à craindre qu'il ne parvienne à s'introduire également dans les autres provinces. Nous enjoignons donc à tous les Vice-rois et Gouverneurs de publier une proclamation défendant, sous les peines les plus graves, la vente de ce livre. Pour les compositions littéraires faites au temps des p.24 examens, que l'on se conforme religieusement aux prescriptions jusqu'ici en rigueur. Que les Commentaires de Tchou-tse aient donc toujours, aux yeux de 


\section{Le philosophe Tchou Hi}

tous, l'autorité suprême. Ne souffrez jamais que l'on y introduise des opinions contraires aux siennes. ce qui porterait grand dommage à notre littérature. Ainsi vous montrerez que vous partagez Notre extrême sollicitude à procurer la splendeur des lettres et l'orthodoxie de l'enseignement. Respect à cet ordre!»

De tout ce qui précède il ressort que la gloire de Tchou $\mathrm{Hi}$ et son autorité n'ont fait que croître, depuis le début du $13^{\mathrm{e}}$ siècle jusqu'à nos jours. Sa mémoire a été honorée par les princes des quatre dernières dynasties, sans une exception. II a été, et il est encore, universellement considéré comme l'Interprète autorisé de la vraie tradition, comme le Préservateur de la pure orthodoxie. Très rares sont ceux qui ont osé s'écarter, sur des points même de moindre importance, de la voie qu'il a tracée dans ses Commentaires pour l'intelligence des anciens livres. Pas un lettré chinois de quelque valeur, qui ait essayé de combattre dans son ensemble le système cosmogonique et psychologique dont Tchou $\mathrm{Hi}$ a été, sinon le fondateur, du moins le principal expositeur et le patron. La masse des étudiants puise dans ses livres les idées du matérialisme le plus absolu. Grâce à ses enseignements, l'esprit et le cœur d'un peuple immense semblent, pour longtemps encore, hélas! fermés aux nobles aspirations pour lesquelles le bon Dieu les a faits. Mais le bras divin n'est pas raccourci ; et la sainte Eglise du Christ distribue à toutes les nations les paroles de la vie éternelle.

Puissions-nous, par nos prières et nos travaux, hâter, ne fûtce que d'un instant, l'heureux jour où le Verbe de Dieu, dissipant 


\section{Le philosophe Tchou Hi}

enfin les ténèbres épaisses qui couvrent cette terre, sera connu, aimé, adoré de tous, puisqu'il est lui seul la Voie, la Vérité, la Vie de tout homme venant en ce monde !

@ 
Le philosophe Tchou Hi

DEUXIÈME PARTIE

POINTS PRINCIPAUX

DE LA DOCTRINE DE TCHOU HI 


\title{
Le philosophe Tchou Hi
}

\author{
CHAPITRE I \\ PRINCIPES GÉNÉRAUX DU MONDE
}

\section{§ 1. ÉVOLUTION COSMIQUE.}

p.27 On chercherait en vain dans les livres chinois l'idée de création, au sens complet du mot, c'est-à-dire de production du néant. Pour les philosophes de l'Extrême-Orient, comme pour les Grecs et les Romains de l'antiquité païenne, l'éternité de la matière est un dogme fondamental. D'après eux, le monde a toujours existé et existera toujours, roulant dans un cercle sans fin d'évolutions successives. Une période de chaos succède avec une régularité fatale à l'éclosion ou à l'épanouissement des êtres ; et, après une durée que Chao K'ang-tsié fixe à 129.600 ans, tout sera de nouveau englouti dans le Chaos, qui épargnera cependant les éléments d'une nouvelle reconstitution.

Cette opinion singulière sur la durée de l'évolution cosmique est adoptée aussi par ${ }^{1}$ Tchou $\mathrm{Hi}(\mathrm{III}, 6)$ et par plusieurs des auteurs cités dans le Sing-li ta-ts'iuen. Ils appellent cette période Yuen ou la Grande Année, qu'ils représentent par la figure cijointe d'un cadran formé de douze subdivisions (hoei). Dans le premier Hoei (Tse), le Ciel ouvre le Chaos ou Grand Réceptacle.

\footnotetext{
1 Pour ne pas accumuler outre mesure les citations de textes chinois, nous renvoyons à notre traduction du chap. $49^{\mathrm{e}}$ des Euvres de Tchou Hi, qui forme la $3^{\mathrm{e}}$ partie de ce travail. Le chiffre romain I indique la première section ; II, la $2^{\mathrm{e}}$; III, la $3^{\mathrm{e}}$; Les chiffres arabes indiquent les paragraphes.
} 


\section{Le philosophe Tchou Hi}

A la deuxième heure (Tch'eou), la Terre apparaît à son tour. De leur union féconde doivent sortir tous les êtres de l'Univers. Voici comment un savant lettré Ou Lin-tch'oan du temps des Song, $\left(4^{\mathrm{e}}\right.$ Empereur de la dynastie méridionale, 1195-1225), décrit l'évolution initiale du Chaos (Cf. Appendix):

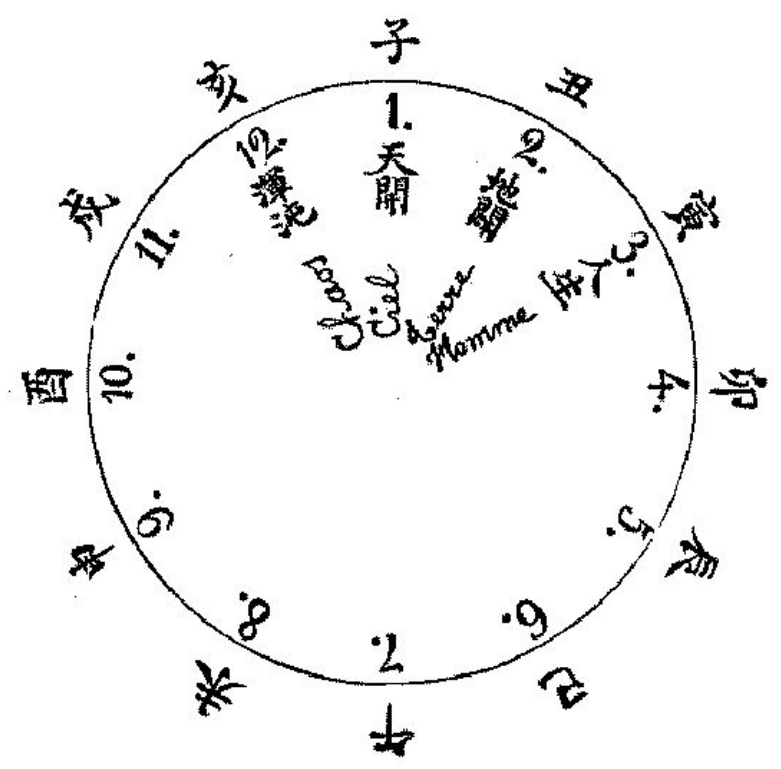

«p.28 La période cosmique (Yuen) est de 129.600 ans. Elle se divise en douze Hoei, de 10.800 ans chacune. Lorsque le ciel et la terre, dans leur révolution, atteignent le $11^{\mathrm{e}}$ Hoei $(\mathrm{Siu}$,$) tous$ les êtres sont renfermés; c'est la fin de l'homme et de tout ce qui existe entre le ciel et la terre. Encore 5.400 ans et le Hoei Siu est passé. La $5.400^{\mathrm{e}}$ année après le commencement du $12^{\mathrm{e}}$ Hoei (Hai) est le milieu de cette division: alors la portion de matière lourde et grossière qui, en se solidifiant, avait formé la terre, se désagrège, se dissout et, avec la matière légère et plus subtile du ciel, se mélange en une seule masse : on appelle cet état Hoen-t'oen ou Chaos. Ce mélange chaotique de la matière pure et grossière tourne d'un mouvement de plus en plus rapide; et, lorsqu'après un autre espace de 5.400 ans le Hoei 


\section{Le philosophe Tchou Hi}

Hai touche à sa fin, les ténèbres sont à leur dernier degré de densité. Et voilà une fin du monde (litt. du Ciel et de la Terre).

Au point Tcheng la grande période recommence, une nouvelle ère s'ouvre: c'est le commencement du $1^{\text {er }}$ Hoei (Tse.). Le Chaos dure encore, on l'appelle T'ai che ou Grand début, parce que c'est le début d'une nouvelle période. On l'appelle aussi la Grande Unité parce que la matière subtile et grossière ne forme qu'une seule masse chaotique, qui ne s'est pas encore divisée. Dès lors, la lumière va augmentant par degrés (insensibles). Après une durée de 5.400 ans, au milieu du Hoei (Tse), la partie légère et subtile de la matière universelle, ( $\left.K^{\prime} i\right)$ s'élève dans l'espace, formant le soleil. la lune, les planètes p.29 et les constellations d'étoiles : ce sont les luminaires ou signes célestes dont l'ensemble constitue le ciel (visible).

Après un autre espace de 5.400 ans, le Hoei Tse (la $1^{\mathrm{e}}$ heure du cadran cosmogonique) touche à sa fin. Voilà pourquoi l'on dit que «le Ciel s'ouvre (ou paraît) dans Tse». Cependant la portion plus grossière de $K^{\prime} i$ est demeurée au centre, sans toutefois s'être formée en une masse solide: aussi la terre n'existe pas encore.

Une nouvelle période de 5.400 ans s'écoule : c'est le milieu $\mathrm{du} 2^{\mathrm{e}}$ Hoei (Tcheou). La matière plus pesante se tasse; elle commence à se solidifier, formant l'humus et les minéraux (divers). L'élément humide de la matière devient l'eau qui coule et reste liquide, tandis que l'élément calorique devient le feu qui brille et ne s'éteint pas. L'eau, le feu, I'humus et les minéraux ont ainsi leur forme spéciale et tous quatre ensemble composent 


\section{Le philosophe Tchou Hi}

la Terre. C'est pourquoi l'on dit que « la Terre a paru (litt. s'est ouverte) en Tch'eou, $2^{\mathrm{e}}$ heure $»$.

Encore 5.400 ans, le Hoei Tch'eou se termine; alors le $3^{e}$ Hoei Yn commence ; 5.400 ans s'écoulent à partir de ce point ; et au milieu de la $3^{e}$ heure (Hoei) les êtres humains commencent à naître entre les deux i. e. le Ciel et la Terre. De là l'expression «l'homme est né en $\mathrm{Yn}{ }^{1}$.

\section{$\S$ II. LI ET K'I}

L'univers et chacune de ses parties sont composés de deux principes coéternels, infinis, distincts mais inséparables. On les nomme $\mathrm{Li}$ et $\mathrm{K}$ 'i. Li est le principe d'activité, de mouvement, d'ordre dans la nature; ce que nos évolutionnistes contemporains $\mathrm{H}$. Spencer, Darwin, Hackel appellent une force de développement inhérente à la matière, qui sans elle resterait inerte et, à son retour périodique au chaos, demeurerait dans une irrémédiable confusion (I. 9, 24). C'est le dominans ille in nobis deus de Cicéron, le Spiritus intus alit..., le Mens agitat molem de Virgile ( $/ E n$. VI.). K'i est la masse gazeuse, aériforme, indispensable à son coprincipe Li, qui sans elle ne saurait agir, ni même exister, car il manquerait de point d'appui. Li est un principe nécessaire, aveugle, inconscient, semblable au Fatum

\footnotetext{
${ }^{1}$ Le lecteur aura peut-être remarqué que depuis l'apparition de I'homme sur la terre jusqu'au règne du chaos, c'est-à-dire depuis la $3^{\mathrm{e}}$ heure jusqu'au commencement de la douzième, il y a neuf divisions horaires. Ne pourrait-on pas avec quelque bonne volonté voir là une tradition des neuf âges qui, d'après la Bible, précédèrent le Déluge ?
} 


\section{Le philosophe Tchou Hi}

des Latins (I. 10). II ne peut y avoir entre ces deux coprincipes priorité ou postériorité de temps ; on doit p.30 pourtant concéder à Li une certaine priorité de raison et de dignité, comme étant la source universelle de la vie, de la sensation, de l'intelligence et des cinq Vertus morales (Bonté; Justice; Convenance ; Sagesse ; Loyauté) (I. 5).

Li est imperceptible aux sens. K'i peut avoir une forme sensible; Li est illimité, K'i est compris dans des bornes fixes, lorsqu'il se condense pour former des êtres particuliers ; Li est le fondement de l'unité, est la source de la diversité entre les êtres. Voilà pourquoi, dit Tchou-tse, nous accordons la priorité à Li sur son coprincipe.

Le point de départ de l'évolution du monde a été nommé par Tchang-tse (Tcheng-mong, initio) le Grand Calme (T'ai houo). Alors les éléments subtils de la matière universelle sont dans un parfait repos ; mais bientôt, sous l'impulsion du principe actif Li, le Grand Vide (T'ai hiu) commence la série périodique de ses transformations :

« Totam infusa per artus

Mens agitat, molem et magno se corpore miscet ».

Voyons, avant de passer outre, ce que nos philosophes entendent par leur T'ai hiu. Admettraient-ils ici quelque chose de ce qu'ils appellent les détestables erreurs de Lao-tse et de Bouddha ? - D'après Lao-tse, le Non-Etre (Ou), le Néant absolu, a précédé l'Etre et lui a donné naissance. D'après la doctrine Bouddhique, en dehors du Non-Etre, il n'y a rien de réel ; tout n'est qu'illusion. 


\section{Le philosophe Tchou Hi}

Les lettrés, eux, enseignent l'éternité de la matière, et rejettent l'idée du néant absolu. Par le mot Ou (Non-Etre) ou T'ai hiu (Grand Vide) ils désignent seulement l'état de la matière universelle, alors que ses atomes sont tellement dispersés dans l'espace qu'ils sont imperceptibles aux sens. "II répugne, dit Tchang-tse, que le Grand Vide existe sans la matière $K^{\prime} i$ : et cette matière ne peut pas ne pas se condenser pour former tous les êtres; et les êtres ainsi formés ne peuvent pas ne pas se dissoudre de nouveau pour reconstituer le Grand Vide dans sa forme première. Or, tous ces changements d'état se font d'une manière spontanée, fatale.

La condensation et la dispersion des atomes dans le T'ai hiu peuvent se comparer à la congélation et à la fonte de la glace dans l'eau. « Nous savons pour sûr, dit le même auteur, que p.31 le Grand Vide n'est que le K'i lui-même (en différents états) ; il n'y a donc pas de néant absolu. Aussi les anciens sages, lorsqu'ils dissertent de la nature et du premier principe ( $\mathrm{Li}$ ), se bornent à mentionner les mouvements réguliers et les transformations de la matière. Tous ceux qui croient à la légère qu'il y a distinction de Etre et Non-Etre, montrent par là qu'ils manquent de science philosophique ».

Les deux principes, formel ( $\mathrm{Li})$ et matériel $\left(\mathrm{K}^{\prime} \mathrm{i}\right)$, essentiellement inséparables, bien que distincts, constituent par leur éternelle union la Grande monade (Tai-i), être infini, intrinsèquement doué d'activité par la présence intime de Li qui le compénètre et en fait comme un animal immense, capable d'engendrer toutes choses en lui-même et de sa propre substance. Avant que la monade n'ait produit ses actes en se 


\section{Le philosophe Tchou Hi}

fractionnant à l'infini, on l'appelle aussi Hoen-t'ien et Hoen-luen, c'est-à-dire matière encore à l'état informe du chaos.

Lié-tse appelait la matière première à l'état invisible T'ai-i, parce qu'elle est le sujet de toutes les productions et transformations dans la nature. Devenue visible par la condensation des atomes, il la nomme T'ai-tchou. Un lettré moderne, Hiu Yong-tch'ai, décrit comme il suit les divers états par lesquels I'Univers passe, avec une régularité fatale, du chaos à l'ordre et de l'ordre au chaos. Le passage est cité dans le Singli ta-tsiuen : «Le monde immense (litt., ciel et terre) est formé de la matière première avec ses deux modes ( $Y n$ et Yang), tantôt imperceptible aux sens, tantôt visible dans ses transformations nécessaires, éternelles et sans fin. II fut certainement un temps où tout était dans le chaos; puis se fit l'ouverture, l'éclosion du monde. Mais avant l'apparition de Fou-

hi, combien de temps s'était déjà écoulé depuis l'Ouverture du monde, je l'ignore. Le Chaos et l'Ouverture sont deux états dans l'évolution de la matière, l'un de progression et de libre expansion, l'autre de déclin et puis d'arrêt : c'est ce que le I king désigne par les deux caractères [] et [].

«Lorsque la matière avec ses deux modes évolue et se répand librement (ce qu'on exprime par les mots [] et [], alors le ciel, formé de la portion matérielle plus pure et plus subtile, s'élève et flotte en haut, tandis que la terre se condense et demeure en bas. Les hommes naissent et se multiplient entre le ciel et la terre. Alors paraît une nouvelle série de grands rois et de sages princes. La perfection humaine atteint son apogée. Après un si beau début, un tel épanouissement des êtres, il 


\section{Le philosophe Tchou Hi}

semblerait que le monde ne dût plus revenir à la confusion du chaos primitif. Mais le mouvement d'évolution de la matière ne peut pas toujours être en progrès, ni son expansion se faire sans p.32 obstacle. Quelque cent mille, ou peut-être seulement quelque dix mille ans s'écouleront, après quoi le progrès sera sûrement suivi d'une période de déclin ; après la libre expansion viendra l'arrêt, l'obstruction.

« Enfin, au dernier point de déclin et d'obstruction, la matière plus subtile, qui s'était élevée pour former le ciel, en redevenant impure s'abaissera par degrés : la matière condensée qui, en se tassant, avait formé la terre, se désagrégera. La multiplication si grande des humains diminuera aussi, puis s'arrêtera complètement. Alors les cinq éléments n'auront plus leur action propre. L'eau et le feu agiront contrairement à leur nature. Le feu, au lieu de briller dans l'espace, pénètrera dans les profonds abîmes. L'eau, au lieu de remplir les cavités terrestres, s'élèvera en bouillonnant (cf. III, 4). Ainsi l'eau et le feu agiront l'un et l'autre contrairement à leur propension naturelle; mais l'eau doit être l'agent principal qui réduira le ciel et la terre au chaos. Tout ce qui a été produit auparavant, redevient dès lors une masse confuse. Et, lorsque le monde rentre ainsi dans le Chaos, la seule chose qui ne périt pas, c'est la matière primordiale.

« Cette matière première conservée sera l'instrument d'un nouvel état de progrès succédant à la période de déclin, et de libre expansion après un temps d'arrêt. Quelque cent ou quelque mille ans peut-être se passent; puis la matière céleste, qui s'était abaissée en se chargeant d'impuretés, redevient pure et s'élève de nouveau ; la matière terrestre, qui s'était désagrégée, 


\section{Le philosophe Tchou Hi}

reprend sa densité et s'entasse; les êtres humains, détruits jusqu'au dernier, reparaissent sur la terre et s'y multiplient. Pendant que la matière universelle évolue, progresse et se répand sans obstacle, tout ce qui existait à l'état de chaos retrouve son épanouissement dans un ordre nouveau. Ainsi donc le monde passe graduellement de l'éclosion des êtres au chaos, par la même raison qu'il avait d'abord progressivement passé du chaos à l'épanouissement. Et, au début de l'ère nouvelle, il doit nécessairement y avoir des hommes d'une intelligence et d'une sagesse extraordinaires, qui gouvernent comme lieutenants du ciel, et ainsi la perfection des humains est à son apogée. Au commencement de chaque Ouverture du monde, il paraît un sage Fou-hi ». (Cf. texte chinois à I'Appendice).

\section{$\S I I I . T^{\prime} A I-K I$.}

T'ai-ki () est un autre nom du principe d'activité (Li), considéré maintenant par rapport à la formation prochaine des êtres. Il peut se définir : I'ensemble des énergies de la masse p.33 universelle, la cause formelle prochaine du monde dans chacune de ses parties (cf. II ; 1, 2 et passim. Le commentateur classique du Li-ki donne de T'ai-ki la définition suivante, où le $\mathrm{P}$. Prémare a dû voir un vestige bien marqué du dogme de la Trinité : c'est le principe d'unité des trois Agents universels ([], i. e. le Ciel, la Terre et l'Homme).

Tout être physique ou moral, les portions parfaites (Yang) et imparfaites (Yn) de la matière, les cinq éléments, les passions même de plaisir, de joie, de colère, de tristesse; tout sans 


\section{Le philosophe Tchou Hi}

exception est informé de T'ai-ki et le possède dans son intégrité. II est en toutes choses, et cependant reste un, sans division. C'est, dit Tchou $\mathrm{Hi}$, comme la lune qui éclaire la nuit : elle est une au ciel; et lorsqu'elle répand sa douce lumière sur les fleuves et les lacs, on la voit reflétant partout son disque, sans que l'on puisse dire pour cela que la lune est divisée et perd son unité (II. 11). «Jamais, s'écrie Mr. E. J. Coulomb, dans son livre Le secret de l'Absolu, jamais la philosophie occidentale n'a atteint ces hauteurs! » Pauvres Occidentaux, espérez; bientôt la lumière se lèvera pour vous. Le grand Coulomb et son vénérable ami Arthur Arnould vous apportent la sagesse de l'Extrême-Orient! Oyez et pâmez-vous d'enthousiasme ; bénissez les apôtres du T'ai-ki !

Tcheou Lien-k'i commence son premier ouvrage par les mots Ou ki eul t'ai ki. L'expression prêtait à diverses interprétations : elle ne manqua pas de soulever bien des disputes. Les uns y voulurent voir admise par le fondateur de la nouvelle Ecole la doctrine taoïste du Néant, qui aurait précédé la naissance du monde, et d'où serait spontanément sorti le T'ai-ki, cause plus immédiate de tous les êtres. Pour donner plus de crédit à leur interprétation arbitraire, ils allèrent jusqu'à forger un texte dans lequel, disaient-ils, le maître avait lui-même expliqué ainsi sa pensée : «Sorti du néant, il devint Grand Extrême. »

Mais Tchou Hi rejette avec indignation un pareil commentaire inventé à plaisir. Suivant lui, la phrase Ou ki eul t'ai ki ne veut pas dire qu'en dehors de T'ai-ki il existe un être éternel qui serait le Néant Absolu, mais que dans le Non-Etre relatif qui, comme on l'a vu précédemment, constitue le Grand Vide, réside 


\section{Le philosophe Tchou Hi}

$\mathrm{Li}$, le premier principe éternel informant la matière universelle, dont les atomes dispersés sont encore imperceptibles aux sens. Dans la phrase en litige, la particule est donc une simple conjonction et n'implique pas une idée de conséquence ou de déduction. Ou ki ne doit pas être pris comme un substantif, mais comme un adjectif qualifiant T'ai-ki. Tcheou-tse dit donc qu'il fut un temps où ce T'ai-ki, qui à présent se manifeste à nous par la matière condensée dans les êtres corporels, se tenait encore caché dans la matière invisible et sans forme.

Tchou Hi trouve d'ailleurs dans le contexte même une preuve sans réplique contre les assertions de ses adversaires. Car Tchou-tse emploie bientôt après le terme $\mathrm{Ou}$ ki comme synonyme de T'ai-ki, lorsqu'il dit []. Et puis il ajoute que si, pour Lao-tse, I'Etre et le Non-Etre sont deux choses tout à fait opposées, il n'en est pas de même pour Tcheou-tse. Celui-ci ne reconnaît entre l'un et l'autre qu'une différence d'état accidentelle. Ou signifie pour lui la matière informée par Li, mais imperceptible encore ; Yeou, au contraire, est la matière dont les atomes condensés ont déjà pris une forme sensible. Donc la particule du passage en question n'infère aucune idée de causalité du premier terme à l'égard du second, mais une simple conjonction de deux idées équivalentes.

\section{$\S$ IV. YN ET YANG.}

Partant de ce fait d'expérience ${ }^{1}$ que le chaud et le froid sont les causes qui produisent et altèrent toutes choses et que la cha-

${ }^{1}$ Cf. P. Longobardi, Traité sur quelques points de la Religion des Chinois, p. 34 


\section{Le philosophe Tchou Hi}

leur provient du mouvement, le froid du repos, nos Philosophes enseignent que la Matière comme un globe infini, animée par son coprincipe $\mathrm{Li}$, se mit un jour en mouvement sous son influence dirigeante ([], diriger, ordonner). Le mouvement sépara peu à peu l'élément igné et l'élément aqueux, qui s'étaient mélangés durant le règne du Chaos (III), et produisit bientôt la chaleur et la lumière ${ }^{1}$. Dès lors, les atomes de la matière première formèrent dans le Grand Vide comme deux courants distincts, positif et négatif. doués de qualités diverses, dont le dosage, gradué à l'infini, déterminera la perfection ou I'imperfection relative des êtres, au physique et au moral ${ }^{2}$. « II est curieux, remarque le Dr. W. A. P. Martin (Hanlin Papers p. 215 : On Oriental Dualism), de voir le phénomène de la lumière uni à celui du mouvement. p.35 Les anciens chinois auraient-ils prévu la théorie de l'ondulation et toute la doctrine moderne de la Thermodynamique? La théorie physique qui rapporte tout à Yn et à Yang, prend sa source dans le I king, le plus ancien ${ }^{3}$ de leurs Livres sacrés ».

\footnotetext{
1 Section 49 des œuvres de Tchou Hi.

2 Cf. Zottoli Cursus Litter. sin. $3^{m}$ Vol. p. 520.

3 Le I King, auquel on doit accorder au moins 3.000 ans d'existence, n'est cependant pas le plus ancien des livres chinois; à moins qu'on ne veuille donner le nom de Livre aux quelques symboles de Fou-hi, qui servirent de thème à Wen Wang et à son fils le prince de Tcheou, pour leurs élucubrations fantaisistes, devenues le texte de ce livre canonique entre le $12^{\mathrm{e}}$ et le $13^{\mathrm{e}}$ siècle seulement avant l'ère chrétienne. Les commentaires ou Appendices n'y furent ajoutés que six ou sept siècles plus tard. Les premières Annales du Chou-King existaient plus de mille ans avant l'œuvre du roi Wen, le véritable auteur du I King. De même, plusieurs des Odes du Che King remontent audelà de l'avènement des Tcheou. II n'est donc pas vrai que le I King soit Antiquissimus Sinarum Liber (titre de l'ouvrage du P. Régis publié seulement en 1831 à Stuttgard par Jules Mohl); the most ancient of their classical writings, comme le dit le chanoine Mc Clatchie (Introduction to the Yî King) ;
} 


\section{Le philosophe Tchou Hi}

Le Dr. J. Legge, à la page 45 de son Introduction du I King, donne la traduction du passage où, pour la première fois, il est fait mention de Yn et Yang; il se trouve dans le paragraphe $4^{\mathrm{e}}$ du $5^{\mathrm{e}}$ Appendice, d'après la division adoptée par lui ; pour les Chinois, c'est la $8^{\mathrm{e}}$ des dix parties ou Ailes qui composent le Commentaire de ce livre. L'auteur se pose ensuite cette question : « Do we find (here) Yang and Yin not merely used to indicate the quality of what they are applied to (i. e. les lignes des symboles), but at the same time with substantival force, denoting what has the quality which the name denotes (i. e. la matière elle-même en ses deux modes ou manières d'être) ? Had the doctrine of a primary matter of an ethereal nature. now expanding and showing itself full of activity and power as Yang, now contracting and becoming weak and inactive as Yin : had this doctrine become matter of speculation when this Appendix was written?»

Mr. Legge avoue franchement que la plupart de ceux qui se sont jusqu'ici occupés du I King tiennent pour l'affirmative, sans soulever là-dessus le moindre doute. «The Chinese critics and commentators for the most part ( $y$ en a-t-il un seul qui soutienne évidemment le contraire ? Je ne le crois pas), assume that it had. - P. Regis, Dr. Medhurst, and other foreign Chinese scholars repeat their statements without question. I have sought in vain for proof of what is asserted ». La meilleure preuve, à notre avis, c'est que la question n'a jamais été disputée entre les nombreux interprètes de ce livre antique. Et, si quelques-uns nous disent, comme dans le spécimen rapporté dans la note de

the oldest of their sacred Books, comme le répète ici W. A. P. Martin. (Cf. J. 


\section{Le philosophe Tchou Hi}

la page 44, que «les Sages (i. e. Fou-hi et Wen Wang), pour faire correspondre p.36 leurs symboles avec les principes sur lesquels repose la nature des hommes et des autres êtres, nommèrent ces symboles Yn et Yang .... » ne supposent-ils pas, dis-je, par cela même, qu'une réalité a parte rei répond à ces noms?

De plus, au chapitre [] du Li ki, on lit ces mots qui nous semblent un argument concluant: [] 1. Il s'agit bien ici de la matière première, au sens que nous avons vu plus haut, et cette matière, animée d'un mouvement circulaire, manifesta ses deux modes intrinsèques d'inégale perfection et doués de qualités opposées.

Le Kia yu, livre très ancien, bien qu'il n'ait été publié que vers le milieu du $3^{\mathrm{e}}$ siècle par Wang Sou (P. C. 240), qui l'avait trouvé chez un descendant de Confucius à la $22^{\mathrm{e}}$ génération, reproduit ce chapitre du Li-ki; et, au mot [], l'éditeur ajoute cette explication []. Le [] dit que l'Empereur sacrifie au Ciel sur le Tertre du Midi, afin d'être plus près du siège de Yang.

Dans son commentaire du Hong-fan, Lieou-Hiang (A. C. 80-9) appelait le soleil la quintessence de la matière la plus parfaite. Les Commentateurs du [], Tsouo Kieou-ming, Kong Yang-kao et Kou Liang-chou rapportent que, pendant la durée d'une éclipse de soleil, les magistrats convoquaient le peuple; on battait le tambour, on offrait des pièces de soie, on frappait l'instrument des veilles, on attachait les dieux lares avec des fils de soie, et dans une circonstance aussi critique tous unissaient leurs efforts

Legge's I ntrod. Yî King p. 6-7).

${ }^{1}$ [CSS : phrase non traduite par l'auteur] 


\section{Le philosophe Tchou Hi}

pour soumettre la matière imparfaite $(Y n)$ et aider le triomphe de Yang.

II ne fallut donc pas, comme le croit Mr. Legge, plus de mille ans après l'achèvement du I King, pour que la doctrine d'une matière première eût sa place dans l'enseignement de l'école confucéenne: It took more than a thousand years after the closing of the Yi to fashion in the Confucian school the doctrine of a primary malter. We do not find it fully developed till the era of the Sung dynasty, and in our eleventh and tenth centuries. » Il est vrai, la philosophie matérialiste dans son ensemble ne reçut son plein développement que sous l'impulsion de Tchou $\mathrm{Hi}$ et des lettrés de son époque. Mais les idées des lettrés de ce pays étaient déjà profondément matérialistes avant que ne fût conçu et rédigé ce système, qui nous semble ne cadrer, hélas ! que trop bien avec les idées exprimées dans les ouvrages chinois d'une très haute antiquité, peut-être dès avant l'avènement des Tcheou.

p. 37 La matière avec ses deux modes se nomme Yn-yang tche k'i. Sous l'action motrice et ordonnatrice de $\mathrm{Li}$, la masse immense se meut avec une rapidité toujours plus grande: ses deux portions de qualités inégales se mélangent diversement, et de leur union naissent les cinq éléments, qui entreront désormais comme agents constitutifs des êtres, dans les transformations subséquentes de la nature. A cause de leur degré de perfection relative, ils se livrent entre eux une lutte perpétuelle; et leur influence se neutralisant sans cesse, ils se succèdent l'un l'autre au pouvoir. Ces cinq monarques, qui se disputent ainsi l'empire du monde, avec des alternatives fatales 


\section{Le philosophe Tchou Hi}

de succès et de défaite, sont l'Eau, le Feu, le Bois, le Métal et I'Humus. Le premier a son domaine régulier, sa résidence plus spéciale au Nord; le second, au Sud; le troisième, à l'Est ; le quatrième, à l'Ouest, et le cinquième, au Centre.

(1) 


\title{
Le philosophe Tchou Hi
}

\author{
CHAPITRE II 1
}

\section{LES TROIS AGENTS}

\section{§ I. CIEL ET TERRE.}

Par l'effet du mouvement giratoire continu et extrêmement rapide d'où naquirent la chaleur et la lumière, les molécules les plus subtiles de la matière s'élevèrent insensiblement jusqu'au sommet du neuvième orbe céleste. Ces neuf orbes ne sont pas des sphères parfaites, détachées les unes des autres, mais se développent en spirale continue, comme un ressort de montre. La matière y est d'une pureté et d'une clarté toujours plus grande, à mesure qu'elle s'élève du centre dans l'espace. Elle devient de plus en plus consistante, à mesure qu'elle se rapproche de la circonférence extérieure; et la neuvième et dernière spirale du sommet forme comme une écorce très dure. Là, le mouvement de rotation est le plus rapide (III. 3, 34).

Ainsi fut formé le ciel ; il comprend le soleil, la lune et les étoiles qui tournent sans cesse autour de nous (III. 1), enfin l'atmosphère, où se répandent les cinq éléments, qui constituent par leur mélange la matière immédiate dont tous les êtres icibas sont composés.

1 [css: la mise en page de l'en-tête du chapitre II n'est pas faite dans le livre-papier. On ne peut la retrouver qu'à partir de la table des matières.] 


\section{Le philosophe Tchou Hi}

Cependant les molécules plus grossières, froides et ténébreuses se déposaient, se condensaient pour former la Terre, qui demeura immobile au centre du système, semblable à une grande $_{\text {p.38 }}$ et large feuille que l'air environne de toutes parts. Elle doit sa stabilité à la révolution très rapide de la machine ronde: si celle-ci s'arrêtait un seul instant, aussitôt la Terre s'enfoncerait comme un vaisseau qui sombre.

Le Ciel et la Terre existent maintenant à part. Mais dans quelle relation sont-ils entre eux, quant à leur nature et quant à leurs opérations? Et d'abord sont-ce deux êtres substantiellement différents dans leurs éléments constitutifs, ou bien leur différence n'est-elle qu'accidentelle ? - La réponse est facile. Nous avons dit comment ils ont été formés, l'un recevant en partage les particules les plus subtiles de la matière préalablement élaborée, l'autre les plus grossières; mais tous deux intimement compénétrés dans toutes leurs parties par Li, principe essentiel de vie, de bonté, d'intelligence, dépendant toutefois, pour la manifestation de son activité, des qualités plus ou moins parfaites de la matière qu'il informe.

Les éléments matériels qui entrent dans la formation du Ciel, n'opposent point de résistance au principe actif ; celui-ci trouve donc en lui un instrument docile, au moyen duquel il manifeste par de merveilleux effets sa bonté, son excellence sans mesure. Le Ciel est de tous les êtres le plus digne d'honneur, le plus parfait, le plus intelligent, la source de tout bien. Les titres les plus magnifiques lui sont donnés dans le Chou King, où il est appelé Chang T'ien, Ciel supérieur, Hao T'ien, Ciel brillant, Hoang T'ien, Ciel souverain ; ou bien encore Ti, Roi, Chang Ti, Suprême 


\section{Le philosophe Tchou Hi}

Dominateur, Hoang Chang $\mathrm{Ti}$ et Hoang T'ien Chang Ti, Ciel Souverain et Suprême Régulateur. $\mathrm{Ce}$ dernier titre orne aujourd'hui encore la tablette de l'Autel du Ciel, où l'Empereur offre seul des sacrifices. II semblerait que dans les Annales les mots T'ien et Chang-Ti désignent également bien la même idée ; cependant, d'après Tchou Hi, il y a entre T'ien et Chang-Ti cette différence, que le premier s'emploie lorsqu'il est question de protection et d'entretien des êtres inférieurs qui lui doivent l'existence, et le second pour indiquer l'idée de puissance et de gouvernement.

Les modernes matérialistes ne doutent aucunement qu'ils n'aient le vrai sens des anciens Livres, tel que l'enseignaient les Sages Confucius et Mong-tse; et peut-être ne serait-il pas si facile de prouver le contraire, à moins qu'on ne réussisse à démontrer que la logique avait autrefois en Chine plus d'empire sur les esprits que de nos jours. Quoi qu'il en soit, loin de trouver étranges et de rejeter ces beaux noms donnés à $\mathrm{T}^{\mathrm{r}}$ ien, ils en ont inventé plusieurs autres non moins honorables. Ils l'appellent le Maître, le Gouverneur, le Grand Formateur du Monde. p.39 C'est en vérité à faire croire, au premier abord, qu'il s'agit de notre vrai Dieu dont la Providence dirige et règle toutes choses: comme, par exemple, lorsque Tchou $\mathrm{Hi}$, dans son commentaire, explique $\mathrm{Ti}$ par T'ien tche tchou-tsai, le Gouverneur du ciel. Mais il est clair que tout l'ensemble de la doctrine philosophique de maître Tchou et des auteurs modernes en général, empêche absolument qu'on ne donne à cette expression, ou à d'autres semblables, un sens spiritualiste. Ti, dit Tchou-tse, n'est autre que Li agissant en maître (III. 20) : c'est 


\section{Le philosophe Tchou Hi}

donc la force inhérente à la matière céleste, qui lui fait produire les êtres dans un ordre nécessaire et fatal. Cette propension naturelle à la production des êtres est également exprimée par le mot Sin (mens). Un disciple demandait si, dans l'expression T'ien ti tche sin, Sin avait le sens de Tchou-tsai ? - «Oui, répondit le maître, il a sûrement le même sens ; mais Tchou-tsai lui-même est l'équivalent de Li, c'est une même chose ». - « Et Ti, est-il aussi l'équivalent de Sin ? »- « Certainement, car ce que Sin (mens, l'âme) est à I'homme, Ti l'est au Ciel (III. 20, 21, $27,29)$.

L'expression T'ien tche tchou-tsai a même parfois un sens plus restreint. Elle signifie un certain endroit du ciel, à l'Est, où se manifeste sa vertu productrice et qui correspond au symbole Tchen, un des huit points qui partagent le zodiaque : il y en a quatre pour le chaud, Yang (printemps, été), quatre pour le froid, Yn (automne, hiver). Quand le soleil arrive à ce point dominant, le printemps commence et, sous l'influence du principe Yang, qui triomphe enfin, tout commence à renaître dans la nature. C'est aussi ce que le philosophe Chao Yong exprime par ces mots Ti tch'ou hou tchen, que le commentateur moderne le plus autorisé explique en ce sens, qu'à un moment précis de la révolution annuelle du monde, le premier principe $\mathrm{Li}$ recommence la série périodique de ses productions et remet tout en mouvement, non par une volonté libre, mais d'après un ordre nécessaire, comme on l'a vu plus haut. Tchou-tsai ou Ti ne sont donc que l'énergie victorieuse de Yang, ou la force de la chaleur pendant les six mois du printemps et de l'été, du moment où elle commence à croître, jusqu'au moment où elle recommence à diminuer. 


\section{Le philosophe Tchou Hi}

Si nous demandons maintenant à Tchou-tse quel est d'après lui, le sens de T'ien (ciel) dans les Livres canoniques et classiques, il nous répondra ce qu'il dit un jour à l'un de ses disciples, qui lui posait la même question : «Dans certains passages, T'ien signifie seulement la voûte azurée; dans d'autres, l'énergie, la force par laquelle le ciel produit et dirige tout ; parfois il désigne le principe immatériel ( $\mathrm{Li}$ ) qui l'informe et l'anime; mais p.40 jamais un être personnel qui de là-haut jugerait et condamnerait les mauvaises actions des humains. » - « S'il en est ainsi, pourquoi donc dit-on que le Ciel et la Terre sont inexorables ? » - «Cela veut dire simplement que tous les êtres sont condamnés à périr un jour ». (III. 27, 29)

Et voilà comme les lettrés modernes répondent aux textes si nombreux du Chou king qui, pris en eux-mêmes, sembleraient démontrer d'une manière si évidente que les anciens chinois entendaient par les mots de Ciel et de Chang $\mathrm{Ti}$, non pas une pure abstraction ou une force inhérente à la matière, mais bien un Etre suprême, vivant et pensant, agissant librement, souverainement sage, bon et tout-puissant (l. 16). Mais il est impossible de savoir au juste quelles idées les anciens attachaient à ces mots.

Ce qui est certain c'est que dès avant l'avènement de la troisième dynastie le Chou-king parle déjà du Ciel ou Chang-Ti et de la Terre comme de deux puissances unies pour la production de toutes choses. Quand le roi Ou annonce à ses nobles assemblés son intention d'attaquer l'empereur Tcheou-sin (Cheou), il leur parle du Ciel et de la Terre «père et mère de tous les êtres » et leur dit qu'il a eu soin d'offrir un sacrifice à Chang-Ti et à la 


\section{Le philosophe Tchou Hi}

Terre souveraine pour le succès de la présente expédition. Dans une autre allocution à ses féaux sujets, il accuse le tyran d'avoir négligé d'offrir les sacrifices traditionnels au Ciel et à la Terre. D'où il suit que les idées matérialistes ne commencèrent pas seulement à s'introduire à l'avènement de la dynastie des Tcheou ; elles existaient depuis longtemps déjà. Mais, à partir de cette époque, elles allèrent s'accentuant de plus en plus, entretenues par le I King, que Wen-Wang et le duc de Tcheou avaient composé pour expliquer à leur guise et au profit de leur politique les mystérieux symboles de Fou-hi. C'est dans le paragraphe sixième du canon de Choen que nous trouvons la première mention du culte religieux des anciens chinois. Voici le passage : «Alors il (Choen) offrit à Chang Ti le sacrifice Lei, aux six Vénérables le sacrifice Yen, aux montagnes et aux fleuves le sacrifice Wang; il étendit aussi son culte à l'universalité des Esprits.

De l'aveu de Legge lui-même, les commentateurs, bien avant l'époque des Song, donnaient ici comme l'équivalent de ChangTi, le Ciel, ou le Ciel et les Cinq Ti, c'est-à-dire les cinq éléments. Et ce ciel dont ils parlent est le ciel matériel, comme il appert du contexte et de tout l'ensemble de la doctrine de Ma Yong ( $P$. C. 79-166), de Wang Sou (P. C. 240), de Kong Ngan-kouo ( ${ }^{\mathrm{e}}$ s. A. C.) etc. ${ }^{1}$.

«Je ne puis douter, dit Legge (Shoo King, p. 34 note) que ${ }_{p .41}$ Chang Ti ne soit, ici le nom du vrai Dieu ; mais la vérité sur son être et son culte était déjà pervertie dès cette époque reculée

1 Ma Yong, ajoute Legge (loc. cit.), pensait que Chang Ti est l'Etre suprême : «Ma Yong held chat Shang Te was 'the supreme One' » - Non ... 


\section{Le philosophe Tchou Hi}

(2255 A. C.), ainsi qu'on le voit dans la suite du paragraphe ». Que Chang Ti soit, dans ce passage, le nom du vrai Dieu, la chose ne nous semble pas si évidente. En tout cas, l'idée qu'y attachent les lettrés chinois de la plus haute antiquité jusqu'à nos jours ne s'accorde pas avec celle que nous avons de Dieu. Ceux d'entre les protestants qui veulent se servir du terme Chang Ti auront donc à faire admettre tout d'abord aux chinois une explication de ce mot différente de celle qu'en donnent tous leurs commentateurs autorisés. N'est-il pas à craindre qu'ils ne s'entendent dire: «Eh quoi ! vous un étranger, vous prétendez donc comprendre nos Livres mieux que tous nos auteurs !»

S'il y a pourtant quelque probabilité que le Ti ou Chang Ti des premiers siècles du Chou-king désigne un être personnel, dans le I King cela ne semble plus du tout probable. $\mathrm{Mr}$ Legge traduit ainsi dans ce livre le $8^{\mathrm{e}}$ paragraphe de la $8^{\mathrm{e}}$ partie ou Aile (chez lui, c'est le $5^{\mathrm{e}}$ Appendice) : «God comes forth in Kan (Tchen) (to his producing work); He brings (His processes) into full and equal action into Sun ; they are manifested to one another in $\mathrm{Li}$; the greatest service is done for Him in Khuan, etc. etc En vérité, qu'on l'appelle (comme il plaira) God, avec l'auteur, ou Supremus Imperator, avec le P. Régis, le nom de la divinité sonne bien mal dans ce passage : le sens attaché ici au texte ne repose sur aucune interprétation faite par des auteurs chinois; c'est un sens imposé par le préjugé. «I contend, dit Legge, that God is really the correct translation in English of $\mathrm{Ti} »$. Dans certains passages des premières Annales, passe; mais que dans cet endroit-ci ce soit l'interprétation exacte, nous attendons d'autres preuves que celles que le savant auteur croit être en droit de tirer du témoignage en apparence si évident de Tchou 


\section{Le philosophe Tchou Hi}

$\mathrm{Hi}$, de Kong Yng-ta et de Wang Pi, chef d'une école de divination. Oui, quoi de plus clair, par exemple, que les paroles de Tchou Hi ? Comme elles répondent bien à nos idées chrétiennes ! Mais recourez donc au contexte; jugez d'après l'ensemble de sa doctrine et vous verrez combien ses pensées au fond sont différentes des vôtres. Pour lui Chang Ti n'est que la vertu active du ciel matériel.

Mr Legge nous semble avoir péché ici contre la même règle d'interprétation, que lorsqu'il nous a donné la traduction des formules de prières extraites du Rituel impérial des Ming ${ }^{1}$. 11 p.42 y a appliqué aux mots, surtout au terme Ti, vers le triomphe duquel il dirigeait surtout son travail, des idées du plus pur spiritualisme, tout à fait opposées aux conceptions évidemment matérialistes des interprètes modernes, conceptions universellement acceptées au temps des Ming, et favorisées par les Empereurs de cette dynastie, comme elles le sont encore de nos jours.

Les mêmes préjugés se montrent passim dans sa traduction des Quatre Livres: il s'efforce d'y tout expliquer dans un sens spiritualiste. Et quand il arrive parfois que le texte chinois est si clairement matérialiste qu'il lui devient impossible de le faire cadrer avec le reste de sa traduction, l'auteur s'étonne de ce qu'il considère comme une inconséquence manifeste. Mais non, il n'y a malheureusement que trop de suite dans leurs idées du plus bas matérialisme. Qu'on applique le système de Tchou Hi au Tchong-yong, au Ta-hio, etc.. et I'on verra que tout s'y tient.

${ }^{1}$ Cf. Notions of the Chinese. 


\section{Le philosophe Tchou Hi}

A la page 284 du I ${ }^{\text {er }}$ Volume des Chinese Classics (Ed. 1861) on lit en note: "'without bounds' our infinite. Surely it is strange, passing strange, to apply that term to any created being ». Mais les Chinois ont-ils l'idée de création ? - Le texte, en parlant du Ciel et de la Terre, avait dit : [], ce sont des êtres sans mélange d'imperfection: et Legge écrit en note: «It surprises us, however, to find heaven and earth called 'things' at the same time that they are represented as by their entire sincerity producing all things ». "Nous sommes surpris, toutefois, de rencontrer le Ciel et la Terre désignés comme des choses, en même temps qu'ils sont représentés comme produisant toutes choses par leur entière sincérité ${ }^{1}$.

Puis au paragraphe $9^{\mathrm{e}}$ : "J'ai déjà fait observer que, dans ce passage, on ne nous présente le ciel et la terre que comme des êtres matériels. Et non seulement cela ; mais on nous montre encore des agents partiels, comme les montagnes, les mers et les fleuves, agissant avec la même inépuisable énergie que ces deux corps entiers, ou agents universels. Le [] dit à ce propos : - 'Les collines et les eaux sont des productions du Ciel et de la Terre; le pouvoir qu'elles ont de produire elles-mêmes d'autres êtres montre encore mieux combien le Ciel et la Terre sont inépuisables dans leur énergie productive'. La confusion et l'erreur de contenues dans de semblables idées sont vraiment lamentables ${ }^{2}$. »

\footnotetext{
1 Nous dirons plus loin que le mot sincerity employé ici par l'auteur ne rend pas bien la valeur du mot [], qui signifie plutôt la parfaite conformité d'un être avec sa nature.

2 I have already observed how it is only the material heavens and earth which are presented to us. And not only so; we have mountains, seas and rivers, set forth as acting with the same unfathomableness as those entire bodies
} 


\section{Le philosophe Tchou Hi}

p.43 Oui, sans doute; et ces erreurs sont d'autant plus à déplorer, qu'elles ne sont pas ici exprimées comme en passant et par inadvertance, mais sont la conséquence d'un système purement matérialiste, qui règne sur l'intelligence du peuple chinois depuis de longs siècles.

\section{$\S$ II. MYTHOLOGIE ET TRADITION}

La fameuse question du terme (Term Question) pour rendre en chinois l'idée de Dieu jeta longtemps la division dans l'armée protestante en Chine. La lutte s'est à peu près terminée par un compromis entre les adversaires. On a édité des Bibles en chinois où Dieu se dit Chang Ti, d'autres où il s'appelle Chen : ce fut la condition de l'armistice. Pour ce qui regarde le sujet que nous traitons, on ne lira pas sans intérêt les détails de la lutte très vive qui eut lieu au cours de la campagne entre le Dr. Jh. Chalmers et le chanoine Mc. Clatchie (voir China Review V. III p. 342-354, et Vol. IV. p. 84, 243). Le premier soutient que le Chang-Ti des Anciens Livres dénote un Dieu personnel; le chanoine tient pour Chen; et c'est dans le but de combattre l'opinion adverse et de faire rejeter à jamais les noms de Chang-Ti et de T'ien comme indignes de signifier le vrai Dieu, qu'il publia en 1871 sa Cosmogonie Confucéenne, ou traduction avec notes du $49^{\mathrm{e}}$ chap. des Euvres de Tchou Hi.

and powers. The [] says on this :.... 'The hills and waters are what Heaven and Earth produce, and that they should yet be able themselves to produce other things, shows still more how Heaven and Earth, in the producing of things, are unfathomable'. The confusion and error in such representations are very lamentable. 


\section{Le philosophe Tchou Hi}

L'auteur suppose comme une chose certaine que les doctrines des philosophes modernes sont l'écho sincère des traditions de l'ancienne école de Confucius et de Mong-tse. Quoi qu'il en soit, il a calomnié les uns et les autres en identifiant, dans sa manie d'unité mythologique, le Chang-Ti et le T'ien des King avec le Priape de l'Occident et l'infâme Baal des Phéniciens. Sa conclusion étrange s'appuie sur un passage du I King (liv. III. c. VI) auquel il renvoie en affirmant qu'on y trouve clairement enseignées les horreurs d'un culte abominable «Phallic worship ». (Confuc. cosmog. p. 152)

Sans doute, depuis plus de trente siècles, les Chinois admettent, pour expliquer la production de l'Univers, une double puissance de la matière éternelle qui, par le mélange de ses éléments parfaits et imparfaits, forts et faibles, donne naissance à tous les êtres et les distingue les uns des autres. C'est le Yang et le $\mathrm{Yn}$, le K'ien et le K'oen de leur philosophie, que nos yeux rencontrent partout en ce pays représentés au centre de la figure octogonale du mystérieux Pa koua. II est impossible de ne pas admettre que la Chine a depuis longtemps accepté avec l'ancienne Egypte, la Grèce et la Rome païenne, comme I'Inde des p.44 monuments sanscrits et celle d'aujourd'hui encore, un

système cosmogonique que l'on peut appeler, si l'on veut, a sexual system of the universe. Mais, de ce principe les Chinois ont-ils jamais tiré les mêmes conclusions pratiques que les autres nations ? Cette doctrine a-t-elle eu aussi son contrecoup dans le culte religieux de ce peuple? En trouve-t-on des traces dans le présent, ou du moins dans les monuments historiques 


\section{Le philosophe Tchou Hi}

des anciens temps ? C'est là une question de fait et non une affaire de conclusion logique.

Or, le fait, dans le cas présent, le voici tel que l'exprimait parfaitement le Dr. Williams dans son Middle Kingdom (Vol. II. p. 231) : «Le trait le plus remarquable de l'idolâtrie chinoise est qu'on ne trouve dans ses temples aucune trace de la sensualité déifiée, dans le but de couvrir du masque de la religion et d'autoriser ces débauches de licence et ces orgies qui énervèrent tant d'esprits en souillant tant de cœurs dans nombre de contrées païennes. On ne trouve ici ni Vénus, ni Lakshmi, ni prostitution comme au temple de Mylitta, ni les rites obscènes de la Doorga-puja. La doctrine spéculative des deux coprincipes Yn et Yang n'a jamais dégénéré dans le culte dégradant du Linga et du Yoni de l'Inde ». Peut-être doit-on voir ici une manifestation de cette inconséquence de l'esprit chinois si regrettable souvent dans ses effets. Dans le cas présent, du moins, l'effet est heureux et nous ne saurions trop bénir la Providence d'avoir ainsi préservé ce peuple de l'abîme où tant d'autres se sont perdus.

Abandonné de ses amis eux-mêmes, et resté seul à soutenir sa thèse mythologique, le Chanoine ne voulut pas s'avouer vaincu ; il s'entêta au contraire dans son idée fixe. et des deux côtés on en vint à des expressions très peu charitables. Deux ans plus tard, en 1876, paraissait la Traduction du I King, ouvrage du même auteur fait dans le même but de controverse, en faveur de Chen contre Chang-Ti, soutenue par les mêmes arguments, c'est-à-dire les mêmes préjugés qui l'avaient conduit à appliquer coûte que coûte à la littérature chinoise son système 


\section{Le philosophe Tchou Hi}

outré de mythologie comparée. Le traducteur ne s'est guère préoccupé des questions de philologie et d'histoire, qu'un travail sérieux de traduction d'un livre aussi ancien, aussi complexe que le I King, ne peut manquer d'offrir à chaque page.

Cependant l'introduction, les notes et les appendices, dont il encadre sa traduction fréquemment défectueuse, ne sont qu'une fastidieuse répétition de ses tirades favorites contre Chang-Ti, qu'il ne cesse d'identifier avec la monade hermaphrodite ou le Chaos, avec le Oannes de Babylone et le Baal des Phéniciens. En différents endroits ( $p$. 22, 116, 303, 346) il revient avec insistance, mais sans apporter de preuves tirées des faits, à sa découverte d'un culte immonde que la Chine aurait de tout temps rendu au Ciel et à la Terre sous les symboles des organes sexuels de la génération. En vérité, la critique faite par le China Review p.45 (Vol. 3-5) des deux ouvrages du chanoine Mc. Clatchie n'est nullement trop sévère au fond, bien que l'expression en soit peut-être un peu dure ${ }^{1}$.

Mais tout en rejetant comme dénuées de preuves ces assertions du chanoine protestant, pouvons-nous ne pas admettre que le I King enseigne une mythologie rudimentaire, qui, pour des raisons que nous ne recherchons pas en ce moment, est demeurée toujours à l'état d'embryon? On sait que le roi Wen

\footnotetext{
1 Voici le jugement du Dr J. Legge dans la préface du I King (XVII), Oxford 1882 : His own special object was 'to open the mysteries of the Yî by applying to it the key of comparative mythology'. Such a key was not necessary ; and the author, by the application of it, has found sundry things to which I have occasionally referred to in my notes. They are not pleasant to look at or dwell upon ; and happily it has never entered into the minds of chinese scholars to conceive of them. I have followed canon Mc Clatchie's translation from paragraph to paragraph and from sentence to sentence, but found nothing which I could employ with advantage in my own ". Ce n'est pas flatteur.
} 


\section{Le philosophe Tchou Hi}

manipula les huit trigrammes de Fou-Hi et leur donna à chacun une situation nouvelle correspondant à un point du zodiaque où son influence (virtus) est censée s'exercer. Quel fut au juste le but que se proposait Wen Wang, lorsque prisonnier (A. C. 1143 ou 1142) du tyran Cheou, dernier Empereur de la $2^{\text {de }}$ dynastie, il modifia l'arrangement jusqu'alors reçu des symboles? (cf. Mayer's Chinese reader's manual, p. 355) Était-ce, comme l'ont pensé les philosophes modernes (livre 15 du Sing-li ta ts'iuen), pour marquer d'une manière frappante le désordre causé en ce temps dans l'empire par les passions brutales du tyran qui le gouvernait, et les malheurs que ne tarderait pas à produire un tel état de choses, si l'on n'y portait remède au plus tôt ${ }^{1}$ ? En tout cas, le remède fut radical; ce fut le renversement de la dynastie Chang au profit de la famille princière des Tcheou (A. C. 1122-255).

Voici le passage du I King auquel nous faisions allusion. II se trouve dans la $8^{\mathrm{e}}$ section ou Aile qui a pour titre «Dissertation sur les Trigrammes». L'auteur traite d'abord de leurs dispositions diverses par rapport aux saisons de l'année et aux points de l'espace d'après Fou-Hi et Wen Wang. Puis il poursuit en ces termes: "K'ien est le Ciel, c'est pour cela qu'on le nomme père; K'oen est la Terre, et pour cela on la nomme mère. En Tchen se fait la première union (l'élément fort domine), le résultat est un mâle et pour cela on l'appelle le premier fils. En Suen pour la première fois l'élément faible l'emporte; il en

\footnotetext{
1 “V. g. si symbolum Li, ignis, supponatur loco symboli K'ên, aquæ, utriusque elementi inordinatio principi (Wen) visa est non minus apta ad significandas ruinas et clades Reipublicæ malæ ordinatæ, quam naturales ab hieme aut imminente, aut sæviente, rerum generatarum corruptiones." (cf. I King du P. Régis I., p. 23.24, 67-68).
} 


\section{Le philosophe Tchou Hi}

résulte une femelle ; c'est pourquoi on l'appelle la fille aînée. En p. 46 K'an pour la seconde fois l'élément fort, en Li l'élément faible dominent, donnant naissance au second fils et à la seconde fille. En Ken et en Toei pour la $3^{e}$ fois l'élément fort, puis le faible remportent tour à tour ; de là proviennent le plus jeune fils et la plus jeune fille ».

« Cette étrange manière de parler, dit Legge (Introd. du I King p. 49), fut l'origine de la fable d'un mariage entre Kien et K'oen (le Ciel et la Terre); et rien d'étonnant si quelques hommes à l'imagination ardente et mal réglée y ont cru voir Noé, sa femme avec leurs trois enfants et leurs brus. N'avonsnous pas dans les deux cas une famille de huit personnes (an ogdoad) ? » Quoi qu'en puisse dire le savant docteur, nous croyons qu'il n'est pas si déraisonnable d'attribuer à un souvenir assez obscur d'ailleurs de la tradition primitive un langage aussi singulier que celui du I King en cet endroit. Quelle autre explication rend suffisamment raison de ces appellations de père, de mère, puis de garçons et de filles (formant 3 couples) ?

Rien d'étonnant, après tout, qu'un livre aussi ancien ait conservé quelques vestiges de la tradition primitive, reconnaissables à nous qui, grâce à Dieu, avons reçu la vérité entière. Les exagérations sont faciles dans cette voie, comme dans celle de la philologie et de bien d'autres: l'imagination s'y peut donner libre carrière, lorsque la raison lui lâche la bride; mais, d'un côté comme de l'autre, il faut éviter l'extrême.

Les premiers peuples descendants de Noé par ses trois fils ont sûrement dû garder durant plusieurs générations le souvenir de leur commune origine : puis la fable est venue donner à l'histoire 


\section{Le philosophe Tchou Hi}

un travestissement plus ou moins grossier suivant le génie des peuples. Peut-être un tel souvenir reste-t-il caché dans ce passage du I King ; c'est tout ce que nous disons.

De même dans les théories des philosophes chinois sur l'éternité de la matière et la succession indéfinie des mondes, qui tour à tour sortent du chaos pour s'y replonger et en sortir de nouveau, n'est-il pas permis de reconnaître un souvenir obscurci et faussé de la première apparition de notre globe formé du chaos, puis de sa destruction partielle sous les eaux du Déluge et sa réapparition du sein des grandes eaux ?

Le Chan. Th. Mc. Clatchie M. A, a longuement développé cette idée dans une suite d'articles publiés par le Chinese Recorder, (année 1876-77, p. 7 Paganism). Loin de nous d'admettre toutes ses conclusions qui sont évidemment exagérées; nous ne le citons que pour le point spécial que nous traitons ici.

\section{§ III. CIEL PÈRE ET TERRE MÈRE.}

p.47 Au second siècle avant J. C., un auteur célèbre de la dynastie Han, Tong Tchong-chou disait, à propos des rites observés par les Empereurs lorsqu'ils offrent des sacrifices sur le tertre circulaire : "Le maître souverain des hommes considère dans le ciel son père, dans la terre sa mère, son frère aîné dans le soleil et dans la lune sa grande sœur. Le sacrifice au Ciel est réservé au chef de la nation ; mais tous doivent respecter le Ciel et la Terre, parce que c'est à eux que toutes choses doivent leur existence, ainsi que dit le Mémorial des Rites, au chapitre Li- 


\section{Le philosophe Tchou Hi}

t'ong: Le Ciel et la Terre, produits eux-mêmes de la matière première, deviennent à leur tour les ancêtres, les parents de tous les autres êtres.

Tchang-tse commence ainsi son Si-ming : « Le Ciel est notre père, comme la Terre est notre mère commune : de l'un j'ai reçu le souffle ( $k$ ) qui m'anime, de l'autre ma forme extérieure, et par l'union de ces deux éléments j'apparus un jour au sein du chaos. »Et Tchou-tse commentant ce passage ajoute : «On ne saurait refuser au Ciel et à la Terre les noms de père et de mère et il n'est pas moins certain que la distinction des sexes provient de la participation à la nature de l'un plus que de l'autre de ces deux agents. »

La propension naturelle du Ciel et de la Terre, disait déjà le I King, est d'engendrer et de nourrir les êtres. Ne serait-ce pas cette idée qui aurait donné lieu à une cérémonie très ancienne, en usage encore de nos jours dans les mariages païens, d'après laquelle les nouveaux mariés se prosternent ensemble et adorent le Ciel et la Terre, sans doute pour en obtenir une heureuse fécondité ? En tout cas, la superstition populaire a consacré cet enseignement des philosophes chinois en célébrant, le $16^{\mathrm{e}}$ jour de la $5^{\mathrm{e}}$ lune, la fête de l'union du Ciel et de la Terre source de toutes choses, sous le titre de T'ien- ti tsao-hoa.

\section{GÉNÉRATION SPONTANÉE.}

Le premier couple de chaque espèce animale est immédiatement engendré, dit Tchou $\mathrm{Hi}$ (III. 35), par la 


\section{Le philosophe Tchou Hi}

transformation de la matière première ou l'union des éléments

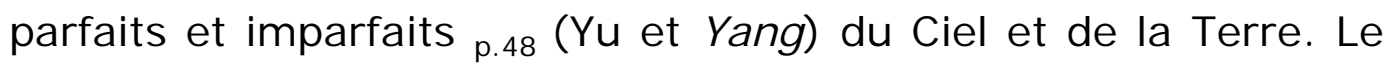
mâle participe davantage du Ciel, la femelle de la Terre. Cette production directe et spontanée s'appelle $\mathrm{K}^{\prime} \mathrm{i}$ hoa : telle est la manière dont naît la vermine, laquelle, dit le commentateur, naît spontanément et vient au jour sous l'action de la chaleur. Dans la suite, les êtres de même espèce se reproduisent par semence ; cette génération s'appelle Hing hoa.

Quel fut le premier ancêtre de notre race ? Les écrivains soidisant philosophes de la dynastie Song l'appellent Pan-kou et admettent sans critique les fables absurdes que d'anciens compilateurs de légendes attribuaient à ce personnage de leur invention. Hou Jen-tchong ( $1^{\mathrm{e}}$ moitié du $12^{\mathrm{e}} \mathrm{S}$.) dit que P'an kou naquit dans le Grand Vide, on ignore à quelle époque. II pénétra parfaitement les lois du Ciel et de la Terre ainsi que les évolutions des deux Principes de la Nature « et par là devint le chef des Trois Agents i. e. le Ciel, la Terre et l'Homme) ». Ainsi commença le développement de l'évolution du chaos. Un autre nous apprend que «le Ciel fut son père, la Terre sa mère, et pour cette raison il fut appelé «Fils du Ciel ». - Quant à la compagne du premier homme, la légende ne nous en dit pas un mot: elle n'était après tout, comme le sont toutes ses filles, qu'un être essentiellement inférieur.

\section{§ IV. ÉGALITÉ.}

Nous avons déjà vu précédemment que tous les êtres sans exception ont une commune origine, étant constitués par les 


\section{Le philosophe Tchou Hi}

mêmes principes. Tchou $\mathrm{Hi}$ commente ainsi le paragraphe $23^{\mathrm{e}}$, $n^{\circ} 3$ du T'ong chou :

«Si par la pensée nous parcourons de bas en haut l'échelle des êtres, nous voyons que les cinq éléments qui les composent, ne sont eux-mêmes que la matière première avec ses deux qualités (i. e. éléments parfaits et imparfaits, Yang et $Y n$ ), et cette matière, à son tour, dépend du Li unique, son principe d'action. Si maintenant du sommet nous revenons en bas, nous voyons le principe $\mathrm{Li}$ devenant la forme substantielle des myriades d'êtres en général, et de chacun en particulier. Par lui l'action du Ciel p.49 opère les transformations sans fin, et tout être individuel reçoit sa nature et son destin. Ce principe d'ordre et d'activité, qui pénètre ainsi toutes les parties de la masse universelle, peut se comparer au grain de millet qui d'abord produit une tige; de la tige sort une fleur; après la fleur vient un fruit, lequel est du grain. Ainsi après une série de transformations le grain semé est revenu à sa forme originelle. Un seul épi contient une centaine de grains, et chaque grain a en lui toute la perfection de son espèce. »

De même, tout être à sa naissance reçoit par l'intermédiaire du Ciel, constitué agent universel, la perfection intégrale du premier principe immatériel (Li) (Len-yu ch. 8, comment.). Considéré du côté du Ciel qui l'infuse, ce principe individualisé s'appellera ming, T'ien-ming, Destin ou mandat céleste. Tchou Hi le définit en ces termes: T'ien-ming est l'émanation du principe céleste se communiquant à chaque être en particulier et constituant la raison d'être de toutes les choses morales et physiques. 


\section{Le philosophe Tchou Hi}

Dans l'homme, ce commandement du Ciel est la lumière et la voix de la raison, qu'il lui faut suivre sans écart. Ne pas s'y conformer c'est offenser le Ciel. (Cf. Len-yu, ch. 2, comment.). Demander pardon au Ciel ne signifie pas autre chose pour le confucianiste moderne que se soumettre de nouveau par un retour sincère aux lois de la droite raison. Cette conversion s'opère en travaillant à purifier la faculté intellectuelle de la rouille des passions : c'est le but que s'est proposé l'auteur de la Grande Etude ou Etude des Grands, qui commence son enseignement par ces mots : "L'objet de la Grande science est de rendre sa splendeur à la faculté intelligente. » Sur quoi le commentateur officiel fait cette glose: «Ming-té signifie la substance que tout homme a reçue du Ciel et qui forme sa nature. Dans son état de pureté, d'activité et de splendeur native, elle peut embrasser la raison universelle et réfléchir toutes choses. Seulement lorsque la matière l'étreint et que les passions la recouvrent comme d'un voile, elle s'obscurcit et se trouble pour un temps, sans toutefois que sa clarté naturelle disparaisse jamais complètement. »

T'ien-tao est la Loi ou la Règle générale du Ciel dans ses opérations, d'après laquelle, en tant que cause très universelle, il se communique aux êtres inférieurs, leur donnant une propension naturelle, qui les fait agir nécessairement dans un ordre merveilleux. La nature de chaque individu et la Loi du Ciel, d'où il reçoit cette nature, ne sont au fond qu'un p.50 seul et même principe (Len-yu, ch. $3, \mathrm{n}^{\circ} 12$, comm.). 


\section{Le philosophe Tchou Hi}

FRATERNITÉ.

« Le Ciel et la Terre sont notre père et notre mère, dit Tchang-tse ${ }^{1}$; les hommes sont tous mes frères et les autres êtres inférieurs sont mes compagnons. » Mais si hommes et choses ont pour substance la substance du ciel et de la terre et pour nature la nature du ciel et de la terre; d'où viennent donc entre eux ces degrés divers de perfection accidentelle ? Tchou $\mathrm{Hi}$ nous l'a déjà dit; la distinction des êtres et leur inégalité proviennent uniquement de l'élément matériel 2 .

Les qualités de la matière peuvent se réduire à quatre principales indiquées par les mots Tcheng (droit, parfait); P'ien (incliné, défectueux); T'ong ou k'ai (perméable, ouvert) ; Ché (obstrué, obscur). T'ong et Tcheng sont des qualités de la matière plus subtile et ceux qui les possèdent sont au rang des Humains. P'ien et Ché sont des qualités défectueuses et sont proportionnellement propres aux bêtes, aux plantes et aux minéraux ${ }^{3}$. Tcheng et T'ong se subdivisent encore pour mettre entre les hommes des différences multiples, depuis le plus haut sommet où règne le Saint, I'homme idéal, l'égal du Ciel et de la Terre, jusqu'au degré le plus infime où l'homme se distingue à peine de la brute, suivant le mot de Mong-tse (ch. 4, cf. comment. ibid.).

Le favori du destin, qui naît en temps et lieu favorables et sous l'influence propice d'une bonne étoile, obtiendra

1 Si-ming, Comment.

2 Len-yu, ch. VIII, § 16.

3 Sing-li ta ts'iuen, ch. 26. 


\section{Le philosophe Tchou Hi}

infailliblement le Tcheng dans sa pureté parfaite, et dès lors il ne saurait manquer d'être un Saint, un savant, un héros, I'homme de la droite raison. Tels furent Yao et Choen, Wen Wang, Tcheou kong, Confucius. - Ceux qui ont reçu du ciel et de la terre ce qu'il y a de moins pur dans le Tcheng et le T'ong, sont fatalement grossiers, sauvages, d'une conduite déréglée, rebelles à l'instruction : ce sont à peine des hommes, ils n'en ont que la forme extérieure. Entre ces deux extrêmes, il y a cependant place pour le commun des hommes, les sages d'une p.51 vertu et d'une prudence ordinaire, tous ceux, en un mot, qui sont susceptibles de perfectionnement par le moyen de l'éducation ${ }^{1}$.

La partie de la matière d'une qualité infime, P'ien ou Ché k'i contient aussi des degrés divers d'imperfection : la moins viciée constitue les animaux plus ou moins grossiers, suivant son degré d'impureté; la plus basse est le partage des plantes et des minéraux ${ }^{2}$. On le voit, de cette doctrine à la recherche des influences occultes des astres et des éléments, c'est-à-dire aux absurdités de l'astrologie et de la géomancie (Fong-choei), il n'y a qu'un pas facile à franchir. Depuis longtemps, hélas! le pas est fait.

De cette doctrine découlent aussi des théories qui font si fréquemment l'objet des amplifications littéraires: la fraternité

\footnotetext{
1 Sing-li ta ts'iuen, ch. 26.

2 Les Bouddhistes admettent aussi comme un principe de leur système religieux, pour une autre raison cependant, que l'homme ne diffère pas de l'animal dans sa nature, mais seulement en perfection relative. Les âmes des animaux, disent-ils, sont encore imparfaites, à cause du petit nombre de leurs mérites, qui ne suffit pas à contrebalancer la masse de leurs démérites accumulés dans leur vie précédente (Mgr. Bigandet, Légende de Gaudama, p. 67).
} 


\section{Le philosophe Tchou Hi}

universelle, le respect de tons les êtres qu'il faut traiter suivant leur nature, la subordination des divers degrés de la hiérarchie sociale, les droits sans limites des parents sur leurs enfants ${ }^{1}$, etc.

Tous les hommes sous le ciel sont frères, ils ne forment qu'une immense famille, et au centre de cette famille se tient la Chine $_{\text {p.52 }}$ unie comme un seul homme ${ }^{2}$. «Notre prince est le fils aîné de nos communs parents; les grands ministres sont les familiers, les aides du frère aîné. En respectant la vieillesse, nous remplissons nos devoirs envers des aînés; en aimant les petits et les faibles, nous traitons comme il faut nos frères puînés. » - Tchou $\mathrm{Hi}$ commence en ces termes le développement de cette pensée: «Tous les hommes de l'univers sont les enfants du Ciel et de la Terre; mais le monarque seul a reçu du Ciel et de la Terre le pouvoir de régir en maître absolu et les hommes et les choses : aussi l'appelle-t-

\footnotetext{
1 Voici en quels termes la doctrine du pouvoir absolu des parents est exposée au bon peuple dans un commentaire des Instructions du Saint Edit : " Les enfants sans piété filiale ont encore une manière de parler tout à fait déraisonnable. Ils disent 'Je voudrais bien pratiquer la piété filiale, mais que puis-je y faire si mes parents ne m'aiment pas ?' En vérité ne sait-on pas qu'avec les parents il ne faut pas parler de droits ou de torts. Les parents sont comme le ciel. Le ciel produit-il un brin d'herbe, s'il se développe au printemps, cela vient du ciel; si la gelée de l'automne le fait périr, cela provient également du ciel. Le corps que les parents ont engendré, il dépend d'eux qu'il vive, comme il dépend d'eux qu'il meure. Qu'a-t-on à parler de droits et de torts ? » Faut-il s'étonner que, en conséquence d'une pareille doctrine, l'infanticide si commun en ce pays y reste généralement impuni ? D'ailleurs, la peine théoriquement stipulée par la loi montre assez le droit reconnu aux parents sur la vie de leur progéniture : soixante coups de bâton et un an d'exil à 500 stades. Cette peine, dont on peut d'ailleurs se racheter à prix d'argent, est beaucoup plus légère que celle qui frappe un vendeur de dominos ou de cartes à jouer.

2 Tchou Hi, commentaire du Si ming.
} 


\section{Le philosophe Tchou Hi}

on Tsong tse «Grand Fils »1. » « Les saints, poursuit Tchangtse, sont ceux de nos frères dont la bienfaisante influence est unie à celle de nos communs père et mère. Les sages sont ceux dont les talents et la vertu dépassent le niveau ordinaire de leurs frères. Enfin les misérables, malades et perclus, les orphelins et les veuves, tous les déshérités de la fortune sont des frères malheureux. » La conclusion est aussi juste qu'elle pouvait l'être : mais qu'il est triste de voir à quoi aboutissent en pratique pour le bonheur et la paix de la famille humaine toutes ces théories humanitaires de nos lettrés païens! Leur altruisme philanthropique ne va pas loin; l'intérêt égoïste qui l'accompagne l'étouffe en chemin.

1 Telle est la base philosophique de l'origine du pouvoir et de son étendue, comme aussi la raison du titre donné à l'Empereur, T'ien tse, fils du Ciel. Le monde entier est à lui et quiconque ne se soumet pas à son autorité est un rebelle. 


\section{Le philosophe Tchou Hi}

\section{CHAPITRE III}

\section{L'HOMME.}

\section{§।. SING.}

p.53 Confucius on le sait, ne livrait pas indifféremment à tous ses disciples ses idées sur la nature. C'est ce que nous apprend Tse-kong qui, plus favorisé que les autres, avait reçu sur ce point les confidences de son maître (Len-yu ch. III. $\S 12^{\mathrm{e}}$ ) ; mais il n'a pas jugé à propos de les communiquer à la postérité. Tsese (petit-fils de Confucius, si toutefois il est l'auteur du Tchongyong, semble avoir été le premier à affirmer «que tous les hommes naissent avec une nature parfaitement bonne, que la vertu consiste à y conformer sa conduite, et que la vertu ellemême se perfectionne par l'instruction. » Le commentateur fait sur le texte la glose suivante: «La nature est le principe immatériel Li (communiqué à un être quelconque et individualisé en lui). Le ciel forme toutes choses de la matière première avec ses qualités parfaites et imparfaites ( $Y n$ Yang) et les cinq éléments. K'i devient leur partie sensible, corporelle ; Li leur est communiqué comme un ordre, une impulsion, un principe dirigeant intérieur. Ce principe, par l'infusion duquel tout homme et tout être sont produits et qui est en chacun la puissance des 


\section{Le philosophe Tchou Hi}

cinq vertus morales, dans l'état de supériorité ou de soumission (suivant le sexe), nous l'appelons Sing, la nature ${ }^{1}$. »

Dans la suite, cette proposition trouva d'ardents contradicteurs. Les uns soutinrent que la nature de l'homme n'est de soi ni bonne ni mauvaise; elle n'a pas plus de tendance vers le mal que vers le bien: l'éducation de chacun et les circonstances décideront de sa conduite future. Telle fut l'opinion de Kao-tse, comme elle est rapportée dans le $6^{\text {e }}$ livre des œuvres de Mong-tse. Ce dernier la combattit énergiquement, soutenant que I'homme est né avec p.54 une tendance naturelle vers le bien, le mal étant pour lui un acte contre nature ${ }^{2}$. «De même, dit-il, que l'eau coule naturellement en bas et qu'il faut lui faire violence pour la faire remonter vers sa source, ainsi le cœur de l'homme tend au bien et fuit ce qui est mal. La nature doit être originairement bonne; car, puisqu'elle est le principe céleste que le ciel nous communique, il n'est pas de nature qui soit intrinsèquement mauvaise ${ }^{1}$. »

D'où vient alors que la plupart des hommes sont mauvais ? Quelle est la raison de leur dépravation? La négligence personnelle jointe à l'influence des circonstances extérieures. Les saints et les sages ne diffèrent du commun des hommes que parce qu'ils connaissent, apprécient et font valoir le trésor qu'ils possèdent. «Celui, dit Mong-tse, qui perfectionne son esprit par l'étude arrive à connaître sa nature; connaissant sa nature, il connaît le ciel. » Et là-dessus Tchou $\mathrm{Hi}$ fait cette glose : «L'esprit (mens) est la partie active, lumineuse, intelligente

1 Tchong-yong, Comment.

2 Mong-tse, $6^{\text {e }}$ livre. 


\section{Le philosophe Tchou Hi}

dans I'homme, ce par quoi il est capable d'embrasser la raison des choses, et de correspondre à tout. La nature est ce principe formel qui réside dans l'intime de mon esprit et dont le ciel est le point d'origine. Tout homme. possède cet esprit dans son intégrité ; mais s'il ne scrute à fond la raison des choses, il finira par s'obscurcir et dès lors il ne pourra plus lui donner toute la mesure de perfection dont il est susceptible. Au contraire, quiconque peut mettre en exercice la capacité entière de son esprit, sans en rien laisser dans l'inaction, celui-là saura pénétrer la raison de tout, sans que rien échappe à sa connaissance. La raison des choses une fois connue, la source même de cette raison, de ce principe commun des êtres, ne restera pas étrangère à mon esprit. »

Siun-tse ( $3^{e}$ siècle av. J. C. ) vint ensuite et proposa une thèse diamétralement opposée à celle de Mong-tse. Un des 20 chapitres de ses Fuvres est consacré à soutenir que la nature de l'homme est radicalement et totalement vicieuse, et que ce qu'il a de bien n'est qu'artificiel et surajouté à sa nature.

Vers le commencement de l'ère chrétienne parut Yang-tse 2,

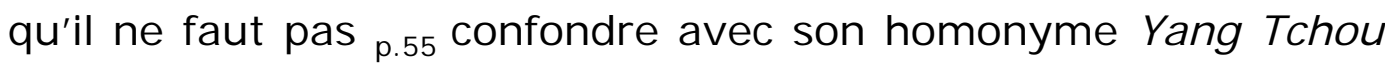
( $4^{\mathrm{e}}$ ou $5^{\mathrm{e}}$ siècle av. J.-C. ), l'épicurien chinois, dont les doctrines hétérodoxes ont été vigoureusement attaquées par Mong-tse, qui caractérise son système par ces mots []. Yang-tse se pose

\footnotetext{
1 I bid.

2 Yang Hiong est l'auteur d'un petit traité philosophique intitulé [], qui a eu plusieurs éditions; l'une d'elles est précédée d'une préface de Se-ma Koang. En 1395, la tablette de Yang Hiong fut retirée du Temple de Confucius sur les réclamations de quelques lettrés de la stricte orthodoxie, qui le jugeaient indigne de cet honneur, parce que, d'un côte, il n'avait pas enseigné la vérité intégrale et que, de l'autre, il n'avait composé aucun commentaire sur les Livres canoniques ou classiques.
} 


\section{Le philosophe Tchou Hi}

entre Mong-tse et Siun-tse et fonde son système sur un compromis entre les principes opposés des deux champions. D'après lui, tous deux auraient raison, s'ils n'étaient trop exclusifs. II prétend donc les accorder en disant que la nature humaine est originellement un mélange de bien et de mal. Tout homme a en lui quelque chose de bon et quelque chose de mauvais. La différence morale entre les hommes vient donc uniquement de ce que les uns cultivent et développent avec soin la partie bonne de leur nature, tandis que les autres se laissent entraîner sur la pente du vice.

Longtemps plus tard, vers la fin $\mathrm{du} 8^{\mathrm{e}}$ siècle et le commencement du 9 ${ }^{\mathrm{e}}$, Han Wen kong (768-824) inventa une théorie nouvelle qui mettait d'accord, croyait-il, les vues opposées de Mong-tse et de Siun-tse sur la nature de I'homme. II avance donc que les hommes se partagent en trois classes : la première comprend ceux qui sont bons sans mélange de mal ; la $3^{\mathrm{e}}$ ceux qui sont mauvais sans aucun mélange de bien; la $2^{\mathrm{e}}$ ceux en qui le mal et le bien sont mêlés. Les premiers possèdent naturellement toutes les vertus dans leur perfection; ceux de la $3^{\mathrm{e}}$ catégorie sont dépourvus de vertus et n'ont d'inclination que vers le vice : ceux de la $2^{\mathrm{e}}$ ont toutes les vertus, mais dans un degré plus ou moins parfait. Ces derniers seuls peuvent par leur application monter au premier rang, ou, par leur négligence, tomber au dernier ; tandis que la position des classes supérieure et inférieure est fixée par un décret immuable du ciel : ils sont fatalement et à jamais bons ou méchants. L'opinion de Han Yu est d'ordinaire exprimée en la forme suivante :

[] : c'est la classe des saints, des hommes parfaits. 


\section{Le philosophe Tchou Hi}

[] : c'est I'homme supérieur, avec ses quelques défauts qu'il s'efforce de corriger.

[] : c'est l'homme vicieux, incorrigible.

Telle est la théorie de la nature humaine qui prévalut du $9^{\mathrm{e}}$ au $12^{\mathrm{e}}$ siècle, Iorsqu'elle fut supplantée par des conceptions nouvelles.

p.56 Les docteurs de l'école moderne enseignent, nous l'avons vu, que la nature est une seule et même chose avec le principe immatériel ( Li), qui s'unit au principe matériel ( $\left.K^{\prime} i\right)$ pour produire tous les êtres sans exception. Li est parfaitement bon ; la nature est donc en soi essentiellement bonne, car elle n'est autre chose que Li en tant que communiqué à chaque être par le ciel.

Mais si le principe immatériel est bon, d'où vient le mal moral ? II provient, dit Tchou $\mathrm{Hi}$, de l'imperfection du principe matériel : de la qualité de ce dernier dépend le degré plus ou moins grand de sagesse et de bonté d'un être quelconque : les hommes sont supérieurs aux autres animaux et aux autres êtres, parce qu'ils ont reçu en partage une portion plus pure du principe K'i. La diversité que nous remarquons entre les hommes vient de ce que à quelques-uns échoit en partage une matière plus épaisse, à d'autres une matière plus pure et plus dense. Ces derniers naîtront intelligents et enclins à la vertu, tandis que les autres seront vicieux et d'une intelligence bornée. II arrive parfois que la portion de matière reçue est pure et brillante, mais manque de densité; dans ce cas, le possesseur sera intelligent sans être vertueux : si, au contraire, la matière était dense, mais non transparente, on aurait la vertu sans l'intelligence. 


\section{Le philosophe Tchou Hi}

Ainsi, d'après ces philosophes, le principe actif (Li), communiqué par le ciel à tous les êtres et constituant leur nature, tend sans cesse à se manifester au-dehors tel qu'il est, souverainement bon et intelligent. La matière seule offre à son action une résistance passive plus ou moins grande, absolue ou partielle ${ }^{1}$. Cette nature, de soi toute parfaite, sera dans le sage semblable à une pierre précieuse dans une eau limpide; dans I'homme vulgaire, comme la même pierre précieuse dans une eau bourbeuse. Le principe immatériel devenu la nature individuelle d'un pomme quelconque peut se comparer au soleil et à la lune : la matière est le nuage qui intercepte leur clarté ; ou bien encore à un globe de feu, la matière alors est la cendre qui le couvre ; dès que la cendre livre un passage, aussitôt le feu brille. La source de toute ignorance, de tout mal moral en I'homme est donc la p.57 matière, en tant qu'elle empêche ou gêne la manifestation du principe immatériel.

A cette question : la nature de l'homme est-elle bonne ? Les modernes ne diront pas simplement oui, comme Mong-tse; ils ne nieront pas non plus, comme Siun-tse ; mais ils distingueront entre la nature considérée en soi hors du composé, et la nature unie au principe matériel. La première, au moment qu'elle émane du ciel, est très bonne et sans aucun mélange

1 Que l'on rapproche cette doctrine de celle du poète latin, au Livre VI de l'Enéide :

Principio cœlum ac terras...

Mens agitat molem et magno se corpore miscet.

Inde hominum pecudumque genus, vitæque volantum,

Et quæ marmoreo fert monstra sub æquore pontus.

Igneus est ollis vigor et cœlestis origo

Seminibus, quantum non noxia corpora tardant

Terrenique hebetant artus moribundaque membra. 


\section{Le philosophe Tchou Hi}

d'imperfection. Dans ce sens ils acceptent l'axiome de Mong-tse (Sing pen chan) comme très orthodoxe. Mais la nature individualisée, concrétée dans la matière et qu'ils appellent K'i-tche tche sing, on peut et l'on doit la dire imparfaite, car elle est un mélange de bien et de mal. Dans l'homme saint cependant, nous trouvons une exception à la loi générale : en lui, la raison céleste (Li) dirige toutes les actions ; la matière n'offre aucun obstacle à l'intelligence du vrai, ni à la pratique du bien. Quant aux autres hommes, l'instruction devra tendre à réformer ce que la nature a de défectueux, à chercher la pierre précieuse cachée dans la boue, à la nettoyer pour la rendre pure et brillante. II faut pour réussir en cela une volonté forte, énergique, une persévérance à toute épreuve; à ce prix, la victoire restera au principe immatériel.

Tchou Hi attribue à Tchang-tse et aux deux frères Tcheng I'honneur d'avoir les premiers découvert et exposé la doctrine du K'i-tche tche sing, ou nature composée. Ils ont par là, dit-il, bien mérité des anciens sages, dont ils ont fait comprendre la vraie pensée, et tous les lettrés à venir leur en devront une éternelle reconnaissance. Dans son commentaire de l'ouvrage de Tcheoutse intitulé T'ong chou, Tchou Hi rapporte l'explication donnée par Tch'en Choen de l'axiome de Mong-tse (sing pen chan). Sur cette question, comme dans les autres, on voit avec quel soin les docteurs de la nouvelle école évitent de se poser comme les inventeurs d'un système nouveau : ils ne veulent que renouer le fil des vraies traditions de l'antiquité, en revendiquant le sens des anciens livres corrompu depuis la mort de Mong-tse, le dernier sage. 


\section{Le philosophe Tchou Hi}

Tchen Choen disait : « D'où Mong-tse a-t-il tiré son axiome : sing chan (la nature est bonne, ou la bonté même) ? De ce mot du maître dans sa glose sur le I king: «Un Yn et un Yang s'appellent Tao (le principe universel). Ce Tao en évolution, ou considéré en soi à l'instant de l'émanation, est le bien sans mélange ; formant un être, il en devient la nature. Les mots I yn i yang tche wei tao signifient seulement ce qui constitue un T'ai$\mathrm{ki}$; Ki tche tché wei chan veut dire que, au moment de l'émanation transformatrice, ce qui engendre, nourrit un être et lui est communiqué, ne contient en soi rien qui ne soit absolument bon: il s'agit ici du temps ou T'ai-ki est en p.58

mouvement et progresse. Chan (Bonté) indique le principe immatériel Li ou Tao, au début de l'émanation. Tch'eng tche tché wei sing signifie que chacun des êtres reçoit ce principe (Tao li) très bon, qui devient ainsi sa nature individuelle: alors commence la période de repos et d'inaction du T'ai-ki. Dans cette phrase de la glose, Sing et Chan sont équivalents; car Chan n'est que $\mathrm{Li}$ en tant que déterminé à former un être particulier. Ce que le maître nomme ici Chan (Bonté) est donc la source même, le point de départ de l'acte transformateur, alors que I'homme, ou un être quelconque, n'est pas encore engendré. Chan est pris comme substantif, comme un être réel. Mong-tse, en disant Sing chan (la nature est bonne), parlait de la nature concrète, individualisée dans tout être lors de sa formation. Dans cet axiome, Chan est donc pris adjectivement, et veut dire que la nature, avant le réveil des passions par le choc des choses extérieures, est pure et parfaitement bonne. En effet la Bonté, émanant directement de la source formatrice, n'est pas encore détériorée au moment où elle produit un être et s'appelle sa 


\section{Le philosophe Tchou Hi}

nature. Ainsi donc Mong-tse et le maître ont puisé à la même source le sens qu'ils donnent au mot Chan. » (V. le texte chinois dans I'Appendice III).

Confucius disait (Len-yu ch. 9: «La nature rapproche les hommes entre eux; mais les habitudes diverses tendent à les éloigner. » Sur ce texte, le commentateur dit que la nature dont il est ici question est la nature dans le composé. Cette nature concrète, individuelle est dans les hommes inégalement bonne ou mauvaise. Durant les premières années, la différence est encore peu sensible; mais par l'application au bien elle se fait bonne, par les actes mauvais elle se pervertit.

Ainsi s'établit la distinction morale entre les hommes. Et Tcheng-tse ajoute : «II s'agit ici de la nature considérée dans le composé et non en soi dans sa source. Car, dans ce dernier cas, elle n'est autre chose que le principe universel $\mathrm{Li}$, qui ne saurait rien avoir que de bon: c'est ce que Mong-tse a exprimé en disant que la nature est bonne. »

La doctrine des deux plus grands sages de la Chine sur la nature est renfermée toute entière dans ce quatrain, que les jeunes écoliers répètent à tue-tête dès les premiers jours de leurs études: []. Tel est le début du San tse king, ou Livre classique (par membres) de trois caractères 1.

\section{§ II. PERFECTIBILITÉ DE L'HOMME.}

${ }^{1}$ [css : lire le San tse king sur internet, dans la belle édition des classiques Wengu. ] 


\section{Le philosophe Tchou Hi}

«p.59 Le principe actif Li qui devient la nature de chaque être est le même en tous les hommes, depuis les sages Yao et Choen jusqu'au plus humble roturier. Cependant les actes de nos facultés subissent l'influence de la matière, qui est pure ou impure. Quiconque est formé d'une matière plus pure est un sage ; celui qui a reçu en partage une matière trouble et impure est d'une intelligence bornée. Mais, par l'application à l'étude de la sagesse, on peut toujours, quel que soit le degré de pureté ou d'impureté de la matière, parvenir à la perfection et revenir à la bonté originelle de sa nature. C'est ce que firent Tch'eng-tang et Ou Wang. »

Ainsi parle Tcheng-tse. II n'admet donc pas qu'il y ait un seul homme, si mal doué soit-il, qui ne puisse par des efforts sérieux avancer constamment dans la voie du bien. Une parole de Confucius semblerait contraire à cette thèse. Le philosophe partage les hommes, au point de vue de la perfection et de la sagesse, en quatre catégories : dans la première il place ceux qui, ayant la sagesse infuse, sont de tout point parfaits; dans la seconde, ceux qui sont bien doués et qui s'adonnent avec ardeur à l'étude; ceux d'une capacité inférieure, mais qui travaillent à vaincre les obstacles provenant de la matière grossière de leur être, forment la troisième classe ; au quatrième et dernier rang viennent ceux qui ne font rien pour surmonter les obstacles provenant de leur constitution. La première et la dernière de ces catégories sont à jamais immuables: les parfaits ne peuvent déchoir, les plus déshérités resteront irrémédiablement stupides ${ }^{1}$.

1 (cf. Len-yu, ch. XVI, 9, vers. fin.). 


\section{Le philosophe Tchou Hi}

Ces derniers mots pourraient faire supposer que certains hommes sont condamnés par leur constitution même à une incapacité radicale d'atteindre le vrai et de faire le bien, sans qu'il dépende de leur volonté de s'élever à un état meilleur. II n'en est rien, disent les commentateurs. L'homme le plus grossier peut arriver à la vertu, quoique avec plus de peine et lentement peut-être ; il suffit pour cela que, suivant l'expression de Mong-tse (ch. IV, $1^{e}$ p., $n^{\circ} 10$ ), il n'étouffe pas les instincts de sa bonne nature et qu'il ne s'abandonne pas à une lâche indolence.

\section{LE SAGE}

p.60 Les saints sont rares; le ciel n'en produit qu'à de longs intervalles. Mais quiconque n'a pas la sainteté en partage dès le jour de sa naissance, doit par de constants efforts sur lui-même tendre à se rapprocher de ce type de la perfection. II ne peut sans doute l'atteindre; songer à l'égaler serait une vaine illusion. Yen-hoei lui-même, le disciple chéri de Confucius, le plus diligent à l'acquisition de la sagesse, ne parvint qu'au point de demeurer trois mois fixé dans la vertu parfaite. Mais, tout le temps de sa courte carrière, il ne cessa de s'appliquer à l'étude qu'il avait à cœur. Et quel but poursuivait-il avec tant d'ardeur ? II voulait arriver à reproduire en lui la conduite même du Saint. «L'homme, dit Tcheng-tse commentant un passage du Len-yu (ch. 3, n²9), est la quintessence du ciel et de la terre, jointe avec ce qu'il y a de plus pur dans les cinq éléments. Sa nature originelle est pure et calme. Antérieurement à tout acte, elle 


\section{Le philosophe Tchou Hi}

possède dans leur intégrité les cinq vertus naturelles ${ }^{1}$, i. e. la bonté, la justice, la convenance ou bienséance ${ }^{2}$, la prudence, la fidélité. Quand le corps est formé, le choc des choses extérieures fait sentir son contre-coup jusque dans l'intime de l'être. L'émotion intérieure cause la manifestation des sept passions, qui sont: la joie, la colère, la tristesse, la crainte, l'amour, la haine, la concupiscence. Les passions s'enflamment de plus en plus ; la nature se déprave. Aussi les aspirants à la sagesse, en s'appliquant à réprimer leurs passions et à les faire rentrer dans le calme, n'ont qu'un seul but, rectifier leur cœur et entretenir leur nature vertueuse (Cf. Len-yu, ch. 3. $\mathrm{n}^{\circ} 29$ comment.).

Un jour que Yen Yuen demandait à son maître par quel moyen on peut atteindre à la vertu parfaite, celui-ci lui répondit : «En se domptant soi-même et en revenant à la ligne du devoir ${ }^{3}$. » «Jen ou la vertu parfaite, dit à ce propos Tchou $\mathrm{Hi}$, est l'état d'intégrité du cœur originel (de notre cœur d'enfant, suivant l'expression de Mong-tse). Or, tendre par ses actes à cette ${ }_{\text {p.61 }}$ perfection, c'est agir de façon à reconstituer la bonté native de ce cœur. La vertu parfaite du cœur n'est autre chose que le principe immatériel (Li), mais inévitablement entamé par les passions humaines. Voilà pourquoi celui qui veut redevenir parfait aura certainement à vaincre ses tendances dépravées et à rentrer dans l'ordre harmonieux de la droite raison. Ainsi, par

${ }^{1}$ Elles s'appellent aussi les cinq vertus communes ou constantes.

2 [] ne signifie pas ici de simples règles conventionnelles de politesse, mais la tendance de la nature morale et intelligente de l'homme dans la voie de ce qui convient, et de ce qui est requis par la droite raison; c'est, en un mot, l'amour de l'ordre universel, comme dit Tcheng-tse.

3 Len-yu, XII, I. 


\section{Le philosophe Tchou Hi}

la conformité de toutes mes actions au principe céleste, l'intégrité native de mon cœur sera reconstituée en moi. »

\section{RÉTRIBUTION.}

La sagesse doit montrer la vertu sous des couleurs assez attrayantes pour que sa seule vue captive les cœurs à jamais. Les charmes de la vertu, la vertu pour elle-même, tel est le thème habituel des compositions littéraires. Mais, nos lettrés le savent bien, la masse du peuple reste insensible à ces belles déclamations : il ne saurait être conduit dans la voie du bien par des motifs aussi purs, aussi dégagés de tout intérêt propre. C'est pour cela que, lorsqu'ils veulent exciter le peuple à revenir à la bonté première de leur nature, en résistant à leurs passions mauvaises, ils sentent le besoin d'appuyer leurs exhortations sur la croyance d'une juste rétribution pour les bons et les méchants, telle que les anciens Livres l'enseignent.

II n'est jamais question de récompense ou de châtiment dans une autre vie. Le lettré orthodoxe rejette l'idée de ciel et d'enfer comme une invention des Bouddhistes. «Si vous connaissez la vraie doctrine, disait l'Empereur Yong-tcheng à son peuple, vous savez qu'il n'y a pas de paradis en dehors d'un cœur pur et brillant de vertu, comme il n'y a pas d'autre enfer qu'un cœur ténébreux et noirci par le vice. » Le I king parle sans doute d'une rétribution en rapport avec la vertu et le vice; mais le sujet de la récompense ou du châtiment est la famille, dans un avenir plus ou moins éloigné, et non l'individu lui-même, auteur des bonnes ou des mauvaises actions. Jamais dans le Chou king ni 


\section{Le philosophe Tchou Hi}

aucun autre Livre canonique ou classique, l'espérance de bonheur ou la crainte de maux dans une vie d'outre-tombe ne sert comme argument pour exciter au bien ou détourner du mal.

Les exhortations au peuple publiées par les lettrés, dans un style d'ordinaire assez simple, forment un genre spécial de littérature, qu'on nomme K'iuen che wen. Le thème en est fort peu varié et le développement n'est qu'un long et ennuyeux verbiage d'un terre à terre et d'une pauvreté d'idées incroyable. Le meilleur spécimen et le plus soigné du genre est sans contredit I'Amplification du Saint Edit. A la fin de chacune de ces Instructions paternelles de l'Empereur à son peuple, le p.62 mobile régulièrement invoqué pour l'émouvoir est la crainte des maux de toutes sortes qui viendront l'accabler, s'il est méchant ; s'il est vertueux, au contraire, il peut espérer les biens du corps, les honneurs, la fortune, avec la jouissance d'une vie longue et tranquille.

Quand on leur objecte que la répartition des biens et des maux ne se fait pas toujours en ce monde suivant la mesure des mérites de chacun, puisque nous voyons souvent la vertu opprimée et le vice triomphant; les plus savants répondent avec Tchou $\mathrm{Hi}$ que c'est là une exception à la règle générale, provenant de ce que la matière universelle s'est peu à peu viciée sous l'influence des mauvaises actions des hommes. La réponse leur semble sans réplique (Cf. I. 27).

Les vices qui dégradent en l'homme la bonté originelle de sa nature proviennent de trois sources différentes : premièrement, de sa constitution physique influant sur la disposition de l'esprit ; 


\section{Le philosophe Tchou Hi}

secondement, des désirs immodérés des sens ; troisièmement, de l'ambition de la supériorité (Toi et Moi).

Seul le Saint est exempt de lutte intérieure ; il ne ressent, lui, aucune difficulté à faire le bien. Tous les autres éprouvent l'antagonisme en eux de deux tendances opposées, qui sans cesse les sollicitent. L'égoïsme ou le cœur humain est l'irréconciliable ennemi du cœur parfait que le ciel a mis en nous. Procurer à tout prix le triomphe de la raison sur ses passions, fortifier la volonté contre les révoltes de la chair, telle est donc la préoccupation constante du sage ou de l'homme supérieur. Pour cela il doit arriver à se connaître par un examen attentif, rigoureux de ses pensées et de ses désirs, une active vigilance de tous les instants. II s'adonne tout entier à l'acquisition de la sagesse, non pour le seul plaisir de savoir, mais pour diriger chacune de ses actions d'après les principes de la droite raison. II doit se rendre tellement indifférent à l'estime des hommes, que l'oubli, le mépris, la pauvreté, la souffrance ne puissent le faire malheureux. Le sage trouve la joie en lui-même, dans la conscience du devoir accompli. Le but de ses efforts est de connaître à fond la doctrine des anciens et d'imiter leur conduite vertueuse. Sujet aux attraits du mal, il peut parfois faillir ; mais ces faiblesses ne sont que momentanées, comme les éclipses du soleil et de la lune, et son énergie les rendra de plus en plus rares ${ }^{1}$.

Mais, en fin de compte, le Sage a-t-il l'espoir d'atteindre à la sainteté ? D'après certaines paroles de quelques philosophes, on pourrait croire que la transition est possible du degré de p.63

${ }^{1}$ Cf. Len-yu, XIX, 21. 


\section{Le philosophe Tchou Hi}

Kiun-tse à celui de Cheng jen. Toutefois, la plupart le nient absolument. Tchou Hi cite à ce propos ce mot de Tchang-tse: «Je puis bien faire des efforts pour avancer sans jamais marrêter ; mais probablement le reste ne dépend pas de moi et dépasse mon pouvoir. » Un autre dit encore : «Par des efforts répétés nous pouvons arriver à une haute vertu : mais quant à nous rendre la vertu tellement naturelle que nous la pratiquions sans aucun effort, cela est au-dessus de nos forces. » C'est un privilège spécial du saint, suivant le mot de Mong-tse: Qui magnus, jam in naturam id transformat, [naturali veluti ductu rectum agens], dicitur sanctus ${ }^{1}$. Voilà pourquoi Yen-tse luimême, avec les meilleures dispositions et sa volonté très énergique, est toujours resté quelque peu en deçà du terme de la sainteté.

Cependant, par la pratique persévérante de la vertu, on peut s'en rendre les actes de plus en plus faciles. "Le Sage, dit Mong-tse ${ }^{1}$, est doué par la nature de la bonté, de la justice, de l'amour de l'ordre et de la prudence. Ces quatre vertus ont leur racine dans le cœur, d'où elles se manifestent par tout le corps : les quatre membres obéissent à leur impulsion, sans attendre un commandement exprès. » Et Tcheng-tse commente ainsi ce passage : «La bonté, la justice, les rites et la prudence sont les quatre vertus essentielles à la nature humaine ... Se t'i pou yen eul yu signifie que mes membres, sans attendre un ordre exprès de ma volonté, pourront saisir spontanément ma pensée. En effet, si la matière dont je suis formé est pure et brillante, sans nulle entrave des passions déréglées, les quatre vertus de ma

${ }^{1}$ Cf. Zottoli Curs. Litt. sin. Vol. II. p. 627, n 24. 


\section{Le philosophe Tchou Hi}

nature pousseront leurs racines dans mon cœur. Qu'elles s'y fortifient, aussitôt elles se manifesteront au-dehors par leurs effets ; sans attendre de moi un ordre formel, tout mon corps et chacun de mes membres s'empresseront d'obéir à l'impulsion donnée. »

La conduite du Sage sert de modèle à quiconque veut tendre à la sagesse. Les commençants ont les yeux fixés sur lui, comme lui-même contemple le Saint; ils l'admirent et s'efforcent d'approcher de sa perfection. Le Saint, lui, regarde le ciel et l'imite sans faiblesse. L'état d'équilibre et d'harmonie est le partage du Saint; il suit la voie du ciel et ne peut en déchoir. Le Sage suit la voie de l'homme et doit remonter plus ou moins péniblement le courant des passions. Le Saint est naturellement parfait ; p.64 donc aussi souverainement intelligent. Le Sage tend sans cesse vers la perfection, et il en approchera d'autant plus que son intelligence s'éclairera davantage par l'étude. C'est ce que le Tchong-yong exprime en ces termes : «Celui qui possède l'intégrité de sa nature a dès lors l'intelligence parfaite; et celui qui étend les bornes de son intelligence, s'approche d'autant de la perfection ${ }^{2}$. »

D'après nos philosophes, la connaissance du devoir a pour effet nécessaire la pratique de la vertu. Ils ne disent pas comme le poète païen : Video meliora proboque, deteriora sequor! Non, dans leur orgueil insensé, ils font taire le témoignage de leur conscience pour exalter d'une façon monstrueuse les forces de la raison et de la volonté humaine. Ils prétendent arriver par leurs

${ }^{1}$ Cf. Zottoli ibid. p. 607, $\mathrm{n}^{\circ} 21$.

2 Tchong-yong, $n^{\circ} 21$. 


\section{Le philosophe Tchou Hi}

propres efforts à connaître le bien et à l'accomplir, sans qu'ils aient besoin d'appeler à leur aide aucune puissance supérieure. En cela d'ailleurs ils ne sont que trop conséquents avec leurs principes du matérialisme le plus dégradant, principes qui doivent conduire logiquement le lettré chinois au plus absolu fatalisme.

«S'il dépendait de moi d'obtenir la richesse, disait Confucius, il n'est si vil métier que je ne ferais volontiers pour l'obtenir ; mais, puisque cela ne dépend pas de mes efforts, je veux suivre mon goût pour l'étude ${ }^{1}$. » De qui donc cela dépend-il ? De l'inexorable destin, répond Tchou $\mathrm{Hi}$; et il cite à l'appui le témoignage de Sou Tong-p'ouo et celui de Yang Koei-chan. «Si, dit ce dernier, le Sage ne court pas après l'or et les honneurs, ce n'est pas qu'il éprouve pour eux quelque répugnance; c'est qu'il sait bien que la répartition des richesses et des honneurs provient de l'action fatale du ciel et que, par conséquent, on ne saurait jamais les obtenir contre la décision du destin ${ }^{1}$. »

\section{$\S$ III. LE SAINT.}

Au-dessus du Sage, brille d'un éclat exceptionnel le chefd'œuvre de la Nature, l'homme idéal, le type achevé de la perfection, le Saint. Sous le rapport de la nature originelle, c'està-dire considérée hors de la matière qui l'individualise, le Saint n'est rien de plus, rien de moins qu'un être quelconque, Ce qui le

${ }^{1}$ Cf. Len-yu, IV, 11. 


\section{Le philosophe Tchou Hi}

distingue d'entre tous et en fait un être ${ }_{\text {p.65 }}$ privilégié, c'est que sa substance matérielle est d'une pureté, d'une subtilité extrême, semblable à un diamant de la plus belle eau, qui n'offrirait aucun obstacle au passage des rayons lumineux. L'homme, dit Tchou-tse, est constitué physiquement par la portion plus pure de la matière; mais, de cette quintessence elle-même la partie super-fine est le partage du Saint.

Dans les premiers siècles qui suivent le chaos, lorsque le monde est encore dans la force de sa jeunesse renouvelée, la matière étant plus pure doit nécessairement produire des êtres plus parfaits : c'est l'âge d'or, le temps où de sages princes font des peuples heureux. «Alors, dit Hiu Yong-tchai I'homme est à l'apogée de sa perfection; au commencement de chaque période cosmique apparaît un Fou-hi. Mais, à mesure que le monde vieillit, la matière se charge d'impuretés, les Saints deviennent plus rares, l'humanité se dégrade, l'univers revient insensiblement au chaos, son point de départ. Voici la liste des personnages reconnus officiellement comme Saints : $1^{\circ} \mathrm{F}^{\prime} \mathrm{ou}-\mathrm{hi}$ (2852-2738 av. J.-C.) ; $2^{\circ}$ Chen-nong (2737-2697); $3^{\circ}$ Hoang-ti (2697-2597)； $4^{\circ}$ Yao 2356-2258); $5^{\circ}$ Chen-nong (2255-2205) ; $6^{\circ} \mathrm{Yu}$ (2205-2197) : $7^{\circ}$ Tch'eng-t'ang (17661753) ; $8^{\circ} \mathrm{I}-y n$ (mort en 1713) ; $9^{\circ}$ Pi-kan (1222) ; $10^{\circ}$ WenWang (1231-1135); $11^{\circ}$ Ou Wang (1169-1116); $12^{\circ}$ Tcheoukong (mort en 1105); $13^{\circ}$ Lieou-hia Hoei (env. 600); $14^{\circ}$ Confucius (551-479).

${ }^{1}$ La même doctrine fataliste se voit encore dans le Len-yu ch. VII, $2^{\mathrm{e}} \mathrm{p} . \mathrm{N}^{\circ}$ 27, Comment. 


\section{Le philosophe Tchou Hi}

Le dernier dans l'ordre chronologique, Confucius occupe cependant depuis longtemps parmi ses congénères le premier rang d'honneur: il est le Saint par excellence. A propos de ce passage du Len-yu (chap. 5) où Tse-kong disait : «Certainement le Ciel l'a doué sans mesure: il doit être un Saint » ; Voici ce qu'enseignait un précepteur de K'ang-hi à son impérial élève: «Toutes les fois que le Ciel a fait naître des Saints, il a mis certaines limites à leurs talents et à leur vertu ; mais quant à notre Maître, pas de semblables bornes. Le Ciel a élargi tellement pour lui la mesure des talents et des vertus, qu'il a atteint le point de la sainteté la plus excellente. »

Si donc nous voulons nous faire une idée aussi exacte que possible de ce qu'est un Saint aux yeux des lettrés chinois, il nous faut recueillir avec soin ce qu'ils nous disent de leur maître. En lui l'organisation matérielle était très parfaite ; aussi le principe céleste se manifestait-il non seulement dans ses paroles, mais ${ }_{\text {p.66 }}$ dans chacune de ses moindres actions, dans son silence même et son repos. Un jour Confucius dit à ses disciples: «Je voudrais ne rien dire. » Maître, reprit Tse-kong, si vous ne parlez, qu'aurons-nous à transmettre à la postérité ${ }^{1}$ ? 》 Làdessus, la glose fait cette réflexion: Les disciples, pour la plupart, ne considéraient le saint homme que d'après ses paroles; ils ne remarquaient pas cette influence du principe céleste qui coulait en lui sans obstacle et se manifestait dans tout son extérieur, avant même qu'il n'exprimât oralement ses pensées. Aussi ne percevaient-ils que ses paroles et non ce qui en était le mobile intérieur. Le principe actif ( $\mathrm{Li})$, essentiellement

${ }^{1}[\underline{\text { Len-yu, XVII, 18. }] ~}$ 


\section{Le philosophe Tchou Hi}

pur et bon, n'a rien perdu de sa liberté d'action, de sa clarté, de sa bonté en venant informer la portion de matière qui est échue au Saint. Celui-ci agit toujours et spontanément en parfaite conformité avec ce principe: c'est la raison même de sa perfection. Le Tchong-yong exprime cette idée lorsqu'il donne au Saint la qualification de [].

L'idéal de l'humanité réalisé dans la personne du Saint, la perfection absolue qui est son partage, est bien ce que signifie le terme []. Rémusat l'a rendu par «la perfection » et «la perfection morale»; le P. Intorcetta par «vera solidaque perfectio ». Legge le traduit par « sincerity », « simplicity or singleness of soul », «the disposition to, and capacity of, vhat is good, without any deteriorating element, with no defect of intelligence, or intromission of selfish thoughts. » Ces derniers mots décrivent très bien les effets de [] signalés par Tchou $\mathrm{Hi}$; mais ils n'expriment pas assez clairement ce qu'il est en soi. Tchou $\mathrm{Hi}$ en donne cette définition: []. Cet état de conformité est le propre du Saint. II nous semble que ce qui rend le mieux l'idée de Tch'eng d'après les philosophes chinois, c'est la «Conformité » parfaite d'un être avec sa nature, ou avec le principe d'ordre universel qui est en lui. C'est par cette conformité que l'homme devient l'égal du Ciel et de la Terre ${ }^{1}$.

Tch'eng, dit Tcheou Lien-k'i, est synonyme du T'ai ki, ou Li que chaque être reçoit tout entier ${ }^{2}$; mais il peut être, et il est généralement, limité dans ses effets par l'imperfection de la matière qui le renferme. Dans le Saint ces limites n'existent

${ }^{1}$ Cf. Legge, Chinese Classics, Doctrine of the mean, ch. 21, note.

2 Tchong-yong, $\mathrm{n}^{\circ} 25$. 


\section{Le philosophe Tchou Hi}

pas ${ }^{1}:$ p.67 $1 \mathrm{l}$ agit constamment en conformité avec sa vertueuse nature. Son intelligence perçoit sans effort la raison intime de chaque chose ; sa volonté n'éprouve aucune difficulté à se porter au bien et à demeurer ferme dans la voie de la justice, de l'ordre et du devoir ${ }^{2}$.

Tous les auteurs lui attribuent comme qualité essentielle la science innée, infuse. La plupart semblent croire qu'elle n'a pas de limite, mais s'étend à tout sans exception : rien n'est caché au regard du Saint; il est omniscient 3. Tchou Hi cependant enseigne que l'objet de cette science embrasse seulement les principes généraux, d'où le Saint tirera sans peine, dans le cours de sa vie, les conclusions pratiques nécessaires pour le bien des hommes. C'est l'opinion que Yn Yen-ming (1100), un des commentateurs du Len-yu, exprime en ces mots: "Lorsque Confucius, qui, comme Saint, possédait la science infuse, nous répète avec insistance qu'il aimait à étudier, il ne faut pas croire qu'il ne parlait ainsi que par pure modestie et pour exciter ses disciples au travail, par la force de son exemple. Non, car la science innée n'a pour objet que les principes généraux. Quant à l'application particulière de ces principes, comme, par exemple, les détails pratiques du cérémonial et de la musique, les choses célèbres de l'antiquité, les évènements des temps anciens et modernes, le Saint lui-même ne peut que par l'étude en avoir une connaissance certaine ${ }^{4}$. » Mais, dès que l'occasion amène devant son esprit les questions les plus difficiles, aussitôt, sans

1 T'ong-chou, Comment.

2 T'ong-chou, Comment.

3 Tchou-tse.

4 Tchou-tse. 


\section{Le philosophe Tchou Hi}

effort, il les pénètre à fond; ses décisions sont claires, ses jugements infaillibles ${ }^{1}$; car il est doué d'une pénétration sans mesure. «L'esprit du Saint, dit Tchou-tse, est parfaitement pur et brillant, il contient dans son ampleur la raison de toutes choses. A la plus légère impression reçue il répond à l'instant, et rien dans la nature n'échappe à sa pénétration. » (Mong-tse, ch. 13. Comment.).

L'homme parfait peut lire dans l'avenir la prospérité ou la ruine des dynasties. Tous les changements, en bien et en mal, qui doivent arriver dans l'Empire, il les connaît d'avance d'une science certaine, par l'observation des phénomènes de la nature, la disposition de l'herbe divinatoire et les lignes qu'il remarque sur la carapace de la merveilleuse tortue. La raison de ce p.68 pouvoir de claire vue est, dit Tchou Hi, que le Saint n'a devant les yeux de son intelligence aucune trace d'égoïsme ou de fausseté, puisqu'il est de tout point conforme à la Nature ; rien ne l'empêche donc d'apercevoir les choses les plus subtiles. Par sa connaissance admirable, il ressemble aux Koei-chen ${ }^{2}$.

Le Saint est de plus le parangon de la perfection morale; il possède toutes les vertus à un degré éminent ${ }^{3}$. Constant dans la voie du juste milieu. il agit suivant la droite raison. «Tout homme, dit Mong-tse, a reçu du Ciel ses sens avec leurs fonctions déterminées ; mais le Saint peut seul en faire un usage parfait, parce que, ajoute le commentateur, seul il sait se conformer de point en point à la direction du principe intérieur

1 Mong-tse, chap. $V$; T'ong chou.

2 Tchong-yong, § 34, Comment.

3 T'ong-chou, Comment. 


\section{Le philosophe Tchou Hi}

(Li) qui l'anime et le dirige ${ }^{1}$. » Ce passage, dit aussi Tch'engtse, signifie que le Saint suit en tout la voie que la nature a tracée aux hommes, et par là il fait un bon emploi de ses sens... Le vulgaire possède bien aussi le principe directif $(\mathrm{Li})$, mais il l'ignore; le sage ordinaire s'y conforme, mais non pas parfaitement ; seul le Saint peut faire un emploi correct de ses sens 2 . »

Jamais la passion ne l'émeut; il se possède dans un calme que rien ne saurait altérer. Le principe céleste incorporé dans sa personne se manifeste et brille au dehors pour éclairer les hommes et les porter au bien. Tout en lui, ses moindres actions, ses paroles, jusqu'à son repos et son silence même sont autant de leçons, que les sages seuls perçoivent et dont ils font leur profit ; mais, si le vulgaire et les hommes vicieux ne sont pas transformés, la faute en est uniquement à leurs mauvaises dispositions et à leur volonté dépravée; car la sagesse du Saint est d'elle-même capable d'éclairer tous les esprits, comme sa vertu a la force de changer tous les cœurs. Son influence bienfaisante est sans bornes, comme l'influence même du Ciel. «De même, dit Tchou $\mathrm{Hi}$, que dans le cours régulier des quatre saisons, dans la production et la conservation des êtres de l'univers, se voient partout avec évidence les effets de l'évolution du principe céleste, sans que le Ciel doive pour cela rompre son silence; ainsi tout dans le Saint, l'action et le repos, révèle

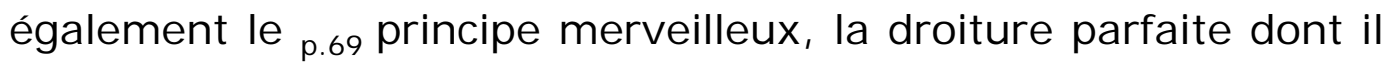

1 Mong-tse, chap. III, n. 38.

2 Ibid. Comment. 


\section{Le philosophe Tchou Hi}

est plein. » Et il conclut par ce cri d'enthousiasme : «En un mot, le Saint est le Ciel personnifié ${ }^{1}$ ! »

Le I King avait depuis longtemps déjà représenté I'homme parfait, comme l'égal du Ciel en perfection : « Ses vertus, y estil dit, égalent celles du Ciel et de la Terre; il brille comme le soleil et la lune; sa régularité est comparable à celle des quatre saisons; son influence rappelle celle des esprits. Si son action devance le Ciel, le Ciel ne la contrarie pas ; s'il suit le Ciel, il se conforme aux saisons. Et si le Ciel même ne lui résiste pas, combien moins les hommes et les esprits lui résisteront-ils ${ }^{2}$ ? » Tse-se, petit-fils de Confucius, nous fait dans le Tchong-yong une description qui semble bien n'être que le développement du passage précédent du I King. Le Saint nous y est dépeint comme transformant les hommes par la force de son exemple et de ses enseignements, et conduisant tous les êtres jusqu'au complet épanouissement de leurs nature. II aide et assiste le Ciel et la Terre dans la production et la conservation de toutes choses; il est le troisième agent de l'univers (Tchong-yong, comment.), l'égal même du Ciel ${ }^{3}$.

\footnotetext{
${ }^{1}$ Len-yu, XVII, n. 18 Comment.

2 Cf. I King. J. Legge rend ainsi la fin de ce passage : « ... in his relation to what is fortunate and what is calamitous, (he is) in harmony with the spiritlike operations (of Providence). He may precede Heaven, and Heaven will not act in opposition to him ; he may follow Heaven, but will act (only) as Heaven at the time would do. If Heaven will not act in opposition to him, how much less will men! How much less the spirit-like operations (of Providence) ! » Que I'on remarque cette progression descendante qui subordonne à I'homme parfait les mystérieuses opérations de la Providence, et fait toutes ces opérations de moindre importance que l'homme lui-même. Mais qu'est-ce donc que la Providence, sinon Dieu dirigeant toutes choses par sa sagesse? Or, il est évident que l'auteur de cet Appendice du I King n'a pas de cette Providence la moindre idée, pourquoi donc la lui prêter ? II ne semble pas même qu'il ait l'idée d'un être distinct et indépendant de la matière.

3 Cf. Tchong-yong $n^{\circ} 22,26,31$.
} 


\section{Le philosophe Tchou Hi}

Le Saint sait qu'il est inébranlablement fixé dans le bien, hors d'atteinte des passions humaines, qu'il domine sans lutte; il se rend témoignage à lui-même, en face du Ciel, de la rectitude de ses intentions, de l'innocence de ses actes, et le Ciel ne saurait le contredire en rien. Nos philosophes se font de la prière une idée très étroite: ils ne la conçoivent que comme un acte de propitiation par l'aveu de ses égarements et la soumission sincère aux lois de la raison. "Le Ciel, dit Tchou $\mathrm{Hi}$, est le premier principe de toutes choses, vénérable sans égal. Agir

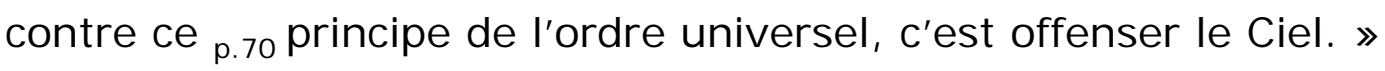
Or, le Saint agit toujours en parfaite conformité avec la raison ; il est donc impeccable. Alors qu'a-t-il besoin de prier? Sa vie n'est-elle pas plutôt une prière incessante ? Telle est l'explication que donne le Commentateur du refus qu'opposa Confucius malade à ce que l'on fit des prières pour lui : «Le Saint, dit-il, ne commit jamais de fautes; il ne pouvait se convertir à la vertu, car toute sa conduite était d'accord avec l'Esprit du Ciel ${ }^{1 .}$. La vue de son excellence le portera-elle du moins à adresser au Ciel un mot de gratitude pour l'avoir mis au-dessus du commun des hommes ? Non; et, de fait, le Ciel pouvait-il ne pas le faire tel qu'il l'a fait, puisqu'il agit fatalement ?

Voilà, dans ses grands traits, l'homme parfait de la philosophie chinoise, tel qu'il nous est représenté dans la personne de Confucius, qui passe aux yeux d'un peuple immense pour avoir été le beau idéal de l'humanité 2 .

${ }^{1}$ Cf. Len-yu, VII, 34. Comment.

2 « He was a Chinese of the Chinese; he is also represented, and all now believe him to have been the beau idéal of humanity in its best and noblest state. » (Chin. Classics I Vol. Proleg., p. 93). Dix pages plus loin, J. Legge 


\section{Le philosophe Tchou Hi}

\section{$\S$ IV. AMES ET ESPRITS.}

«Celui-là, dit Mong-tse, est saint, qui fait le bien naturellement et sans effort ; celui dont la sainteté est si grande qu'elle échappe à notre connaissance, est qualifié de Chen, parce que, d'après Tcheng-tse, il a atteint le point le plus sublime, le plus merveilleux de la vertu, que l'intelligence humaine est incapable de concevoir. L'idée de Mong-tse dans ce passage n'est donc pas que au-dessus du Saint il y ait un autre degré de personnes spirituelles ${ }^{1}$. »

Ces expressions, et d'autres semblables, fournirent à ses ennemis des armes contre Tch'eng-tse; on l'accusa de nier l'existence ${ }_{\text {p.71 }}$ des Esprits (Koei-chen), dont parlent si souvent les livres les plus anciens. Tchou $\mathrm{Hi}$ prit en mains la défense de son maître : « Non, dit-il, Tcheng-tse n'a pas eu l'intention de nier qu'il y ait des Esprits : il dit seulement que ces Esprits ne sont pas ce qu'enseignent les sectes hétérodoxes, ni ce que croit le vulgaire ignorant ${ }^{2}$. »

termine la biographie de Confucius et formule en ces termes son jugement sur son héros: "I must now leave the sage. I hope I have done him no injustice : but after long study of his character and opinions, I am unable to regard him as a great man. He threw no new light on any of the questions which have a world-wide interest. He gave no impulse to religion. He had no sympathy with progress. His influence has been wonderful, but it will henceforth wane. My opinion is that the faith of this nation in him will speedily and extensively pass away."

1 Mong-tse, I. XIV, 24.

2 Euvres complètes, I. 51, f. 2. 


\section{Le philosophe Tchou Hi}

Et que sont-ils donc alors ? Ce ne sont sûrement pas des êtres spirituels, au vrai sens que nous, chrétiens, donnons à ce mot : car il est indubitable que les philosophes chinois, depuis le douzième siècle du moins, ne semblent pas même avoir l'idée d'un être indépendant de la matière dans son existence et ses opérations.

Tous les phénomènes physiques, intellectuels et moraux, ils les expliquent sans peine à leur façon, par les évolutions nécessaires de la matière avec ses qualités diverses ( $Y n$ et Yang). Tel est le thème invariable de leur rapsodie du [], du [] et de tous les ouvrages qui affichent quelque prétention philosophique.

Mais, en ce point comme en tous les autres, les docteurs de la Renaissance loin de se donner pour des inventeurs de système, tiennent à honneur d'être considérés comme les restaurateurs de la tradition antique, les disciples fidèles du premier maître de la nation, Confucius. La question des esprits est, comme on le sait, une de celles que Confucius refusait de traiter publiquement devant ses élèves; il la jugeait inutile, sans doute, pour la pratique de la vie. Les quelques paroles qui nous ont été conservées de lui sur cette matière prêtent, dans leur ensemble, à l'interprétation matérialiste qu'on leur a donnée dans la suite.

Dans les Appendices du I King attribués à Confucius par tous les lettrés, bien que, au jugement assez fondé de $M r$. Legge, il soit très probable que la majeure partie n'est pas de lui, les mots Koei et Chen reviennent fréquemment, parfois séparés, plus souvent unis ensemble. Nous verrons plus loin à quoi répondent Koei et Chen pris séparément, lorsqu'il s'agit de I'homme.

\section{1}




\section{Le philosophe Tchou Hi}

Recherchons d'abord quel est le sens véritable des deux mots unis dans l'expression Koei-chen ? «I do not see my way, dit Legge, to translate them, when used binomially together, otherwise than by spiritual beings, or spiritual agents ${ }^{1}$. » Mais, si l'on prend le mot «Esprits » stricto sensu, comme signifiant des êtres indépendants de la matière dans leur existence et leurs opérations, c'est supposer à Koei-chen un sens qu'il n'a p.72 certainement pas aujourd'hui dans l'esprit des lettrés et qu'il n'avait très probablement pas davantage à l'époque à laquelle remonte la composition des Appendices du I King. Rien n'empêche cependant d'employer ce terme, en le prenant dans un sens plus restreint de phénomènes mystérieux, d'effets dont la cause échappe à l'intelligence et qui produisent en nous la surprise, l'étonnement, la crainte. « Toute transformation dans les principes parfaits et imparfaits de la nature ( $\mathrm{Yn}$, et Yang, dont la cause échappe à notre connaissance, s'appelle Chen. » Ainsi s'exprime le I King.

Le Li ki (sect. $8^{\mathrm{e}}$ ) rapporte qu'un des disciples, Tsai-ngo, dit un jour à son maître : « J'ai bien entendu les noms de Koei et de Chen, mais j'ignore ce qu'ils signifient. » Et Confucius lui répondit : « K'i (l'esprit vital) est la plénitude de Chen ; P'é est la plénitude de Koei. Unir le Koei au Chen, lorsque nous voulons offrir des sacrifices à nos parents défunts, est le plus grand des enseignements que nous ont transmis nos anciens législateurs. » Le commentateur enseigne que le principe de l'intelligence dans I'homme est le K'i, ou Hoen, tandis que les parties moins subtiles dans l'âme constituent le principe de sensation Ts'ing ou P'é.

1 Introduction to the I King, p. 35. 


\section{Le philosophe Tchou Hi}

Une autre glose dit qu'à la mort, la portion plus subtile et partant plus active dans l'âme intelligente devient le Chen ; la partie plus parfaite, plus déliée de l'âme sensitive devient le Koei. Pendant la vie les deux âmes étaient unies, mais à la mort elles se séparent : le K'i vole en haut, et le P'é descend vers la terre.

Confucius poursuivit en ces termes son instruction à Tsaingo : «Tout ce qui a vie doit mourir, et mort doit retourner (Koei) à la terre; de là le nom de Koei. Les os et la chair, descendus en terre, y redeviennent poussière ; tandis que le $K^{\prime} i$ s'élève et se répand. Celui-ci devient une lumière brillante, et monte comme une vapeur légère, produisant en nous un sentiment de stupeur, de tristesse: c'est la pure essence des êtres, la portion la plus subtile de l'homme, la manifestation du Chen. » Et la glose ajoute : «Le souffle de vie doit un jour se trouver épuisé ; aussi personne ne peut échapper à la mort. Le P'é, qui alors retourne à la terre, et le $\mathrm{K}^{\prime} \mathrm{i}$, qui se répand dans l'air, sont les essences subtiles des choses. »

Le maître continue : «Parce que ce sont là les essences subtiles des êtres, les anciens sages ont cherché, pour les désigner, p.73 un nom très honorable: ils les nommèrent Koei-chen, voulant qu'ils servent de modèles au peuple, et que tous leur rendent hommage et soumission. » «Les Koei-chen, dit le commentateur, sont donc proprement les âmes supérieures et inférieures des hommes et des animaux; mais les sages ne voulurent pas les désigner sous ce nom trop vulgaire : pour faire impression sur l'esprit du peuple, ils les appelèrent Koei-chen, ou êtres spirituels. » 


\section{Le philosophe Tchou Hi}

Tse-se rapporte aussi dans le Tchong-yong une parole de son grand-père sur les Esprits : «Oh ! Qu'elle est grande, s'écriait-il, la puissance des Koei-chen! Nos yeux ne peuvent les voir, ni nos oreilles les entendre ; mais ces esprits sont tellement unis à chacun des êtres, qu'ils n'en peuvent être séparés ${ }^{1}$. » A ce propos, Tch'eng-tse donne cette définition des Koei chen : « $\mathrm{Ce}$ sont les traces sensibles des productions et transformations qui s'opèrent dans la nature. » Tchang-tse exprime la chose autrement: «Koei et Chen, dit-il, sont l'énergie naturelle des deux modes (Yn et Yang) de la matière. » « Et moi, ajoute à son tour Tchou $\mathrm{Hi}$, je pense que, si l'on considère la matière universelle ( $\left.K^{\prime} i\right)$ avec ses deux composants, Koei est l'activité de Yn, Chen l'activité de Yang. Si maintenant l'on considère K'i sans distinguer ses deux modes, alors, en tant qu'il avance, progresse, s'étend (Chen), on l'appellera Chen; en tant qu'il recule, se retire, se replie sur lui-même, revient au point de départ (Koei), on le nommera Koei. Mais, sous ces noms divers, en ces deux états distincts, ce n'est en réalité qu'un seul et même être.

Chen est donc le phénomène de production d'un être quelconque, de sa conservation, de sa croissance, de sa vigueur; Koei est, dans le même être, le phénomène opposé d'affaiblissement, de déclin, de corruption, de mort ${ }^{2}$.

Du principe si souvent énoncé par nos philosophes «omnia unum », on pouvait déjà conclure que les Koei-chen sont, d'après eux, une même substance avec les choses auxquelles ils

1 Tchong-yong, § 16.

2 Euvres, I. 61, f. 2. 


\section{Le philosophe Tchou Hi}

sont unis. Mais, dans le commentaire qu'ils font de ce passage du Tchong-yong (Concorporati sunt rehus et non possunt amoveri), ils s'appuient directement sur le témoignage de Confucius pour affirmer que l'union des Koei-chen avec un être quelconque est tellement étroite, essentielle, que la séparation amènerait infailliblement la destruction de cet être. «Toute chose, dit le commentateur, commence ou cesse d'exister par p.74 l'union ou la séparation des deux principes matériels Yn et Yang, qui en sont la substance même ${ }^{1}$. Or, il est évident qu'un être ne saurait exister séparé de sa substance ${ }^{2}$. Donc les Koeichen sont inséparables des choses, par la raison qu'ils ne sont eux-mêmes que les modes de la matière universelle, avec leurs vicissitudes perpétuelles et fatales de génération, de progrès, d'abord, puis bientôt de déclin et de corruption.

«En un mot, dit Tchou $\mathrm{Hi}$, l'agrégation atomique et la dispersion, le commencement et la fin de tous les êtres, ont pour cause les mouvements de la double matière, qui se contracte ou se dilate, se retire ou s'approche. Cette activité des Koei-chen est la substance même des êtres, et aucun ne peut exister sans elle ; comme tout le reste, I'homme aussi est un composé de Koei-chen ${ }^{1}$. »

Le lettré, l'esprit plein de ces idées, verra des Koei-chen dans tous les phénomènes de la nature ; il ajoutera foi aux contes les plus invraisemblables, trouvant à tout, dans les mouvements de la matière, une explication unique, qui lui semble aussi profonde que convaincante. «Le vent, la pluie, le tonnerre, la rosée, le

1 Tchong-yong, § 16. Comment.

2 Ibid. 


\section{Le philosophe Tchou Hi}

soleil, la lune, le jour, la nuit sont autant de manifestations des Koei-chen : mais ce sont de bons et honnêtes Koei-chen, des esprits de lumière ${ }^{2}$. Quant à ceux qui sifflent sur les toits, ou qui vont se jeter contre la poitrine des gens, ce sont de méchants Koei-chen, des esprits de ténèbres; ils vont, viennent, disparaissent, et changent constamment d'état ${ }^{3}$. II en est d'autres à qui l'on adresse des prières et qui les exaucent, etc.. » Le même principe suffit à rendre compte de tous ces phénomènes: les qualités de la matière plus ou moins subtile, plus ou moins étendue, sont ce qui les distingue les uns des autres ${ }^{4}$.

On comprend quel vaste champ est ainsi ouvert aux croyances absurdes, aux craintes puériles, aux vaines pratiques de la superstition! Le Ciel et la Terre, les Vents, les Nuages, le Tonnerre, la Pluie, les Montagnes et les Fleuves de l'Empire, les mânes des ancêtres et des hommes célèbres à quelque titre ; des animaux même, comme le singe, le renard, le fabuleux dragon ; parfois un serpent, un alligator, une grenouille, une p.75 tortue sont placés dans le Pandémonium impérial et reçoivent, de par l'ordre du Fils du Ciel, les hommages de lettrés érudits et de hauts fonctionnaires, d'ailleurs bien connus pour leur intelligence pratique des affaires ${ }^{5}$.

\footnotetext{
1 I bid.

2 Euvres, I. 51, f. 3.

3 Ibid.

4 I bid.

5 Voir par exemple parmi les Proses anciennes de la dynastie T'ang l'allocution comminatoire de Han Yu à un pauvre crocodile égaré dans la rivière de Canton. II ordonne au monstre, au nom de l'Empereur son maître, d'avoir à changer au plus tôt de domicile; autrement il n'est qu'une bête : [...]. Si, non content du sacrifice qu'on lui fait d'une brebis et d'un cochon, il continue
} 


\section{Le philosophe Tchou Hi}

Les Koei-chen se divisent en trois catégories. La première est celle des Esprits du ciel, formés de la plus pure essence de la matière : ce sont le soleil, la lune, les étoiles et tous les corps célestes qui, dit Tchou $\mathrm{Hi}$, opèrent leurs mouvements et leurs révolutions d'une manière tout à fait mystérieuse. La seconde comprend les Esprits terrestres des collines, des cours d'eau, des arbres et des plantes, dont les transformations se font d'une façon en quelque sorte plus apparente ou moins mystérieuse. La troisième catégorie est celle des mânes ou Esprits des hommes morts (Cf. [] sect. 3, initio, avec comment.).

Dès la plus haute antiquité, les Chinois ont cru à l'existence d'esprits bons et mauvais. Ces derniers, de beaucoup les plus nombreux, sont représentés comme des monstres de la nature, formés des éléments impurs de la matière, qui ne cherchent qu'à nuire aux pauvres humains. Les Rituels anciens et modernes sont pleins de formules d'exorcisme contre l'influence de ces esprits de malice, appelés aussi Yao-chen ou Chen-koai. Ils produisent leur mauvaise influence là où ils naissent: les uns dans les régions de l'air, comme les esprits de la peste et de la sécheresse; les uns sur les montagnes comme les Faunes; d'autres dans les eaux, comme les Naïades. Tchou Hi parle de plusieurs de ces esprits dans la section $51^{\mathrm{e}}$ de ses Euvres, et il cite le [], où il est dit : [].

encore ses brigandages, qu'il sache que bientôt il mourra sous les coups des archers du préfet. (V. Cursus Litter. sin., vol. IV, p. 353). Et tout cela se fait sérieusement. Des scènes de ce genre se passent encore assez souvent de nos jours ; nous pourrions en donner plus d'un exemple tiré de la gazette de Péking. 


\section{Le philosophe Tchou Hi}

La croyance des Chinois à la réelle existence de certains animaux mystérieux est aussi ancienne que leur histoire. Actuellement encore, cette croyance semble aussi fortement enracinée que jamais dans l'esprit des lettrés : et ils en rendent compte avec autant de facilité que des esprits Koei-chen, à l'aide des principes de leur philosophie matérialiste.

p.76 Les Se-ling ne sont pas à leurs yeux de purs symboles. Ils admettront peut-être que les descriptions diverses qu'on en a faites n'offrent aucune certitude; mais leurs concessions n'iront pas plus loin. Confucius ne parle-t-il pas expressément du K'i-lin, espèce de Licorne, qui apparaît infailliblement lorsqu'un sage prince transforme son peuple par l'exemple de ses vertus ? Le Fong-hoang ou Phénix, ne parut-il pas à la cour de Hoang-ti, pendant que ce vertueux monarque jeûnait pour se préparer au sacrifice ? II vint encore au temps de Choen rendre témoignage à la vertu de ce prince et à la beauté harmonieuse de sa musique. Et qui pourrait mettre en doute la réalité de cette merveilleuse Tortue qui, sortant du fond de la rivière Lo, vint apporter au grand $\mathrm{Yu}$, en quelques traits d'une écriture mystérieuse, la révélation de tous les secrets de la nature. Sur ce point, le témoignage de Confucius est formel.

Le Dragon enfin, qu'on représente sous la forme d'un de ces monstrueux sauriens antédiluviens, que la science a récemment découverts dans les terrains anciens, est un être réel : I'histoire en fait foi. C'est un dragon qui apporta à Fou-hi la table des symboles. D'après le dictionnaire [] (200 P. C.) l'espèce Dragon est la principale des 360 espèces diverses de reptiles à écailles : le Long peut à volonté se rendre visible ou disparaître. Au 


\section{Le philosophe Tchou Hi}

printemps, il monte dans les airs et, l'automne venu, il se cache dans les profondeurs des eaux. "II peut, disait déjà Koan-tse $\left(7^{\mathrm{e}}\right.$ s. A. C. $)$, se réduire à la dimension d'un ver à soie, ou se gonfler de manière à remplir tout l'espace entre le Ciel et la Terre. S'il veut monter, il s'élève jusqu'aux nuages; s'il veut descendre, il pénètre jusqu'aux sources de l'abîme ${ }^{1}$. »

Avant de clore ce paragraphe, il nous faut répondre à une question, qui sera sans doute venue à l'esprit de plusieurs de nos lecteurs, en voyant les paroles étranges de Confucius sur cette importante matière. On ne saurait le nier, une part très lourde de responsabilité pèse ici sur la mémoire du premier maître de la nation chinoise. Qu'on relise avec attention les passages cités plus haut (ils contiennent le peu qu'il a dit au sujet des Esprits), et l'on sera forcé de conclure qu'il est vraiment difficile, sinon tout à fait impossible, d'excuser Confucius de la note de matérialisme. «En tout cas, suivant la judicieuse remarque de J. Legge (Chin. Classics, Vol. I, Proleg., p. 101), par sa manière de dire, il a conduit ses compatriotes à nier, comme les Sadducéens d'autrefois, l'existence de tout être spirituel, et à croire que les sacrifices aux morts ne sont qu'une formalité purement extérieure, une manière d'exprimer ce qu'exige d'eux le principe de la piété filiale mal compris et mal appliqué. »

p.77 Le P. Zottoli (Cursus litter. sin., Vol. III, p. 565), tire une conclusion pareille du passage du Li-ki dont nous avons donné plus haut la traduction: "Quod si ex his materialistam dicere velis Confucium, cui haec communiter attribuuntur, pluribus

${ }^{1}$ Cf. Mayer's Chinese Reader's Manual 1 $1^{\text {e }}$., n 389, 134, 299, 451. 


\section{Le philosophe Tchou Hi}

interpretum explanationibus consonabis, et illi injuriam fortasse non facies: tam male enim tamque parce, in re tanti momenti, de industria est locutus, ut in suspicionem haud immerito venire possit, sin minus aperti erroris at certe perplexæ ambiguitatis nocentisque incuriæ... » L'auteur termine sa note par ces mots, qui nous semblent de nature à exciter la vigilance et la paternelle sollicitude de tous ceux qui travaillent en ce pays à gagner des âmes au vrai Dieu, et à accroître le nombre des adorateurs en esprit et en vérité : «Interim illud quisque videt, si hæc pueris discenda traduntur, quanto præcauto opus sit, ne incautæ juventuti a flexiloquis magistris impuræ doctrinæ propinentur. » Or, qu'on ne se fasse pas illusion, le poison de ces doctrines funestes n'est pas confiné à un passage ou deux seulement des Livres classiques ou canoniques; les commentateurs l'ont fait pénétrer partout, comme le prouvent à l'évidence les citations nombreuses que nous en avons faites au cours de ce travail.

\section{VIE ET MORT.}

L'homme, comme tous les autres êtres, est formé d'une portion de la matière universelle animée par le principe Li. La seule différence est que la matière qui constitue I'homme est plus pure que celle des êtres inférieurs. Dès que l'union des deux composants est faite, l'homme existe. Au début de la vie, il n'y a que la forme extérieure avec l'âme grossière: c'est encore l'état de repos initial et d'inertie. Bientôt, sous l'action du principe intérieur, le mouvement commence ; la partie supérieure ou plus 


\section{Le philosophe Tchou Hi}

subtile de l'âme se développe et prend le nom de K'i ou énergie vitale. K'i ou Hoen, est dans I'homme le principe intelligent ; P'é, ou Ts'ing, le principe de sensation ${ }^{1}$. La vie est l'effet de l'union de $K^{\prime} i$ et de Ts'ing, et elle durera tant que ces deux principes demeureront unis; leur séparation amènera la mort. L'une et l'autre de ces âmes peuvent p.78 se développer, accroître leur vigueur. L'âme inférieure sera d'aillant plus vigoureuse, que la substance corporelle sera mieux nourrie. L'étude et la réflexion développeront aussi la capacité de l'âme supérieure, jusqu'à ce qu'enfin elle atteigne au plus haut point de lumière et de splendeur intellectuelle.

Cependant, viendra un temps où la quantité de matière que le destin a départie à chacun sera nécessairement épuisée : c'est I'heure fatale de la dissolution du composé, la mort. Au moment de la séparation, l'âme supérieure, ou l'air chaud, monte dans l'espace et s'en retourne au ciel, d'où elle était venue. Dès lors, la chaleur vitale quitte les membres par degrés insensibles: c'est l'âme inférieure qui retourne à la terre, son lieu d'origine. «Voilà, conclut Tchou $\mathrm{Hi}$, comment tout ce qui a vie doit nécessairement mourir, et ce. qui a commencé doit avoir un terme. »

La substance pure, légère, subtile, que I'homme avait reçue du ciel, et qui constituait son âme intelligente, il l'a rendue au ciel ; la substance plus grossière et plus pesante, qui formait son

\footnotetext{
${ }^{1}$ Ainsi donc l'âme supérieure est désignée par le nom générique de la matière $\left(K^{\prime} i\right)$; tandis que [], qualificatif de la matière propre à l'homme, indique l'âme inférieure.
} 


\section{Le philosophe Tchou Hi}

corps et ses humeurs, il l'a rendue à la terre, dont il l'avait reçue ; il ne lui reste donc rien.

On voit par là quel sens les lettrés attachent au passage de leurs Annales où la mort de l'Empereur Yao est exprimée par ces mots: II monta et descendit; ou encore au passage du Cheking, où l'on dit que le roi Wen est au ciel montant et descendant aux cotés de Chang-ti. Tout ce qui reste de ce prince, c'est la portion de matière céleste qui formait naguère son âme vertueuse et qui, mélangée maintenant à la masse atmosphérique, s'en va errant au gré des vents. L'âme séparée du corps est, à la lettre, une âme errante (a), ainsi que l'appelle le I King ().

Pour prévenir une objection qu'on pourrait lui faire sur l'inutilité des sacrifices aux morts, Tchou Hi s'empresse d'ajouter que les éléments de l'âme humaine, qui à la mort est remontée au ciel, ne se dispersent pas aussitôt, mais conservent encore, pendant quelque temps, une union assez étroite. Ainsi les sacrifices que leurs descendants leur offrent sur la terre ont le pouvoir de les émouvoir et de les attirer, à cause de la communauté de leur substance avec celle de leurs ancêtres. Mais, combien de temps durera cette union des éléments de l'âme, avant que la dispersion totale se fasse pour toujours? Personne ne le sait.

La mort naturelle est celle qui provient de l'épuisement graduel de la substance vitale, que chaque homme reçoit comme sa part de destin. S'il arrive que, dans la pleine vigueur du composé, un accident ou un acte de violence mette subitement un terme à la vie, le mort pourra revenir sous la forme d'un 


\section{Le philosophe Tchou Hi}

spectre effrayant, qui tourmentera son ennemi nuit et jour, jusqu'à ce que justice lui ait été rendue, ou qu'il ne l'ait fait inscrire lui-même à son tour sur le registre des trépassés. Alors seulement, satisfait de sa vengeance, il demeurera en paix ${ }^{1}$.

On le voit, pour le lettré matérialiste, la mort n'est pas, comme pour le chrétien, ou même le Bouddhiste, le passage à une autre existence, qu'il aura faite par ses libres actions heureuse ou malheureuse. Pendant sa vie, si du moins elle a été conforme aux principes de la secte, jamais l'idée d'une sanction posthume n'est venue l'exciter au bien ou le détourner du mal. II ne s'est occupé que du présent. II a pris du temps ce qu'il lui fallait pour la vie présente; de la science et des lettres, ce qu'il lui fallait pour arriver aux honneurs, à l'abondance des biens de la fortune, et en jouir en paix. II s'est peut-être efforcé de fixer ici-bas le souvenir de son nom dans une œuvre littéraire quelconque ou une institution philanthropique. Un de ses plus pressants désirs a été, sans doute, de laisser après lui un descendant qui puisse offrir à ses Mânes les sacrifices funèbres, suivant les anciens rites, qu'il a lui-même observés à l'égard de ses ancêtres.

Puis, le moment de la grande séparation arrive 2. Quoi qu'il fasse pour en détourner sa pensée, évitant même d'en prononcer le nom, la cruelle mort annonce son approche. II faut partir ; c'est l'ordre inexorable du destin ${ }^{3}$ : le sage doit l'accepter avec

1 L'expression [] signifie que l'âme d'un mort réclame encore vengeance d'une injustice dont elle a été victime.

2 Dans le Len-yu (ch. III, 2 p., 8.) on raconte que Pé nieou, un de ses disciples, se mourait: Confucius alla le voir. Par la fenêtre, il lui prit la main et lui fit ses adieux pour toujours.

3 Len-yu (ch. VI, 2 p., 5.) 


\section{Le philosophe Tchou Hi}

calme, puisqu'il n'y peut rien changer. II meurt donc sans qu'une lueur d'espérance vienne éclairer ses derniers instants. Tout son être aura bientôt perdu, avec le souffle de vie, son individualité, et ne sera plus, comme avant les jours de son éphémère existence, qu'un atome imperceptible, indistinct au milieu du Grand Vide sans limites.

Ajoutons que nulle part on ne trouve dans les Livres chinois réputés orthodoxes la notion de l'immortalité, dans le sens d'une existence réelle et personnelle, continuée au-delà du tombeau. Le lettré borne donc tous ses vœux à se perpétuer dans le souvenir de ses semblables, en faisant parler de lui après sa mort. C'est là quelque chose de purement extrinsèque, sans doute; mais, telle est la répugnance naturelle de l'homme pour le néant, qu'il s'attache à tout prix à l'ombre même de l'immortalité : Non totus moriar! 


\section{Le philosophe Tchou Hi}

\section{TROISIÈME PARTIE}

\section{Traduction de la section $49^{e}$ des œuvres de Tchou Hi}

d'après l'édition impériale, $23^{\mathrm{e}}$ vol. 


\section{Le philosophe Tchou Hi}

\section{CHAPITRE I \\ FORME ET MATIERE : VUE D’ENSEMBLE}

(2)

1. p.83 Dans l'univers, il n'y a ni K'i (matière) sans Li (forme), ni Li sans K'i (Ils sont inséparables).

2. Li, existant d'abord, produit le K'i ; c'est ce que l'on déduit de ce passage du I King: un Yn et un Yang (c. à. d. le K'i) s'appelle Tao (c. à. d. devient Tao ou Li en lui servant de réceptacle, et le composé prend le nom de l'élément le plus noble). Ce Sing (i. e. cette Nature, ce composé de Li et de K'i) possède nécessairement J en et I (Bienveillance et Justice).

2. Dès que le Li du Ciel existe, sûrement le K'i existe aussi. Le K'i (matière), en s'agglomérant, forme la substance corporelle et, dès lors, la Nature (Sing) est entière, parfaite.

Question : Lequel des deux éléments a la priorité (de temps), Li ou K'i ? - Réponse: Jamais Li n'est séparé de K'i ; cependant, p.84 puisque Li est imperceptible et $\mathrm{K}^{\prime} \mathrm{i}$ corporel, au point de vue de la dignité, n'y a-t-il pas entre eux quelque priorité et postériorité ? Li est incorporel (c. à. d. ne tombe pas directement et par lui-même sous nos sens), tandis que K'i est grossier et contient des impuretés.

5. On ne peut pas dire qu'il y ait proprement entre Li et $\mathrm{K}^{\prime} \mathrm{i}$ priorité ou postériorité (de temps) ; mais, si l'on considère leur origine, il faut dire que Li a la priorité. Toutefois, Li n'est pas une substance séparée, il existe (nécessairement) dans K'i (la 


\section{Le philosophe Tchou Hi}

matière). Supprimez K'i, Li n'aura plus de point d'appui. K'i se compose des éléments Métal, Bois, Eau et Feu ; Li contient la Bonté la Justice, les Rites, la Prudence.

6. Interrogé sur les relations de $\mathrm{Li}$ et de $\mathrm{K}^{\prime} \mathrm{i}$, le maître répondit: (Tcheng) I-tchoan a parfaitement exprimé la chose, quand il a dit : « Li est un, mais ses fonctions sont diverses. » Prenez ensemble le ciel, la terre et les êtres sans nombre ; ils ne font qu'un seul Li. Quant aux hommes, chacun d'eux a le principe formel ( $L i$, individualisé dans la matière qui lui est propre).

7. Dès que Li existe, $\mathrm{K}^{\prime} i$ existe également ; cependant Li est (comme) la racine. Parlons donc d'abord de Li. On dit, par p.85 exemple: Le T'ai-ki (Grand Extrême) en mouvement produisit Yang (la matière plus parfaite) ; quand il eut épuisé sa force de mouvement, il s'arrêta, et cet arrêt produisit Yn (la matière imparfaite) ; mais, avant le mouvement, n'y eut-il pas repos ? Lorsque maître Tcheng nous dit : «Le mouvement et le repos n'ont pas de commencement », il prend le mouvement lui-même comme point de départ ; mais, c'est comme s'il disait : «Avant le mouvement il y eut repos et, avant le repos, mouvement ». Dans la phrase du I King: «Une révolution de Yn et de Yang s'appelle Tao ; ce qui en procède est bon, ou le Bien », le mot ki (procéder) indique le commencement du mouvement. S'il y avait seulement ouverture et fermeture (de l'univers), sans point de jonction (entre les révolutions sans fin), la fermeture amènerait l'annihilation de toutes choses.

Autre question: Ce point de jonction ( $\mathrm{ki})$, réside-t-il dans I'intervalle du mouvement et du repos ? - Réponse : C'est la fin du repos et le principe du mouvement. Prenez comme exemple 


\section{Le philosophe Tchou Hi}

les quatre saisons. Quand I'hiver est venu, tous les êtres retournent à leur état de repos ; et, s'il n'y avait plus d'activité vitale, l'année suivante tout serait fini. Mais Tcheng produit (ramène) Yuen, et ainsi de suite éternellement.

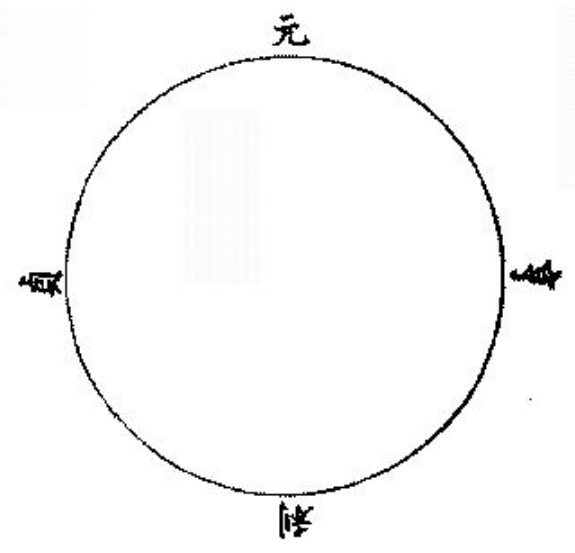

8. p.86 A propos de ce mot: «Dès que Li existe, K'i aussi existe », quelqu'un demanda : « Où était ce Li de l'homme avant que I'homme ne fût ? » Le maître répondit qu'il était au même endroit. C'est comme la masse d'eau de la mer; prenez-en une cuillerée, deux seaux, ou un bol, c'est toujours la même eau de mer. Cependant Li est comme le maître de maison qui reçoit et demeure; moi, je ne suis que l'hôte qui passe. Il est éternel, tandis que moi je ne le reçois que pour un temps.

9. Q. Par quel effet Li manifeste-t-il sa présence dans K'i ? Rép. : Par exemple, si le Yn, le Yang et les cinq Eléments ne se mélangent jamais dans un désordre irrémédiable, c'est l'effet de Li. p.87 Si la matière $\left(K^{\prime} i\right)$ ne s'agglomérait pas, le principe $\mathrm{Li}$ manquerait de point d'appui.

10. Interrogé de nouveau sur ce qu'il a dit précédemment que « Li est d'abord, et puis K'i », le maître répond: Inutile d'exprimer la chose ainsi. Quant à savoir à présent si Li existe d'abord 


\section{Le philosophe Tchou Hi}

et ensuite $K^{\prime} i$, ou bien K'i d'abord et Li après, c'est ce que nous ne pouvons pénétrer parfaitement. Si pourtant une conjecture m'est permise, il me semble que l'activité de $K^{\prime} i$ dépend absolument de $\mathrm{Li}$; et dès que $\mathrm{K}^{\prime} \mathrm{i}$ s'agglomère, $\mathrm{Li}$ y est présent. K'i peut, en se condensant, former des êtres; Li est sans volonté, sans dessein, il ne forme rien; mais partout où $K^{\prime} i$ s'accumule, Li se trouve au milieu. Et maintenant, tout ce qui existe entre le ciel et la terre, l'homme, les plantes, les arbres, les oiseaux et les quadrupèdes, tout sans exception provient d'une semence, et l'on ne connaît pas un seul être né sans semence; lors donc qu'un être quelconque naît spontanément, c'est un effet de K'i. Quant à Li, c'est un monde pur, vide et vaste sans limite, n'ayant aucune partie que nos sens puissent percevoir; il ne saurait évidemment rien former. $\mathrm{K}^{\prime} \mathrm{i}$, au contraire, peut produire les êtres par la fermentation et la condensation.

11. p.88 Objection. Vous dites: «Li d'abord, K'i ensuite » ; mais, il semble qu'on ne peut attribuer à aucun des deux principes priorité ou postériorité. - Réponse : J'accorde une certaine priorité à $\mathrm{Li}$; mais, gardez-vous de dire: «aujourd'hui Li existe (tout seul), et demain K'i existera. » Cependant il y a sûrement priorité et postériorité (i.e. de dignité).

12. Q. Avant qu'il y eût ciel et terre, certainement Li était déjà ; comment cela ? - Réponse : Oui, avant le ciel et la terre, Li existait. Li existant, alors seulement le ciel et la terre purent exister. Sans $\mathrm{Li}$, le ciel et la terre ne seraient pas, ni l'homme, ni les autres êtres; tout manquerait de soutien, de point d'appui. 


\section{Le philosophe Tchou Hi}

Li existant, aussitôt le K'i existe, se met en mouvement, produit, engendre et entretient tous les êtres. - Question : Est-ce Li qui engendre et entretient? - Réponse : Li existe, et conséquemment $K^{\prime} i$ se meut, pénètre, engendre et nourrit (toutes choses) ; Li n'a pas de substance sensible. - Le nom de substance ( $T^{\prime} \mathrm{i}$, appliqué à $\left.\mathrm{Li}\right)$, est-ce une expression forcée, impropre ? - Certainement. - Li est-il infini et K'i fini ? - Quant à des limites, comment en peut-on assigner (à l'un ou à l'autre principe) ?

13. Quelqu'un ayant demandé si Li était premier (dans le temps) et K'i postérieur, le maître répondit : On ne peut pas dire p.89 que $\mathrm{Li}$ et $\mathrm{K}^{\prime} \mathrm{i}$ aient entre eux priorité ou postériorité de temps; mais, quand on remonte par la pensée à l'origine des choses, on s'imagine que $\mathrm{Li}$ existe le premier et $\mathrm{K}^{\prime} \mathrm{i}$ en second lieu.

14. K'o-ki posa cette question : Après que le Grand Formateur a disposé toutes choses, un être, qui s'en va, cesse-t-il à jamais, ou bien revient-il à l'existence? - Réponse: Une fois passé, c'en est fait de lui pour toujours ; et, en effet, comment K'i (la matière) une fois dispersé pourrait-il se réunir de nouveau ?

15. Questionné sur l'expansion et la contraction de K'i, le maître dit: Prenons, par exemple, de l'eau, que nous faisons bouillir dans une marmite: lorsque l'eau s'est évaporée, l'eau de la source viendra tout comme auparavant, sans attendre que l'eau évaporée lui soit restituée.

16. Il est dit dans les Classiques: «Chang-ti infuse au peuple une nature vertueuse »; «le Ciel donnera des charges importantes aux plus méritants »; «le Ciel vient en aide au 


\section{Le philosophe Tchou Hi}

peuple, et lui suscite de sages princes »; «le Ciel produit les êtres et les traite suivant leur capacité : aux bons il envoie des félicités innombrables, et aux méchants des calamités sans nombre»; « quand le Ciel est sur le point d'envoyer au monde quelque malheur extraordinaire, il lui envoie d'abord un homme extraordinaire qui le prévoit. » On demande si ces passages et autres p.90 semblables signifient qu'il existe réellement là-haut dans l'azur un être qui gouverne ainsi en maître; ou bien si le Ciel étant dénué de sensation et de connaissance, ce n'est qu'en vertu de Li que tout se passe de la sorte. - Réponse: Ces passages n'ont tous qu'un même sens ; c'est simplement Li qui agit ainsi. K'i, dans ses révolutions éternelles, a toujours eu des périodes successives de perfection et de déclin, de déclin et de perfection, roulant ainsi dans un cercle sans fin. Jamais il n'y eut déclin qui ne fût suivi de perfection.

17. Quand un homme expire, son estomac se détend ; quand il aspire, son estomac se contracte. Pour ce qui regarde l'expiration et la détente de l'estomac, l'inspiration et la contraction de l'estomac, c'est un phénomène constant. Or, puisqu'il en est ainsi, au montent de l'expiration, lorsque cette bouchée de souffle sort, une autre portion égale se produit aussitôt, et c'est pourquoi l'estomac se détend. Au moment de l'inspiration, ce souffle, qui est en moi, est à son tour rejeté de l'intérieur: voilà pourquoi l'estomac se contracte. Lao-tse dit quelque part que «l'espace entre le Ciel et la Terre ressemble à un T'ouo-yo qui, mis en mouvement, n'est jamais épuisé ; vidé, en a encore plus à rejeter. » Or, le T'ouo-yo n'est autre que notre soufflet moderne. 


\section{Le philosophe Tchou Hi}

18. Li n'agit qu'en s'unissant à K'i.

10. Le printemps, l'Eté, l'Automne, I'Hiver sont le K'i ; Yuen, Heng, Li, et Tcheng en sont les actes (l'énergie), lesquels, dans I'homme, se nomment Bonté, Droiture, Rites et Sagesse. Li possède ces quatre actes Yuen, Heng, Li et Tcheng; et K'i les possède également ; car Li est au centre de $\mathrm{K}^{\prime} \mathrm{i}$, ces deux principes n'étant jamais séparés.

20. Interrogé sur la relation qu'il y a entre Li et le Nombre, le maître répond: De même que de Li suit nécessairement l'existence de $K^{\prime} i$, de même de $K^{\prime} i$ suit l'existence du Nombre; le Nombre, en effet, n'est que la distinction des objets par délimitation.

21. Mon corps est comme une enveloppe dure, à l'intérieur et à l'extérieur de laquelle il n'y a rien autre chose que le K'i (avec ses deux modes Yn et Yang) du Ciel et de la Terre. C'est comme un poisson dans l'eau: l'eau qui l'entoure au-dehors est de même nature que l'eau qu'il avale: et l'eau qui est dans l'estomac d'un cétacé est de même nature que celle qui remplit l'estomac d'une carpe.

$\mathrm{K}^{\prime} \mathrm{i}$ en s'agglomérant produit une forme sensible. Quand $\mathrm{Li}$ s'unit à K'i, le composé a le pouvoir de comprendre et de sentir ; comme lorsque l'on verse de la graisse sur le feu, il se produit aussitôt une grande flamme brillante. Or, ce qui donne p.92 le pouvoir de sentir (le principe formel de la sensation), c'est le principe Li de l'âme; mais, dans la partie la plus subtile de K'i (matière) réside la faculté de sentir. 


\section{Le philosophe Tchou Hi}

23. Ce qui fait que I'homme est homme, c'est que son principe actif $\mathrm{Li}$ est le $\mathrm{Li}$ du Ciel et de la Terre, et son principe matériel K'i est le K'i du Ciel et de la Terre. Li n'a aucun vestige sensible, il est invisible ; c'est donc par K'i qu'on découvre sa présence. - [Les 23 paragraphes qui précèdent sont extraits du [] ].

24. Entre le Ciel et la Terre (i. e. dans l'univers), il y a seulement $\mathrm{Li}$ et $\mathrm{K}^{\prime} \mathrm{i}$, rien de plus. $\mathrm{Li}$, principe supérieur à la forme, impalpable, imperceptible, (mais dépendant de la matière dans son existence), est la source qui donne naissance à tous les êtres : $K ' i$, instrument matériel et sensible, est l'élément qui reçoit la vie. Par conséquent, I'homme et toutes les choses, au moment de leur production, doivent recevoir ce Li et, dès lors, ils ont leur nature propre; ils doivent aussi recevoir le $K^{\prime} i$, ce qui leur donne leur forme extérieure et sensible. [Réponse du philosophe à Hoang Tao-fou].

25. Li et $\mathrm{K}^{\prime} \mathrm{i}$ sont certainement deux êtres distincts ; cependant, si on les considère dans un objet quelconque, les deux apparaissent comme un tout, si parfaitement unis, qu'on ne saurait les séparer, les mettre chacun dans une place différente ; ce qui ${ }_{\text {p.93 }}$ n'empêche pas que ces deux êtres ne soient tout à fait distincts l'un de l'autre. Considérons maintenant le principe Li. Avant qu'un être existe, le Li de cet être futur existe déjà (non encore individualisé) ; mais Li seul existe, car cet être lui-même n'a pas encore d'existence réelle. Dans ce genre d'étude, il faut examiner tout avec distinction et clarté, en comparant le commencement avec la fin; ainsi on évitera toute erreur. [Réponse à Lieou Chou-wen]. 


\section{Le philosophe Tchou Hi}

26. Li vient en premier lieu, et puis $\mathrm{K}^{\prime} \mathrm{i}$; dans ce $\mathrm{K}^{\prime} \mathrm{i}$, Li trouve un point d'appui. Depuis les plus grandes, comme le Ciel et la Terre, jusqu'aux plus petites, comme la fourmi, toutes les choses sont produites d'après cet ordre. Et pourquoi penserions-nous que, pour exister, le ciel et la terre n'ont eu besoin de rien recevoir de ces mêmes principes constitutifs ? Quant à Li, on ne saurait traiter de son existence ou non-existence ; car avant que le Ciel et la Terre ne fussent, il était déjà tel qu'il est à présent. [Réponse à Yang Tche-jen].

Question. Dans le monde entier, il n'y a que Li et K'i. Li est immuable, tandis que K'i est sujet au changement. II est dit dans le Tchong-yong que « la grande vertu obtient ${ }_{\text {p.94 }}$ nécessairement la réputation, I'honneur et la longévité qui lui sont dûs. » Et en vérité il doit en être ainsi. Cependant maître K'ong n'obtint aucune dignité, Yen-tse mourut jeune, et bien des pauvres lettrés, certes, sont morts dans un âge avancé, sans que leur renommée eût pénétré au loin. Ces effets ne proviennent-ils pas de K'i ? D'où l'on voit que le Sage, dans le Tchong-yong, parle du cours ordinaire des choses, et non de ce qui en est une déviation. Voici donc là-dessus mon humble conjecture : comme actuellement $\mathrm{Li}$ est impuissant à exercer sur K'i son influence entière, ces lois de félicité pour les bons et de malheur pour les méchants restent, la plupart du temps, sans effet. Mais est-il possible que telle soit la loi constante, immuable du Ciel et de la Terre ? A mon avis, bien que K'i soit par lui-même sujet au changement, dans son changement, toutefois, il subit aussi l'influence du siècle (i.e. de la vertu ou des vices des hommes). Ainsi, au temps de Yao, Choen et Yu, parce que des Sages 


\section{Le philosophe Tchou Hi}

étaient au pouvoir, l'Empire était gouverné dans la tranquillité ; la paix attirait la paix, et par suite aussi $K^{\prime} i$, étant pur et droit, obéissait à l'influence de Li. Mais, aux époques troublées du Tchoen-tsieou. et des Royaumes belligérants, ce n'étaient plus que supplices, exécutions capitales et cruelle oppression : alors $K$ 'i se vicia sous l'influence des temps, et Li ne fut plus capable de le dominer. N'y aurait-il donc pas en tout ceci quelque relation avec les actions des p.95 hommes ?-Réponse : J'ai déjà répondu à une question semblable dans une précédente dissertation sur la Nature et le Destin. Bien que les impressions (provenant des relations extérieures) soient diverses, il est vrai aussi que le K'i primordial s'est vicié, appauvri. [Réponse à Tcheng Tse-chang].

28. Li existant, K'i existe aussi. Ce K'i est essentiellement double; voilà pourquoi le I King dit: T'ai-ki engendra les deux I (modes); et là-dessus, Lao-tse dit aussi que Tao engendra d'abord un (l'unité ou la monade) et puis un engendra deux. Mais il n'a pas su pénétrer à fond la doctrine de Li. [Réponse à Tch'eng K'o-hieou].

29. Si nous considérons la source unique de toutes choses, il conste que $\mathrm{Li}$ leur est commun à toutes, tandis que $\mathrm{K}^{\prime} \mathrm{i}$ est distinct (en chacune). Quant aux substances si variées de tous les êtres, il faut dire que par l'élément matériel K'i ils se rapprochent; niais Li est en eux très différent. La différence de l'élément matériel $\mathrm{K}$ 'i consiste dans son plus ou moins de pureté ; la différence de Li dépend du degré de liberté d'action que lui laisse le K'i. Puisque nous avons été assez heureux pour 


\section{Le philosophe Tchou Hi}

élucider ce point, aucun doute ne nous est désormais permis làdessus. [Réponse à Hoang Chang-pé].

30. p.96 En quelque lieu que s'agglomère, Li y est aussi ; mais Li est toujours le maître : c'est ce qu'exprime son nom de Miaoho, merveilleux unificateur. [Réponse à Wang Tse-ho].

31. Quant au doute relativement à l'imperfection de Li et de $K^{\prime} i$, je dis que s'il s'agit de la source originelle, Li fut d'abord, ensuite $\mathrm{K}^{\prime} \mathrm{i}$; donc, quant à $\mathrm{Li}$, il ne saurait être question d'imperfection ou de plénitude. S'il s'agit de l'infusion dans les êtres (de ces deux principes), alors il faut dire que K'i une fois aggloméré, aussitôt Li vient et l'informe. Ici donc Li est postérieur à K'i. Là où K'i ne s'est pas aggloméré, Li n'existe pas encore (individualisé). La qualité de l'un des éléments est en proportion avec la perfection de l'autre. Ne peut-on donc pas leur attribuer à tous deux imperfection et plénitude relative? [Réponse à Tch'ao Tche-tao].

On ne peut pas attribuer (directement, immédiatement) à Li perfection ou imperfection, libre communication ou obstruction. Mais, puisque le K'i (la matière) donné aux êtres n'est pas en tous de même qualité, il s'ensuit que, en raison de l'imperfection de K'i, Li aussi s'obtient imparfait ; si K'i est obstrué (étant plus ou moins grossier), il se trouvera nécessairement aussi plus ou moins privé de l'action de Li. Or, dans l'homme lui-même, Li ne saurait être sans quelque imperfection et obstruction. p.97 Hongk'iu dit: «La lumière que nous recevons peut varier pour la quantité et l'éclat, suivant les sujets ; et pourtant c'est une seule et même lumière : il n'y en a pas deux. »Cela est parfaitement dit. [Réponse à Tou Jen-tchong]. 


\section{Le philosophe Tchou Hi}

33. Nous avons expliqué que la matière reçue dans les êtres peut être imparfaite, mais la substance totale de Li n'a jamais de différence: c'est un point acquis. (Tch'eng Ming-tao disait aussi : «Ce qui n'est pas susceptible d'être bourbeux n'est pas de l'eau. » C'est, en d'autres termes, la même idée. [Réponse à Tou Jen-tchong ].

34. Li est pureté parfaite et suprême bonté ; K'i, au contraire, est mélangé et sujet à l'imperfection. Au dedans est l'homme sage ; au dehors, l'homme amoindri. Tout ce qui sert à réprimer l'élément imparfait et à soutenir l'élément parfait de K'i, favorise l'action de Li. Si l'on répare sans cesse, si l'on aide et complète ce qui manque à $K^{\prime} i$, qu'y trouvera-t on bientôt de défectueux ? [Réponse à quelqu'un].

35. Sing (Nature) n'étant autre chose que Li, nous ne devons pas lui attribuer, comme à $\mathrm{K}^{\prime} \mathrm{i}$, condensation et raréfaction. Lorsque nous disons que les esprits subtils (vitaux), l'âme Hoen (l'énergie du principe Yang) et P'é (l'énergie du principe Yn) sont

doués d'intelligence et de sensation, nous exprimons par là p.98 des actes de K'i. Quand celui-ci se condense, ces effets se produisent: quand il se disperse (i.e. à la mort), ces effets ne sont plus. Quant à $\mathrm{Li}$, son existence ne dépend pas de la condensation ou de la dispersion de la matière; seulement supposé Li existant, K'i nécessairement existe aussi, et si K'i se condense quelque part, Li y aura son poste marqué. [Réponse à Liao Tsehoei].

36. Li est doué de mouvement et de repos, conséquemment K'i se meut et se repose : supposez Li sans mouvement ni repos, d'où K'i aurait-il son mouvement et son repos ? Démontrons ceci 


\section{Le philosophe Tchou Hi}

par une preuve évidente: Jen (Bienveillance), c'est le mouvement ; I (Droiture, Justice), c'est le repos ; or, ces vertus en quoi dépendent-elles de $\mathrm{K}^{\prime} \mathrm{i}$, la matière ? [Réponse à Tcheng Tse-chang].

Les treize paragraphes qui précèdent sont tirés du [].

@ 


\section{Le philosophe Tchou Hi}

\section{CHAPITRE II \\ GRAND EXTRÊME (T'Al-KI)}

1. p.99 T'ai-ki est simplement Li (sous un autre nom).

2. Question : Si T'ai-ki n'est pas quelque chose qui existait à l'état chaotique avant la formation du ciel et de la terre, est-ce donc le nom générique de Li individualisé dans le ciel et la terre et chacun des êtres particuliers ? - Réponse : T'ai-ki n'est autre que ce Li (actuel) du ciel, de la terre et de toutes choses. Quant au ciel et à la terre, ils ont en eux le T'ai-ki ; chaque être possède aussi T'ai-ki. Avant le ciel et la terre, certainement Li existait. Et c'est lui qui, mettant la matière en mouvement, produisit Yang ; c'est lui qui, en l'arrêtant, produisit Yn.

3. L'universalité des êtres, les quatre saisons et les cinq éléments proviennent de T'ai-ki. T'ai-ki s'identifie avec la matière p.100 universelle divisée obliquement en ses deux modes. La partie de la matière qui est en mouvement s'appelle Yang ; la partie qui est en repos s'appelle Yn. II se divise encore en cinq éléments et puis se répand pour devenir toutes choses.

4. Question : D'après votre explication de T'ai-ki, pourquoi y a-t-il d'abord mouvement, puis repos, d'abord acte, ensuite puissance (ou inertie), d'abord influence, puis cessation d'influence ? Réponse: Quant à Yn et Yang, l'acte dépend de Yang, et la puissance de Yn. Néanmoins les périodes successives de mouvement et de repos, de Yang et $Y n$ n'eurent jamais de commencement; on ne saurait donc distinguer entre eux 


\section{Le philosophe Tchou Hi}

respectivement priorité ou postériorité. Si nous parlons maintenant du point de départ, nous concevons certainement le mouvement d'abord, puis le repos, l'acte précédant la puissance, et l'influence la cessation d'influence ; et cependant, en réalité, avant la cessation d'influence, il y eut aussi influence (exercée) ; avant le repos, il y eut déjà mouvement. Auquel donc donnerons-nous la priorité sur l'autre? Nous ne pouvons pas parler du mouvement d'aujourd'hui et en faire le point de départ, sans mentionner le repos d'hier. Par exemple, si vous dites « expirer et aspirer » (hou hi), vous parler correctement ; car on ne doit pas dire (hi hou) « aspirer et expirez; » et pourtant, avant l'expiration il y a aspiration, connue avant l'aspiration il y eut déjà expiration.

5. p.101 T'ai-ki n'est pas un être à part; il constitue Yn et Yang, et il réside dans I'Yn et Yang; il constitue les cinq éléments, et réside en eux; il constitue toutes choses, et il réside en elles: c'est $\mathrm{Li}$, et rien de plus; mais on l'appelle T'aiki, ou grand extrême, parce qu'il atteint tout jusqu'aux dernières limites.

6. S'il n'y avait pas de T'ai-ki, le ciel et la terre ne chavireraient-ils pas?

7. T'ai-ki, c'est Li même; ce qui reçoit mouvement et repos, c'est K'i. Lorsque K'i avance, Li avance aussi ; tous deux sont toujours dans une mutuelle dépendance, et ne sont jamais séparés l'un de l'autre. Au commencement, avant qu'il y eût un seul être, Li était seul (avec la matière première) ; dès qu'il fut, il se mit en mouvement et produisit Yang, puis en s'arrêtant il produisit $\mathrm{Yn}$; au point extrême du repos, il reprit son 


\section{Le philosophe Tchou Hi}

mouvement; au point extrême du mouvement, il revint au repos, tournant ainsi dans un cercle sans fin. $\mathrm{Li}$ étant véritablement sans limites, $K^{\prime} i$ participe également de son infinité. Depuis que le ciel et la terre ont été formés, ce principe actif ( $\mathrm{Li})$, qui réside en eux, leur imprime sans cesse leur mouvement giratoire. Le jour a sa révolution diurne, le mois sa révolution mensuelle et l'année sa révolution annuelle; $\mathrm{Li}$ est toujours le moteur universel.

8. p.102 Avant que T'ai-ki se mit en mouvement, c'était le règne de $\mathrm{Yn}$; au centre de $\mathrm{Yn}$ et du repos se trouve nécessairement la racine de Yang, comme au centre de Yang et du mouvement est aussi la racine de Yn. Pourquoi le mouvement aboutit-il fatalement au repos ? Parce qu'il a sa racine dans Yn. Pourquoi le repos arrive-t-il fatalement au mouvement ? Parce qu'il a sa racine dans Yang.

9. Le mouvement et le repos que possède T'ai-ki ne sont que l'émanation de T'ien-ming (i. e. de Li, ainsi nommé en tant qu'il est communiqué aux êtres inférieurs par l'action immédiate du Ciel). Mais, objecte quelqu'un, comment le repos peut-il être un efflux? - Je réponds que c'est la succession régulière de mouvement et de repos qui constitue cet efflux. Par exemple, ne peut-on pas dire, en parlant du temps de l'automne et de l'hiver, le cours de l'automne et de l'hiver ? Et si vous soutenez que le repos ne saurait avoir d'efflux, comment dit-on alors que «le repos engendra, produisit $Y n$ »? Ce mot « engendrer » (appliqué au repos) résout parfaitement la question.

10. Depuis T'ai-ki jusqu'à la transformation et la production de tous les êtres, un principe universel embrasse tout. Ne dites 


\section{Le philosophe Tchou Hi}

donc pas : Ceci existe avant, et cela après. II n'y a, en somme, qu'une Grande Source originelle où tout passe de la puissance à l'acte, de l'état atomique (imperceptible) à l'apparence distincte.

11. p.103 Question: Si tous les êtres participent de la substance du Li unique et en font leur propre substance, il s'en suit que chaque être possède en lui un T'ai-ki ; d'après cela, T'ai-ki serait donc divisé en parties distinctes ? - Réponse : Oui, originairement il n'y a qu'un seul T'ai-ki ; mais, lorsque chaque être l'a reçu en lui, chaque être possède en lui le T'ai-ki tout entier. Par exemple, la lune au ciel est une; et lorsqu'elle répand sa lumière sur les fleuves et les lacs, on la voit partout, sans que pour cela on puisse dire que la lune soit divisée.

12. L'expression «T'ai-ki se divisa » signifie simplement que, par le moyen de Yn et Yang (les deux modes parfait et imparfait de la matière), il enveloppe et compénètre tous les êtres de I'univers.

13. Ce qui a fait désigner cet agent universel par le nom de Ki (Extrême), c'est le sens qu'a ce caractère dans l'expression Tch'ou-ki (gond, pivot, moteur). Les sages l'appelèrent T'ai-ki, voulant montrer par là qu'il est la racine du ciel, de la terre et de toutes choses. Tcheou-tse les suit en cela; mais, en outre, il l'appelle encore Ou-ki (sans limite, infini), exprimant ainsi la merveille de cette nature incorporelle $(m$. à. $m$. sans son ni odeur).

14. p.104 T'ai-ki n'a pas de lieu déterminé, ni de forme sensible; pas de place où il soit circonscrit. Si nous parlons de lui avant qu'il eût manifesté son action, alors, avant toute manifestation, assurément il n'y avait encore que repos. Le 


\section{Le philosophe Tchou Hi}

mouvement, le repos, le $\mathrm{Yn}$ et le Yang, sont des phénomènes sensibles. Or, le mouvement est le mouvement même de T'ai-ki, comme le repos en est le repos; il produit l'un et l'autre, sans que pourtant le mouvement et le repos soient T'ai-ki lui-même. Voilà pourquoi Tcheou-tse l'a nommé Ou-ki. Avant toute manifestation, il ne pouvait s'appeler T'ai-ki, et cependant, dès lors il contenait déjà en lui le Plaisir, la Colère, la Tristesse et la Joie; Plaisir et Joie dépendent de Yang, Colère et Tristesse dépendent de $\mathrm{Yn}$; et avant l'émanation de ces quatre passions, leur raison d'être existait déjà. S'il était question d'elles après leur émanation, j'accorde que l'on puisse les appeler T'ai-ki : mais c'est une matière difficile à traiter ; ceci soit dit uniquement à titre d'essai, d'ébauche. Que chacun pour lui-même étudie cela avec soin.

15. Le mouvement n'est pas T'ai-ki ; il n'en est que l'acte de même le repos n'est pas T'ai-ki ; il n'en est que la puissance ou l'inactivité.

16. p.105 Quelqu'un l'interrogeant sur T'ai-ki, le maître répondit: T'ai-ki est le principe infiniment bon et très excellent. Tout homme a en lui un T'ai-ki, toute chose a également un T'aiki. Le T'ai-ki dont parle Tcheou-tse est l'énergie toute bonne et très excellente qui se manifeste dans le ciel, la terre et toutes choses.

17. Quand je parle de T'ai-ki, je n'en sépare pas Yn et Yang ; quand je parle de Sing (Nature) je le tiens uni à K'i. Si Yn et Yang et K'i n'étaient avec eux, et Sing, quel point d'appui auraient-ils ? Mais si nous voulons les connaître distinctement, nous ne pouvons pas ne pas traiter de chacun à part. 


\section{Le philosophe Tchou Hi}

18. Question : Vous avez dit, Monsieur, en parlant de T'ai-ki, que possédant notre Sing (Nature) dès lors nous avons aussi Yn, Yang et les cinq éléments; qu'est-ce donc que Sing? Réponse: Je pense que j'ai dit cela autrefois; mais à présent mes idées sont changées là-dessus. Le mot Sing (Nature) s'emploie pour Li en tant que nous le recevons du Ciel ; quant à T'ai-ki, il faudrait l'appeler Li. On ne doit pas changer ces termes. Le I King dit: «Une révolution de $\mathrm{Yn}$ et de Yang s'appelle Tao (voie, course, évolution). Tao (ou Li), considéré en soi à l'instant de l'émanation, s'appelle Chan (Bonté sans mélange) ; en tant qu'il constitue l'être qui le reçoit, on l'appelle Sing (Nature). » Ce dernier mot exprime donc ce que le Ciel p.106 confère à l'homme et à tous les êtres, ce que l'homme et tous les êtres reçoivent du Ciel.

19. J'ai dit autrefois que T'ai-ki semble cacher sa tête. Au temps du mouvement, il est Yang ; au temps du repos, il devient Yn.

20. T'ai-ki est Li doué de mouvement et de repos. II ne faut pas, dans T'ai-ki, distinguer le mouvement et le repos de l'inertie et de l'acte. Le repos, en effet, est l'inactivité de T'ai-ki, comme le mouvement en est l'acte. Par exemple, prenons un éventail ; il n'y en a qu'un seul : remuez-le, il est en acte ; déposez-le, il est en puissance (d'éventer). Qu'il soit déposé ou mis en mouvement, c'est toujours essentiellement le même éventail.

21. Liang Wen-chou disait: « Vous parlez de T'ai-ki comme joint au mouvement et au repos. » Non, répliqua le maître, je ne dis pas que T'ai-ki est joint au mouvement et au repos; je dis qu'il possède mouvement et repos. T'ai-ki existe encore après, 


\section{Le philosophe Tchou Hi}

comme il existait avant l'émanation du Plaisir, de la Colère, de la Tristesse, de la Douleur, de la Joie. C'est toujours le même T'aiki se répandant au moment de l'émanation, ou restant caché avant l'émanation.

22. p.107 Interrogé sur T'ai-ki, il répondit: Avant toute manifestation au-dehors, c'était $\mathrm{Li}$ « in actu primo; dès qu'il y a émanation, il y a Tsing ou acte exercé; par exemple, l'expression «Par son mouvement T'ai-ki, produisit Yang» indique un acte.

23. T'ai-ki est comme le faîte d'une maison, ou le plus haut point du Ciel ; arrivé là, il n'y a plus moyen de passer outre ; c'est le point extrême de Li dans un être quelconque. Yang se meut, Yn repose : ce n'est pas T'ai-ki qui met en mouvement ou en repos ; Li seul est intrinsèquement doué de mouvement et de repos. Li est de soi invisible; c'est par Yn et Yang qu'il se fait connaître. Li se tient sur Yn et Yang comme un homme à cheval. Dès qu'il produit les cinq éléments, il se trouve englobé, détenu et fixé dans leur substance matérielle ( $\mathrm{K}^{\prime} \mathrm{i}$-tche) ; chacun de ces éléments est dès lors un être à part, chacun possède sa nature propre (Sing) ; et voilà comment T'ai-ki est présent partout.

24. Question. Ce que maître Lieou appelle le Centre du ciel et de la terre, et ce que maître Tcheou appelle T'ai-ki, est-ce une même chose? - Réponse: Oui, le nom seul est différent. Tchong signifie le point où tout aboutit et s'adapte exactement. La phrase du Chou-king : «Le souverain Chang-ti communique au peuple une nature vertueuse (tchong)», ne signifie pas p.108 autre chose que ce milieu exact, cette harmonie parfaite. Ki n'est pas le centre ; mais lorsque Ki s'individualise en formant un être, 


\section{Le philosophe Tchou Hi}

il est au milieu de cet être. Par exemple, dans ce chandelier, le centre, où se trouve la pointe, est le Ki ou l'axe du chandelier. De ce point à un point quelconque du rebord, il y a exactement la même distance, sans différence aucune.

25. T'ai-ki est quelque chose de grand! Considéré dans son étendue, vers les quatre points cardinaux, le zénith et le nadir, il se nomme Yu; considéré dans sa durée, depuis la plus haute antiquité jusqu'à présent, on l'appelle Tcheou. II n'est rien de si vaste que Yu : dans les quatre directions, il va à l'infini ; en haut et en bas, rien ne le limite : telle est son étendue. Rien n'est comparable à Tcheou pour la durée : depuis les temps les plus reculés jusqu'à nos jours, c'est une succession sans fin. Notre esprit ne doit jamais perdre de vue cette pensée. - Comme quelqu'un lui demandait de qui était cette assertion, Tchou $\mathrm{Hi}$ répondit : Elle est des anciens : Siang-chan la cite fréquemment, mais il se contente du simple énoncé de la chose. Sans développer cette idée dans une suite de propositions connexes (propositions unies par des particules copulatives ou disjonctives), il se contente d'une simple affirmation assez vague. Lisez aussi, Monsieur, le p.109 Si-ming de Hong-k'iu (i. e. Tchang-tse). A première vue, cet ouvrage semble obscur, rempli qu'il est de propositions qui s'enchaînent et se complètent l'une par l'autre; mais le sens en est pourtant facile à saisir. Et lorsqu'on en a compris tout l'ensemble, quelle grandeur on $y$ découvre!

26. Considéré comme une seule et même chose avec Li, principe immatériel, on ne peut pas dire que T'ai-ki soit un être sen- 


\section{Le philosophe Tchou Hi}

sible (Yeou) ; mais si on le considère dans les êtres qu'il forme, on ne peut pas dire qu'il soit imperceptible (Ou).

27. A propos de ces deux assertions de (Chao) K'ang-tsié «Tao est le T'ai-ki» et «Sin aussi est le T'ai-ki, » quelqu'un demanda si par Tao cet auteur veut exprimer le premier principe $\mathrm{Li}$, qui existe de lui-même, informant le ciel, la terre et tous les êtres; et par Sin ce même Li en tant que, dans l'homme, le principe dirigeant de son être. - Réponse : Oui, certainement ; mais T'ai-ki est unique et sans pareil.

28. T'ai-ki est le principe Li existant à l'état concret dans les cinq éléments, le Yn et le Yang ; ce n'est pas une conception abstraite, car comme telle (i. e. considéré indépendamment des êtres), il ne différerait pas de la Nature (Sing), au sens des Bouddhistes.

29. Ki signifie le point extrême des êtres, jusqu'où pénètre l'influence du principe formel ( $\mathrm{Li}$ ou Tao). Ce Li, en tant que p.110 forme universelle du ciel, de la terre et de toutes choses, s'appelle T'ai-ki.

30. T'ai-ki n'est autre que le point extrême que l'on ne saurait dépasser, au-delà duquel il n'y a rien ; très haut, très parfait, très pur et imperceptible, il surpasse toutes choses. (Tcheou) Lien-ki craignant qu'on ne dit que le T'ai-ki a une forme matérielle, sensible, l'a désigné par les mots Ou-ki eul t’ai-ki, signifiant par là qu'au milieu du monde imperceptible existe un principe sans limite, qui pénètre tout.

31. Question : T'ai-ki, dites-vous, n'est autre que Li ; mais ce $\mathrm{Li}$, comment a-t-il mouvement et repos ? Le mouvement et le 


\section{Le philosophe Tchou Hi}

repos sont des propriétés de la matière. Or, puisque le T'ai-ki est imperceptible, peut-être ne devrait-on pas lui attribuer mouvement et repos ? - Réponse : Le mouvement et le repos de K'i ont leur raison d'être dans la puissance de mouvoir et d'arrêter que possède Li. Si Li n'avait pas ce pouvoir, d'où K'i recevrait-il mouvement et arrêt ?

32. A en juger d'après ce qui paraît dans chaque action et objet, Yn et Yang renferment le T'ai-ki ; mais, si l'on considère leur origine, Yn et Yang proviennent eux-mêmes du T'ai-ki.

A la question: "T'ai-ki est donc le principe suprême de l'esprit dans l'homme? Le maître répondit: Tout acte et tout objet ont leur $\mathrm{Ki}$, qui est le point extrême jusqu'où pénètre le premier principe (Tao, ou Li). «Comme, par exemple, demanda quelqu'un, la Bonté du souverain et le Respect du sujet sont des Ki (extrêmes) ? »- « Ce sont là, répondit-il, des Ki (extrêmes) individualisés dans chaque action et dans chaque être particulier. Mais le principe universel ( $\mathrm{Li}$ ) du ciel, de la terre et de toutes choses, c'est le T'ai-ki. Le T'ai-ki, considéré en soi, ne porte pas ce nom : on désigne ainsi les manifestations de son énergie.

34. T'ai-ki est semblable à une racine qui germe et monte, puis se divise en plusieurs branches; puis se divise encore et produit des fleurs et des feuilles, et ainsi de suite, sans interruption. Le fruit une fois formé possède également en lui-même un principe de production sans limite. II va bientôt produire à son tour, et ce sera encore l'action infinie de T'ai-ki. Cette action est incessante ; ce n'est que lorsque le fruit est parfaitement formé, qu'elle s'arrête un instant. Mais il n'est pas vrai que, ayant produit jusqu'à une certaine limite, T'ai-ki alors se recueille en 


\section{Le philosophe Tchou Hi}

lui-même et pendant quelque temps cesse absolument tout acte. - C'est ce qu'exprime la phrase «Tchong che wan ou, mo cheng hou ken: Dans le cours de leur révolution périodique, les êtres de l'univers obtiennent leur plus grande perfection au point qui correspond au diagramme Ken. » (Ken-tche), Ken est le point d'arrêt dans la production et la génération d'êtres nouveaux.

35. p.112 C'est en vertu du seul T'ai-ki que, durant l'automne et I'hiver, chacun des êtres se replie sur lui-même et se tient comme enfermé ; puis soudain, à l'arrivée du printemps suivant, il se remet en action et s'épand en bel ordre. Ce n'est là que le K'i universel, qui alternativement s'arrête et se meut ; semblable en cela à l'homme qui, tant qu'il garde le silence, est en repos, et, dès qu'il parle, est en mouvement. Le bleu, le jaune, le vert, toutes les couleurs qui couvrent nos montagnes sont des manifestations du T'ai-ki.

36. On ne doit pas dire que T'ai-ki soit séparé de Yn et Yang, ni qu'il se confonde avec Yn et Yang.

37. Question: Lorsque vous dites que chaque être a son T’ai-ki, parlez-vous de Li ou de K'i ? - Réponse : Je parle de Li.

38. Le mot de Tcheou Lien-k'i «Ou-ki eul T'ai-ki» signifie seulement que $\mathrm{Li}$ existait sans aucune forme sensible. Tcheoutse craignant que, en dehors de ce T'ai-ki, quelqu'un ne voulût en chercher un autre, le désigne par le qualificatif Ou-ki, sans limite. Puisqu'il l'appelle « sans limite», pourquoi vouloir à tout prix chercher à lui en assigner ?- Quelqu'un ayant demandé si T'ai-ki commence lorsque Yang se met en mouvement, Tchou Hi répondit: Le repos ${ }_{\text {p.113 }}$ de Yn est le racine de T'ai-ki. Mais le repos de Yn provient lui-même de Yang en mouvement. Un arrêt 


\section{Le philosophe Tchou Hi}

et un mouvement font un P'i-ho, c.à.d. une ouverture et une clôture, ou une Révolution; et si nous pénétrons par la pensée au delà de la grande Révolution cosmique (Tse k'i p'i-ho tche ta tché), c'est encore I'Infini. Ne parlons donc pas d'un premier commencement.

39. Question: Que pensez-vous de l'opinion de Nan-hien : « la substance non en activité de T'ai-ki est le repos parfait ? » Réponse : Elle est fausse. Quelqu'un demanda encore si ce qu'on appelle «Tche-tsing » parfait repos, comprend à la fois et la manifestation de l'acte et sa non-manifestation. -Réponse: Ainsi on ferait un T'ai-ki tout à fait irrégulier. [Les 39 sentences qui précèdent sont extraites du []]

40. Entre le ciel et la terre (i.e. dans l'univers), il n'y a que les deux états de mouvement et de repos, qui se succèdent dans un cercle sans fin. II n'y a pas autre chose; et c'est ce que l'on désigne par le mot I (Changement). Or, étant donné qu'il y a mouvement et repos, il faut nécessairement admettre un principe de ce mouvement et de ce repos ; et c'est ce que nous nommons T'ai-ki.

41. T'ai-ki est dans Yn et Yang, comme Yn et Yang sont dans le T'ai-ki. Ils se trompent, ceux qui disent qu'au-delà de $\mathrm{Yn}_{\text {p.114 }}$ et de Yang, il existe à part, dans un état invisible, sans forme et sans ombre, quelque chose qui serait le T'ai-ki.

42. Sing (nature) a une certaine ressemblance avec T'ai-ki, et Sin (esprit), avec $Y n$ et Yang. En effet, T'ai-ki est toujours dans $Y n$ et Yang et ne saurait en être séparé ; et cependant, à parler exactement, ils sont mutuellement distincts: T'ai-ki est T'ai-ki, Yn et Yang sont Yn et Yang. De même en est-il pour Sing 


\section{Le philosophe Tchou Hi}

(nature) et Sin (mens, esprit) [i.e. ils sont distincts, bien qu'inséparables]. C'est ce qu'on exprime en disant qu'ils (T'ai-ki, Yn et Yang, Sing et Sin) sont un et pourtant deux, deux et pourtant un.

N.B. Les trois derniers paragraphes sont tirés du commentaire du T'ai-ki-t'ou, partie Sing Li.

43. Tao est le T'ai-ki du I King. Un est Yang, nombre impair ; deux est $\mathrm{Yn}$, nombre pair ; trois est la réunion des premiers nombres, pair et impair. Lorsqu'on dit que deux engendre trois c'est comme si l'on disait deux et un font trois. Si donc nous considérons Un comme étant le T'ai-ki, il ne faut pas dire alors que Tao a produit Un. [Réponse à Tch'eng T'ai-tche].

44. Le mouvement et le repos, de même que Yn et Yang, n'eurent jamais de commencement. Entre eux il n'y a, à proprement parler, ni priorité ni postériorité d'origine. Si par la pensée on ${ }_{p .115}$ les divise au milieu de leur cours, alors il n'y a pas d'inconvénient à leur attribuer priorité et postériorité (relative).

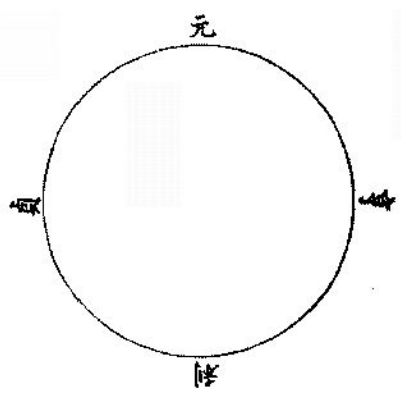

Tcheou-tse dit que T'ai-ki en mouvement engendra Yang ; donc avant qu'il se remuât, il y avait sûrement repos. De même, ajoute-t-il, parvenu au terme du repos, il recommença à se mouvoir ; donc après le repos, certainement il y a mouvement. Prenons comme exemple le printemps, l'été, l'automne et l'hiver, 


\section{Le philosophe Tchou Hi}

ou les 4 points qui divisent le cercle dans lequel l'Univers se meut éternellement, Yuen, Heng, Li et Tcheng : il est impossible qu'il n'y ait pas entre eux relation de priorité et de postériorité. Otez I'hiver, comment aurez-vous le printemps? Supprimez Tcheng, que deviendra Yuen ? Lorsque I'on considère ainsi les choses, il est évident qu'il y a priorité et postériorité. [Rép. à Wang Tse-ho].

45. p.116 Ce que je vous disais dans une précédente lettre, que T'ai-ki n'existe pas en dehors de $\mathrm{Yn}$ et Yang, concorde parfaitement avec ce que vous exprimez dans votre missive, quand vous dites que «sans s'appuyer sur (i. e. indépendamment de) Yn et Yang, il (T'ai-ki) a produit $Y n$ et Yang. » Seulement, voulant signifier que le sensible et l'incorporel restent toujours bien réellement distincts, j'ai dit que « T'ai-ki est au centre de Yn et de Yang. » Et vous, monsieur, considérant qu'il faut éviter que le sensible et le l'incorporel soient confondus dans la même expression, vous dites que « T'ai-ki n'est pas en dehors de Yn et Yang. » Bien que notre point de vue soit un peu différent; au fond, notre sentiment a toujours été le même. (Réponse à Tch'eng Ko-kieou).

46. Le vrai sens de T'ai-ki est l'extension à l'extrême de Li. Dès que Li s'individualise, un être existe, sans qu'on puisse affirmer, entre ce $\mathrm{Li}$ individuel et cet être, un ordre de priorité ou de postériorité. Lors donc que l'on dit que «I contient le T'ai-ki », cela signifie que ce T'ai-ki est au centre de Yn et Yang, et qu'il n'est pas au-dehors. Si maintenant on affirme qu'il est le Grand Centre (Ta tchong), et si l'on parle de ce qu'il était avant la séparation de K'ien (Ciel) et K'oen (Terre), ou bien avant la 


\section{Le philosophe Tchou Hi}

division du Grand Efflux (Ta ien), il est à craindre qu'on ne soit inexact. La partie imperceptible de T'ai-ki s'appelle Tao; la partie inférieure et sensible s'appelle $K^{\prime} i$ p.117 (récipient). Mais, si en parlant de T'ai-ki l'on dit que sa substance se nomme Chen (imperceptible aux sens), ou encore si on parle de lui au temps où, le ciel et la terre n'étant pas encore divisés, le K'i primordial ne formait qu'une masse chaotique, il est également à craindre que I'on n'affirme des choses peu sûres. (Rép. à Tcheng K'okieou).

47. On peut dire que T'ai-ki renferme mouvement et repos; mais alors il s'agit de sa substance propre originelle. On dira aussi avec raison que T'ai-ki est en mouvement et en repos, indiquant par là son évolution dans les êtres particuliers. Mais, si vous dites que T'ai-ki est mouvement et repos, dans ce cas il est impossible de distinguer la partie incorporelle de la partie sensible, et alors l'expression «I yeou T'ai-ki » contient une tautologie. (Rép. à Yang Tse-tche).

48. T'ai-ki est le principe Li des deux Modes (I) des quatre Siang (le soleil, la lune, les planètes et les constellations) et des huit Koua (diagrammes de Fou-hi). On ne peut pas dire qu'il ne soit rien; seulement il n'a pas de forme sensible. Le $\mathrm{Yn}$ et le Yang qu'il engendre sont les deux Modes (I) ; les quatre Siang et les huit Koua proviennent également de lui. Tout cela se fait d'après un ordre nécessaire, spontané ; l'effort humain n'est pour rien dans cet arrangement. Mais depuis Confucius personne ne ${ }_{\text {p.118 }}$ comprenait cette doctrine : ce n'est qu'après Chao K'angtsié qu'elle brilla à nos yeux. L'exposé que cet auteur nous en donne ne peut manquer de plaire par l'ordre et l'élégance. II ne 


\section{Le philosophe Tchou Hi}

faut pas le parcourir sans soin, mais l'étudier avec une grande attention. (Réponse à Lin Hoang-tchong).

49. Avant l'acte, c'est le repos de T'ai-ki; dès que l'acte a commencé, il est en mouvement. (Réponse à Liu Tse-yo).

Chou interrogea le maître sur le sens du mot Ki. «Au fond, disait-il, Tche-ki signifie ce à quoi l'on ne peut rien ajouter : et, pour exprimer le sens de ce principe $\mathrm{Li}$, on emploie cette désignation ( $\mathrm{Ki}, \mathrm{T}$ 'ai- $\mathrm{ki}$ ) indiquant que rien dans l'univers ne lui est supérieur. C'est pour cette raison qu'il est toujours au milieu des êtres, qu'il en est le point central, que sans lui les choses n'ont ni fondement ni direction, et conséquemment manquent de soutien et de point d'appui. De là vient que l'on dira bien que Ki est au centre des choses, mais non qu'il en est le centre. Pour me servir d'une comparaison sensible, il ressemble à la poutre qui est au faîte d'une maison, ou encore à la colonne qui supporte le toit d'un grenier public. Ki est au centre de toutes choses; les quatre points cardinaux et les huit directions se règlent d'après lui ; les myriades d'êtres, comme autant de p.119 branches, ont en lui la racine d'où ils naissent. Dans l'expression du Mémorial des Rites «Ming-ki », et dans cette autre du livre des Vers «Se-fang-tche-ki », le mot $\mathrm{Ki}$ a la même signification. Je ne sais pas si l'opinion que je viens de développer est vraie ou erronée. Le maître répondit: Vous avez bien dit. (Réponse à Tong Chou-tchong).

N.B. Les 8 derniers paragraphes sont extraits des Fuvres de Tchou Hi, partie littéraire. 


\section{Le philosophe Tchou Hi}

\section{CHAPITRE III \\ CIEL ET TERRE : (T'IEN TI)}

1. p.120 Le ciel et la terre n'étaient, dans le principe, que K'i ou la matière universelle composée d'éléments parfaits et imparfaits (Yn Yang). Ce K'i unique, animé d'un mouvement gyratoire, tourne comme une meule. Le mouvement devenant rapide, il se déposa une grande quantité de sédiment grossier, lequel, enfermé sans issue, se condensa et forma la terre au centre. La partie plus pure devint le ciel, le soleil, la lune et les étoiles, qui sans cesse tournent au dehors. La terre resta immobile au centre ; elle n'est pas au bas du système.

2.... Si le ciel s'arrêtait un seul instant, aussitôt la terre tomberait. Mais le ciel tourne d'un mouvement rapide. ...

3. Question: Le ciel est-il d'une substance tangible, sensible ? Réponse: C'est un vent tournant en spirale, sans consistance dans les régions inférieures, mais (de plus en plus) solide vers le $e_{p .121}$ sommet. Les Taoïstes l'appellent «Kang fong » (vent dur). On dit communément que le ciel consiste en neuf sphères (séparées), que l'on désigne chacune par un nom différent. Cela est inexact : c'est seulement une spirale continue à neuf étages. Dans la partie inférieure, la matière ( $\left.K^{\prime} i\right)$ est moins subtile et plus obscure, tandis que dans les régions les plus élevées elle est très pure et très brillante.

4. Au commencement du ciel et de la terre, avant que la matière chaotique ne fût divisée, je pense qu'il n'y avait encore 


\section{Le philosophe Tchou Hi}

que le feu et l'eau. Le dépôt de l'eau forma la terre. Aujourd'hui encore, lorsque d'un lieu élevé nous regardons au loin, les nombreuses collines nous apparaissent semblables aux vagues de la mer. L'eau a dû couler de la sorte : mais, quand s'est-elle condensée, nous l'ignorons. Toiit d'abord extrêmement molle, elle s'est ensuite condensée, et est devenue dure. Quelqu'un émit l'opinion que cela ressemblait au sable soulevé par la marée ; (et le maître) répondit : C'est bien cela. La partie la plus trouble de l'eau forma la terre; la portion la plus pure du feu devint vent, tonnerre, éclairs, soleil, étoiles, etc....

5. Question: Depuis le commencement (m.à.m. l'Ouverture) du ciel et de la terre, 10.000 ans ne se sont pas encore écoulés ; je ne sais ce qu'il y avait auparavant. - Réponse : «Auparavant il $_{\text {p.122 }}$ a du y avoir une autre période de clarté semblable à celleci. » « Le ciel et la terre peuvent-ils périr (complètement) ? 》«Non, ils ne sauraient périr. Seulement lorsque les hommes auront entièrement dégénéré, alors tout rentrera ensemble dans le chaos. Hommes et choses s'éteindront, mais pour recommencer de nouveau. »Quelqu'un demanda comment le premier homme est produit. - Réponse : «II est formé de K'i, la matière première; les parties subtiles des deux modes ( $\mathrm{Yn}$ et Yang) et des 5 éléments s'unirent et lui donnèrent sa forme sensible. C'est ce que les Bouddhistes nomment Houa-cheng (naître par transformation). A présent les êtres qui naissent ainsi sont encore très nombreux, par exemple la vermine. » [C'est la génération spontanée].

6. ... Chao K'ang-tsié pense que 129.600 ans font un Yuen ou période cosmique ; mais, avant cette période de 129.600 ans, il 


\section{Le philosophe Tchou Hi}

y eut encore une autre grande Ouverture (du monde) : et avant celle-là, encore une semblable ; de sorte que cette succession de mouvement et de repos, de $Y n$ et de Yang, n'eut jamais de commencement.

12. ... Parce que l'air ( $\left.K^{\prime} \mathrm{i}\right)$ est très condensé, il est capable de soutenir la terre; sans cela elle tomberait. A la p.123 partie extérieure de l'air, il doit certainement y avoir une écorce ou coque très épaisse, qui le retient et le fortifie ...

15. Si le ciel était de lui-même brillant, le soleil et la lune alors n'éclaireraient pas ; mais le ciel n'est pas de soi brillant ; le noir sombre de minuit est la couleur naturelle du ciel.

19. « L'esprit (mens) du ciel et de la terre est-il actif, ou bien simplement insouciant, inerte ? » (A cette question) le maître répondit : «On ne peut pas dire que l'esprit du ciel et de la terre ne soit pas doué d'activité ; mais il ne pense pas, ne se préoccupe pas à la façon des humains ... »

20. A propos de l'esprit ( $\sin$ ) et du Li du ciel et de la terre, quelqu'un demandait si $\mathrm{Li}$ a bien ici le sens de premier principe (Tao-li) et Sin celui de maître (tchou-tsai). - Réponse : Sin signifie certainement maître, régulateur; mais ce maître, ce regulateur n'est autre que $\mathrm{Li}$ : car $\mathrm{Li}$ n'est jamais en dehors (séparé) de Sin, ni Sin séparé de Li. - « Sin et Ti ont-ils quelque ressemblance entre eux? » - « Jen (I'homme) ressemble à T'ien (Ciel), et Sin (esprit, mens) à Ti ou Chang-ti, suprême régulateur (i. e. ce que Sin est à l'homme, Ti l'est au Ciel).

21. Le Sin (propension naturelle) du ciel et de la terre est de produire les êtres. 


\section{Le philosophe Tchou Hi}

23. p.124 Lorsque tous les êtres sont déjà engendrés et prospèrent, alors le ciel et la terre n'agissent plus suivant leur tendance : mais, dès que tout a dégénéré et exige une nouvelle production, le ciel et la terre reprennent leur activité.

27. Ti n'est autre que Li agissant en maître.

28. La voûte d'azur s'appelle (T'ien) ciel : c'est ce qui tourne sans cesse et se répand de tous côtés. Quant à affirmer qu'il y a là-haut quelqu'un qui juge les mauvaises actions, assurément on ne le peut pas ; mais dire qu'il n'y a rien qui dirige et ordonne, on ne le peut pas davantage. Ici il faut que chacun examine et comprenne bien.

29. Quel est le sens de T'ien (Ciel) dans les Livres canoniques et les classiques ? - Réponse : Chacun doit bien observer et distinguer clairement: dans certains endroits, il (T'ien) signifie la voûte azurée ; dans d'autres, l'acte producteur et ordonnateur ; et parfois seulement Li ou le principe immatériel.

32. L'expression « T'ien ti pou chou » (le ciel et la terre sont inexorables) veut dire que tout est condamné à périr.

35. Au commencement de la génération des êtres, la partie plus subtile de $\mathrm{Yn}$ et Yang se condensa spontanément et forma p.125 deux individus (de chaque espèce) : ils furent engendrés ainsi par la transformation de la matière première, à la façon de la vermine, qui naît spontanément (mot à mot, éclate sous l'action de la chaleur). Lorsque ces deux individus existèrent, un mâle et une femelle, de leur semence naquirent des êtres semblables dans la suite des temps: c'est la transformation corporelle, ou par semence. 


\section{Le philosophe Tchou Hi}

38. T'ien et Ti sont la partie sensible ou moins pure du ciel et de la terre; K'ien et K'oen en sont la partie plus subtile, imperceptible. T'ien et Ti sont l'enveloppe matérielle et visible; K'ien et K'oen, la nature animée, active du ciel et de la terre.

(a) 